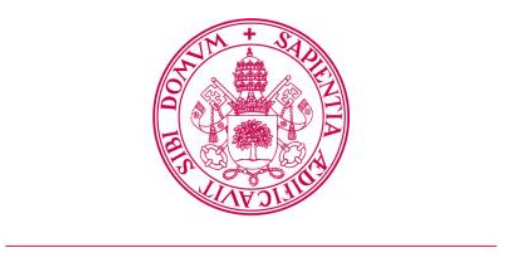

Universidad deValladolid

PROGRAMA DE DOCTORADO EN INGENIERÍA INDUSTRIAL

TESIS DOCTORAL:

\title{
MODELADO BASADO EN DINÁMICA DE SISTEMAS DEL SISTEMA ENERGÉTICO ECUATORIANO
}

Presentada por Flavio Roberto Arroyo Morocho para optar al grado de Doctor/a por la Universidad de Valladolid

Dirigida por:

Dr. Luis Javier Miguel González 


\section{Agradecimientos}

Deseo agradecer a mi director de tesis Luis Javier por su apoyo, paciencia y dedicación en todo lo enseñado durante toda esta investigación, permitiéndome desarrollarme y alcanzar una meta más en mi vida 
A mi familia 


\section{Prólogo}

De acuerdo con la normativa vigente de presentación y defensa de la tesis doctoral RESOLUCIÓN de 8 de junio de 2016, del Rectorado de la Universidad de Valladolid, por la que se ordena la publicación del Acuerdo del Consejo de Gobierno de 3 de junio de 2016, por el que se aprueba la normativa para la presentación y defensa de la tesis doctoral en la Universidad de Valladolid, (Artículo 4. Modalidad de tesis doctoral por compendio de publicaciones).

En la modalidad por compendio de publicaciones el candidato deberá aportar un mínimo de tres artículos científicos que hayan sido aceptados o publicados en un medio de impacto. La memoria de la tesis que siga esta modalidad deberá incluir índice, introducción, un cuerpo formado por los distintos artículos, conclusiones y bibliografía. Los artículos deberán incluirse completos en la memoria, con la referencia precisa de la publicación y con los nombres y la filiación de todos sus autores.

Bajo este sustento esta Tesis Doctoral se presenta como compendio de publicaciones. A continuación, se indican los artículos publicados incluidos dentro del compendio de publicaciones que ha dado lugar a la tesis, los cuales se adjuntan en los capítulos 4, 5 y 6 . Los artículos se han organizado siguiendo el orden conceptual que da forma y sentido a la tesis doctoral.

Artículo 1: Aceptado y publicado.

Título: The Trends of the Energy Intensity and $\mathrm{CO}_{2}$ Emissions Related to Final Energy Consumption in Ecuador: Scenarios of National and Worldwide Strategies.

Revista: Sustainability, volumen 12, número 1, (2019).

DOI: https://doi.org/10.3390/su12010020

Autores: Flavio R. Arroyo M. y Luis J. Miguel.

Web of Science (WoS): Journal Citation Reports (JCR)

Factor de impacto: 2.576 (2020)

Categoría: Environmental Sciences

Artículo 2: Aceptado y publicado.

Título: The Role of Renewable Energies for the Sustainable Energy Governance and Environmental Policies for the Mitigation of Climate Change in Ecuador.

Revista: Energies, volumen 13, número 15, (2020).

DOI: https://doi.org/10.3390/en13153883

Autores: Flavio R. Arroyo M. y Luis J. Miguel. 
Web of Science (WoS): Journal Citation Reports (JCR)

Factor de impacto: $2.576(2020)$

Categoría: Energy \& Fuels

Artículo 3: Aceptado y publicado.

Título: Low-Carbon Energy Governance: Scenarios to Accelerate the Change in the Energy Matrix in Ecuador.

Revista: Energies, volumen 13, número 18, (2020).

DOI: https://doi.org/10.3390/en13184731

Autores: Flavio R. Arroyo M. y Luis J. Miguel.

Web of Science (WoS): Journal Citation Reports (JCR)

Factor de impacto: $2.576(2020)$

Categoría: Energy \& Fuels

Por último, se hace constar que el presente documento adopta el formato de Tesis Doctoral como compendio de publicaciones y por lo tanto consiste en una síntesis de los conceptos teóricos que sustentan los trabajos de investigación publicados en lugar del formato tradicional de documento extenso autocontenido. 


\section{Resumen}

La energía es un recurso que impulsan la actividad económica en un país, para producir y consumir, brindar comodidad y movilidad, contribuir a la salud y el bienestar, pero el continuo deterioro de los recursos naturales podría poner a prueba la capacidad de satisfacer las necesidades de una población. El incremento de la demanda de energía y de las emisiones de $\mathrm{CO}_{2}$ relacionadas con el crecimiento económico es un desafío que requiere un análisis profundo y por otra parte el planteamiento de políticas encaminadas al desarrollo sostenible.

La presente investigación aplica el análisis de escenarios para identificar y analizar las causas que provocan el cambio de las emisiones de $\mathrm{CO}_{2}$ en Ecuador para un período histórico de 2000 a 2016 y una proyección hasta el año 2030. Se ha construido un modelo utilizando la Dinámica de Sistemas en base a un enfoque de escenarios que permiten realizar estimaciones a medio plazo de la Demanda de Energía, del Producto Interior Bruto (PIB), de la Intensidad Energética y de las Emisiones de $\mathrm{CO}_{2}$ en Ecuador.

El modelo incluye los patrones de sustitución de energía de origen fósil por energías alternativas, las estimaciones de desarrollo económico, la demanda energética bajo diferentes escenarios socioeconómicos, el potencial sostenible de las energías renovables y las estimaciones de Emisiones de $\mathrm{CO}_{2}$ relacionadas con el consumo de combustibles fósiles, todas ellas vistas en un marco dinámico. Permite explorar en detalle el sistema energético y sus implicaciones en el cambio climático.

El planteamiento de políticas en el sector energético interactúa con la gobernanza, el cambio climático y el calentamiento son amenazas asociadas con el consumo de energía y las emisiones de $\mathrm{CO}_{2}$, los aspectos de políticas energéticas sostenibles generan un impacto en el consumo de energía y calidad ambiental. Los resultados de la simulación muestran un incremento en la demanda de energía para los tres escenarios, una mejora importante en la intensidad energética y disminución de las emisiones $\mathrm{CO}_{2}$ para los dos escenarios que toman en cuenta planes enfocados al cuidado medioambiental a nivel local, regional y mundial. 


\section{Abstract}

Energy is a resource that drives economic activity in a country, to produce and consume, provide comfort and mobility, contribute to health and well-being, but the continued deterioration of natural resources could test the ability to meet needs of a population. The increase in energy demand and $\mathrm{CO}_{2}$ emissions related to economic growth is a challenge that requires in-depth analysis, and on the other hand, the planning of policies aimed at sustainable development.

This research applies the analysis of scenarios to identify and analyze the causes that cause the change of $\mathrm{CO}_{2}$ emissions in Ecuador for a historical period from 2000 to 2016 and a projection until 2030. A model has been built using the System Dynamics based on a scenario approach that allows medium-term estimates of Energy Demand, Gross Domestic Product (GDP), Energy Intensity and $\mathrm{CO}_{2}$ Emissions in Ecuador.

The model includes the patterns of substitution of fossil energy for alternative energies, estimates of economic development, energy demand under different socioeconomic scenarios, the sustainable potential of renewable energies and estimates of $\mathrm{CO}_{2}$ emissions related to fuel consumption. fossils, all seen in a dynamic frame. It allows to explore in detail the energy system and its implications for climate change.

The policy approach in the energy sector interacts with governance, climate change and warming are threats associated with energy consumption and $\mathrm{CO}_{2}$ emissions, aspects of sustainable energy policies generate an impact on energy consumption and environmental quality. The simulation results show an increase in energy demand for the three scenarios, a significant improvement in energy intensity and a decrease in $\mathrm{CO}_{2}$ emissions for the two scenarios that take into account plans focused on environmental care at the local, regional and world levels. 


\section{Índice General}

Agradecimientos ..................................................................................... i

Prólogo ....................................................................................................ii

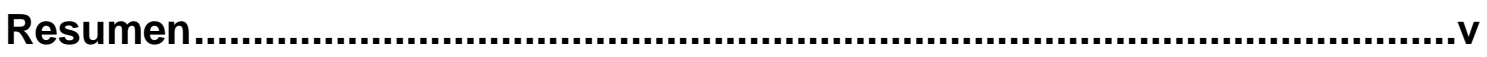

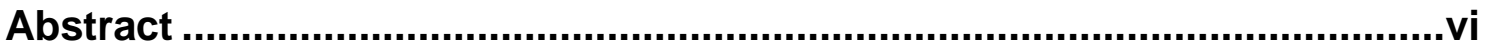

Índice General ............................................................................................. vii

Acrónimos .................................................................................................

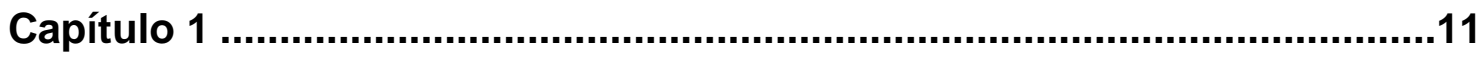

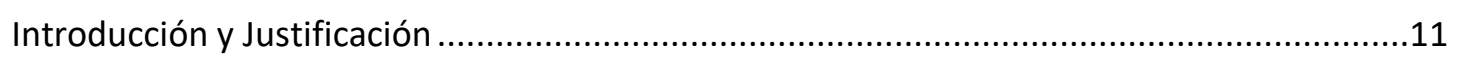

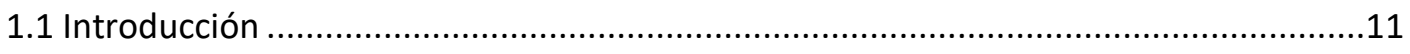

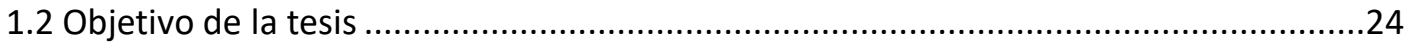

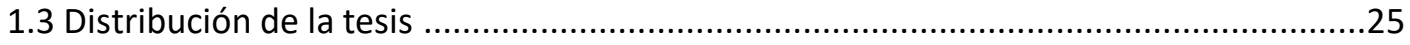

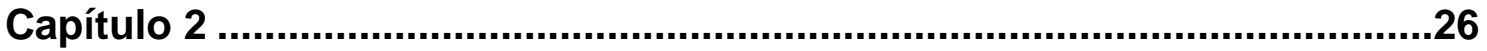

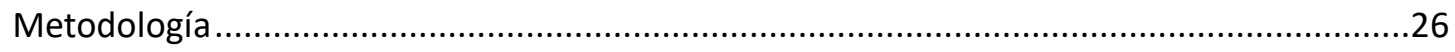

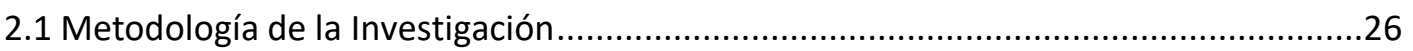

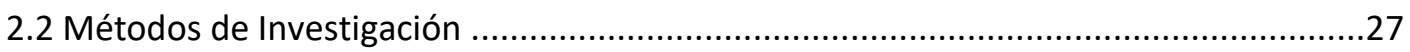

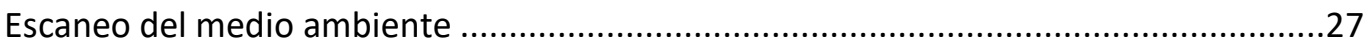

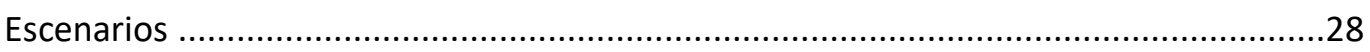

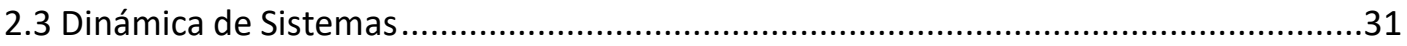

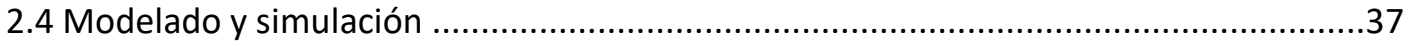

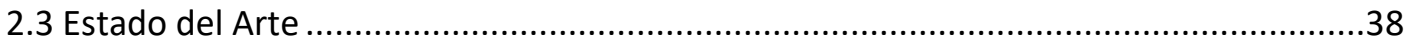

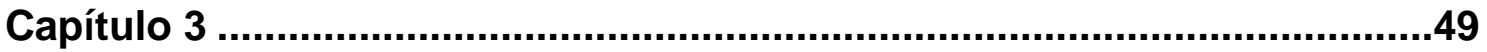

Evolución de la energía en Ecuador................................................................................49

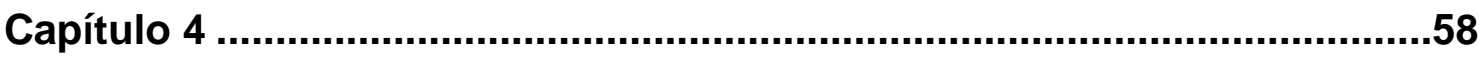

The Trends of the Energy Intensity and $\mathrm{CO}_{2}$ Emissions Related to Final Energy Consumption in Ecuador: Scenarios of National and Worldwide Strategies ...............................................58

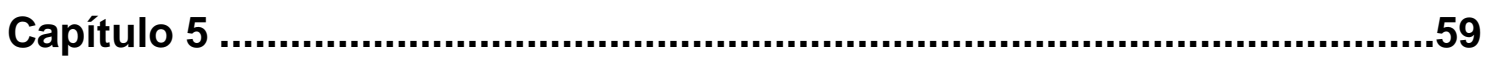

The Role of Renewable Energies for the Sustainable Energy Governance and Environmental Policies for the Mitigation of Climate Change in Ecuador ...................................................59

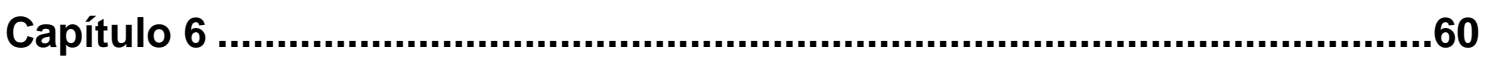

Low-Carbon Energy Governance: Scenarios to Accelerate the Change in the Energy Matrix in

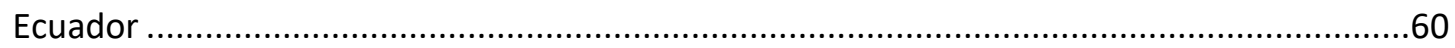

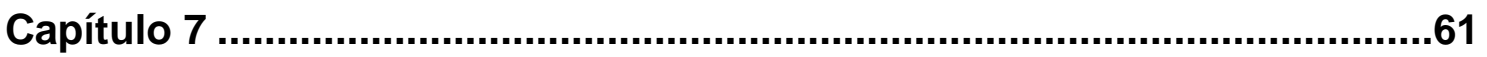

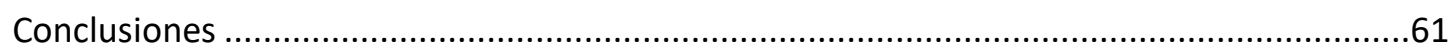


Bibliografía . 


\section{Acrónimos}

a.a. $\quad$ año a año

ARLD Autoregresivo de Rezagos Distribuidos

ASEAN Asociación de Naciones del Sudeste Asiático

BAU Business As Usual

BEP Barril equivalente de petróleo

BRIC Brasil, Rusia, India y China

$\mathrm{CH}_{4} \quad$ Metano

CIVETS Mercados emergentes Colombia, Indonesia, Vietnam, Egipto, Turquía y Sudáfrica

$\mathrm{CO}_{2} \quad$ Dióxido de carbono

DS Dinámica de Sistemas

El Intensidad Energética

ER Energía Renovable

EROI Tasa de Retorno Energético

GEI $\quad$ Gases de Efecto Invernadero

GLP Gas Licuado de Petróleo

Gt $\quad$ Giga toneladas

$\mathrm{GTCO}_{2} \quad$ Giga toneladas de $\mathrm{CO}_{2}$

IEA Agencia Internacional de Energía

INER Instituto Nacional de Eficiencia Energética y Energías Renovables

IPCC Intergovernmental Panel on Climate Change

KBEP Kilo barril equivalente de petróleo

LEAP Sistema de planificación de alternativas energéticas de largo alcance

MAPE Error Porcentual Absoluto Medio

$\mathrm{N}_{2} \mathrm{O} \quad$ Óxido nitroso

ODS Objetivos de Desarrollo Sostenible 
OECD Organización para la cooperación económica y el desarrollo

ONU Organización de las Naciones Unidas

OPEP Organización de Países Exportadores de Petróleo

PIB/GDP Producto Interno Bruto

PPP Paridad del Poder Adquisitivo 


\section{Capítulo 1}

\section{Introducción y Justificación}

\subsection{Introducción}

El cambio climático global ya tiene efectos que se pueden observar en el medio ambiente. Los científicos están muy confiados en que la temperatura global seguirá aumentando en las próximas décadas, en gran parte debido a los gases de efecto invernadero que producen las actividades humanas. El Grupo Intergubernamental de Expertos sobre el Cambio Climático, predice un aumento de la temperatura de entre 2,5 y 10 grados Fahrenheit durante el próximo siglo (Intergovernmental Panel on Climate Change, 2018a). Esto significa que las emisiones de dióxido de carbono $\left(\mathrm{CO}_{2}\right)$ deben disminuir en aproximadamente un 45 por ciento para 2030 y alcanzar el cero neto en 2050. Mientras que el IPCC dice que este objetivo está al alcance, para lograrlo requeriría urgente y transformación social y económica sin precedentes (United Nations, 2019).

El calentamiento inducido por el hombre alcanzó aproximadamente $1{ }^{\circ} \mathrm{C}$ (probablemente entre $0.8^{\circ} \mathrm{C}$ y $1.2^{\circ} \mathrm{C}$ ) por encima de los niveles preindustriales en 2017, aumentando aproximadamente $0.2^{\circ} \mathrm{C}$ por década (Intergovernmental Panel on Climate Change, 2018a). Los impactos del cambio climático incluyen múltiples factores ambientales además del aumento de las temperaturas, tales como los patrones de lluvia, aumento del nivel del mar, aumento de la acidificación del océano y eventos extremos, como inundaciones, sequías y olas de calor (Intergovernmental Panel on Climate Change, 2014a). Los cambios en las precipitaciones afectan el ciclo hidrológico y disponibilidad de agua (Schewe, et al., 2014) (Döll, et al., 2018) (Saeed, et al., 2018). Otros impactos son impulsados por cambios en el contenido de calor del océano, como la desestabilización de las capas de hielo costeras y el aumento del nivel del mar (Bindoff, et al., 2007) (Chen, et al., 2017), mientras que los impactos debidos a las olas de calor dependen directamente del aire del ambiente o de la temperatura del océano (Matthews, Wilby, \& Murphy, 2017) (European Environment Agency, 2017).

Existen múltiples evidencias de que el cambio climático tiene efectos observables y a menudo severamente negativos en las personas, especialmente donde las condiciones biofísicas sensibles al clima y socioeconómicas y las restricciones políticas sobre las capacidades adaptativas se combinan para crear altas vulnerabilidades (Intergovernmental Panel on Climate Change, 2012) (Intergovernmental Panel on Climate Change, 2014c) (Kuriakose, Bizikova, \& Bachofen, 2009) (Mearns \& Norton, 2010). El carácter y la gravedad de los impactos dependen no solo de los peligros ( $p$. ej., cambios en los promedios y extremos climáticos) pero también de la vulnerabilidad (incluyendo sensibilidades y capacidades adaptativas) de las diferentes comunidades y su 
exposición a las amenazas climáticas. Estos impactos también afectan una variedad de sistemas naturales y humanos, como ecosistemas terrestres, costeros y marinos y sus servicios; producción de agricultura; infraestructura; el entorno construido humano salud; y otros sistemas socioeconómicos (Rosenzweig, et al., 2017).

La creciente amenaza del cambio climático global inducido por la actividad humana requiere políticas de cambio climático que aborden este problema en los niveles de gobernanza global, nacional y local. La responsabilidad del cambio climático recae en los países desarrollados y sus patrones de consumo y producción, mientras el sistema socioeconómico permanezca sin cambios, el objetivo del Acuerdo de París tendría que enfrentar numerosos desafíos (Nieto, Carpintero, \& Miguel, 2018). Estos sistemas ahora deben estar preparados para gestionar los problemas emergentes relacionados con la adaptación y mitigación del cambio climático. La adaptación indica el ajuste de las sociedades a un clima cambiante, mientras que la mitigación exige la modificación del comportamiento actual para erradicar las prácticas que conducen a un mayor cambio climático. Además, la gobernanza climática a largo plazo enfrenta la necesidad de superar la "inercia institucional" que interfiere con el desarrollo de respuestas efectivas y rápidas (Meadowcroft, 2009) (Bernauer \& Schaffer, 2010). La gobernanza del cambio climático plantea desafíos difíciles para los sistemas políticos y administrativos contemporáneos, las naciones industrializadas deben asumir el costo del desarrollo (Alves, et al., 2020).

Mitigar el cambio climático al frenar las emisiones de gases de efecto invernadero (GEI), especialmente a través de la gestión de la demanda de energía y la generación de energía renovable (ER) puede reducir significativamente la contaminación ambiental y aumentar la eficiencia en todos los sectores económicos (Hasan, et al., 2020). Aunque los países en desarrollo son cruciales en los esfuerzos mundiales para mitigar el cambio climático, muchos países priorizan el crecimiento económico y la seguridad energética sobre la reducción de emisiones (Dong, Dong, Jiang, Dong, \& Liu, 2018).

La relación entre los problemas ambientales, como el cambio climático y el desarrollo, se origina en el movimiento ambiental de mediados del siglo XX debido a las preocupaciones sobre el agotamiento de los recursos naturales y el medio ambiente no saludable, en gran parte causado por la industrialización y la explosión demográfica (Hasan, et al., 2020). Los ambientalistas argumentaron que la calidad del medio ambiente y el sustento de la vida humana no estarían garantizados en un mercado libre y que el medio ambiente debe ser preservado. El papel desempeñado por la Comisión Mundial de Medio Ambiente y Desarrollo hasta 1987, a través del concepto de desarrollo sostenible (DS), fue crucial para conectar las preocupaciones ambientales con los objetivos de desarrollo y posicionarlos en la agenda internacional. El concepto de DS se definió como "el desarrollo que satisface las necesidades del presente, sin comprometer la 
capacidad de las generaciones futuras para satisfacer sus propias necesidades" (Brundtland Commission, 1987). Diez años después, el Protocolo de Kioto exigió a sus signatarios que tomaran medidas para reducir las emisiones de GEI a la atmósfera. En 2015, se formuló la Agenda 2030, en la que el Objetivos de Desarrollo Sostenible (ODS) 13 requería que los países miembros de la ONU "tomaran medidas urgentes para combatir el cambio climático y sus impactos" (United Nations, 2018). Al año siguiente, el Acuerdo de París fue ratificado para mantener el aumento de la temperatura global promedio a no más de $2^{\circ} \mathrm{C}$ por encima del nivel preindustrial mediante esfuerzos de mitigación y adaptación para reducir los riesgos e impactos del cambio climático (United Nations Framework Convention on Climate Change, 2016).

Los sistemas energéticos continúan creciendo en tamaño y complejidad, varios problemas y desafíos han surgido en la industria energética tanto en las economías desarrolladas como en las economías en vías de desarrollo (QudratUllah, 2016). Las preocupaciones y problemas ambientales globales, junto con las tendencias en el cambio climático global, han sido causas importantes de preocupación en la industria energética (Shafiei, Davidsdottir, Leaver, Stefansson, \& Asgeirsson, 2015). La formulación de políticas energéticas a menudo involucra varias partes interesadas cuyos aportes y expectativas deben tenerse en cuenta, para que estas políticas sean un éxito y alcancen sus metas. Esto ha exacerbado las complejidades dinámicas de los sistemas energéticos, dichas complejidades dinámicas incluyen incertidumbres, relaciones causales no lineales entre variables del sistema, bucles de retroalimentación interactivos y demoras de tiempo (Panda, 2011) (Wolstenholme, 2004). Enfrentados a estos desafíos y otros problemas pertinentes en la industria energética, los responsables de la formulación de políticas energéticas deben diseñar metodologías de simulación dinámica eficientes y efectivas que puedan manejar sistemas energéticos complejos. Debido a la existencia de múltiples factores relacionados con la demanda y el suministro de energía, la dinámica de los sistemas energéticos se ha convertido en un serio desafío para los responsables políticos. Influenciado por los cambios emergentes en el mercado energético, es imperativo considerar aspectos dinámicos complejos inciertos en el proceso de formulación de políticas (Mutingi, Mbohwa, \& Kommula, System dynamics approaches to energy policy modelling and simulation, 2017) (Máttar \& Cuervo, 2017).

La energía sigue dependiendo principalmente de los combustibles fósiles, como el carbón, el petróleo, el petróleo y los productos de gas natural, que emiten dióxido de carbono $\left(\mathrm{CO}_{2}\right)$ (Mirzaei \& Bekri, 2017). Estadísticamente, las emisiones mundiales de $\mathrm{CO}_{2}$ de la quema de combustibles fósiles para obtener energía aumentaron a un máximo histórico de 33.14 Giga toneladas (Gt) en 2018, lo que indica que la difusión actual de las opciones de bajas emisiones de carbono es insuficiente para satisfacer el aumento de la demanda energética 
impulsada por un mayor crecimiento económico (International Energy Agency, 2019b). Por lo tanto, la innovación en los sistemas energéticos es un área que está atrayendo considerables investigaciones para comprender y controlar el cambio climático (Stern, Sovacool, \& Dietz, 2016). Se han generado varios estudios relacionados con las opciones de mitigación y las vías de transición de los sistemas energéticos contra el cambio climático. Algunos de estos estudios han explorado la atractiva integración de nuevos procesos con los sistemas de energía tradicionales para mejorar la eficiencia del sistema y reducir las emisiones (Kang, et al., 2020) (Klemeš, Varbanov, Oclón, \& Chin, 2019) (Jordaan, et al., 2017) (Emodi, Chaiechi, \& Beg, 2019).

El sector energético constituye un sector estratégico en toda economía, motor del sistema productivo y un factor clave para la satisfacción de necesidades humanas. Un adecuado planteamiento del sector energético debe perseguir la soberanía energética, construida sobre una gestión de provisión y consumo eficiente de energía, actualmente enfrenta importantes desafíos por el cambio climático. Está claro que es uno de los sectores que más emite emisiones de carbono por la quema de combustibles fósiles. Por otro lado, la energía tiene un papel crucial en impulsar la economía y promover el desarrollo sostenible de la sociedad. El estado del desarrollo económico y el nivel de vida de las personas en una región determinada influyen fuertemente en el vínculo entre el crecimiento económico y la demanda de energía.

Se considera que la energía es la línea de vida de una economía, el instrumento más vital del desarrollo socioeconómico y reconocida como una de las mercancías estratégicas más importantes (Sahir \& Qureshi, 2007). En la era de la globalización, una demanda de energía en rápido aumento y la dependencia de los países de la energía indica que la energía será uno de los mayores problemas del mundo en el próximo siglo (Saidi \& Hammami, 2015). El crecimiento económico estimula la demanda de energía debido al aumento del consumo, por ejemplo, en los países industrializados, existe una alta tasa de penetración de electrodomésticos modernos y equipos de transporte personal motorizados. En la actualidad el sector energético se enfrenta a serios límites físicos y ambientales a nivel global, siendo el agotamiento de los recursos fósiles y la amenaza del cambio climático dos elementos indudablemente determinantes. El sector energético requiere un proceso de transición hacia una matriz energética sustentable, en el que lograr el acceso universal de toda la población a fuentes de energía apropiada debe constituir un objetivo prioritario (Castro, 2011). Plantear alternativas que permitan armonizar las necesidades energéticas con la sustentabilidad ecológica conlleva una revisión del concepto de desarrollo y la búsqueda de nuevos paradigmas evolutivos para las sociedades.

El sistema energético mundial está interconectado en términos de importación y exportación de electricidad y productos energéticos como el 
petróleo, el gas y el carbón. Todos estos puntos de vista pueden considerarse factores normativos relevantes que pueden guiar los supuestos cuando se diseñan modelos y escenarios de energía. Sin embargo, el cambio climático es quizás el problema más difícil que la humanidad se ve obligada a abordar y exige una acción urgente (Karjalainen, Käkönen, Luukkanen, \& Vehmas, 2014) (Greenleaf, et al., 2009) (IRENA, 2019) (World Energy Council, 2019) (Overland, 2016).

El análisis basado en modelos se usa con frecuencia para analizar tendencias futuras en el sistema energético y para explorar las implicaciones de las estrategias de mitigación a nivel global. Los modelos utilizados para evaluar los sistemas de energía tradicionalmente se centran en los sectores de suministro de energía e incluyen factores macroeconométricos (Fais, Sabio, \& Strachan, 2016) (Edelenbosch, van Vuuren, Blok, Calvin, \& Fujimori, 2020). De hecho, descarbonizar el suministro de energía al cambiar a tecnologías de suministro de energía bajas en carbono (fuentes de energía renovables, energía nuclear o aplicar carbono, captura y almacenamiento), puede ser una estrategia efectiva para mitigar las emisiones de gases de efecto invernadero (Kriegler, et al., 2014) (Krey, Luderer, Clarke, \& Kriegler, 2014), a pesar de las incertidumbres de los pronósticos tecnológicos, cada una de las fuentes de energía renovables tiene un potencial global máximo (de Castro, Mediavilla, Miguel, \& Frechoso, 2013)

Más de la mitad de las emisiones de gases de efecto invernadero (GEI) relacionadas con la energía se producen directamente en los sectores de demanda energética, es decir, en los sectores de la construcción, el transporte y la industria (Intergovernmental Panel on Climate Change, 2014b). Para lograr objetivos climáticos, como los que apunta el acuerdo de París, se requiere reducir todas las emisiones del sistema de energía hacia cero antes de fin de siglo (Intergovernmental Panel on Climate Change, 2018b), por lo tanto, las emisiones producidas por la demanda de energía también deberán reducirse drásticamente (Luderer, et al., 2018). Las emisiones directas no proporcionan la representación completa de la importancia de estos sectores, ya que también impulsan indirectamente las emisiones del lado del suministro y la cantidad de energía primaria utilizada. Además, las políticas de demanda de energía pueden tener importantes beneficios colaterales, como mejorar la seguridad energética y reducir la contaminación ambiental. Los países en desarrollo deben tomar la iniciativa para trazar nuevas políticas energéticas por sí mismos; sin embargo, los países desarrollados deben estar preparados para brindar apoyo, reconociendo que tienen un interés vital en el resultado; sin embargo, los países en desarrollo también tienen algunas ventajas. Pueden aprender de la experiencia pasada, evitar algunos de los errores políticos del último medio siglo y tener la oportunidad de "dar un salto" directamente hacia tecnologías más limpias y eficientes Los gobiernos deben reconocer que se pueden lograr los 
máximos beneficios mediante un enfoque que considere las interacciones de diferentes políticas que responda a las necesidades y limitaciones específicas de cada país. (Johansson, Patwardhan, Nakicenovic, \& Gomez-Echeverri, 2012) (Rao, et al., 2016). Las políticas energéticas que afectan el lado de la demanda suelen cambiar los patrones de consumo de energía de los consumidores, sector comercial y sector residencial al reducir la cantidad de energía requerida para un nivel determinado de producción o servicio. Las políticas que resulten más precisas dependerán en gran medida de la rapidez con la que los países desarrollados y en desarrollo reconozcan y comiencen a actuar sobre su interés compartido en el logro de resultados positivos sobre cambio climático que solo pueden gestionarse trabajando juntos. Las economías de escala podrían explotarse a través de políticas que faciliten el desarrollo de industrias que puedan explotar comercialmente la introducción de productos y servicios innovadores, estándares de eficiencia, estándares de cartera de energías renovables, mercados de 'certificados verdes', etiquetado energético de productos producidos en masa. Se puede esperar que muchos elementos esenciales de una transición energética sostenible se combinen bien con otros objetivos de desarrollo críticos, como mejorar la salud pública, ampliar las oportunidades de empleo, fomentar las industrias nacionales, aumentar la dependencia de los recursos autóctonos y mejorar la balanza comercial de un país

Con el rápido crecimiento económico observado en los últimos años, el nivel de desarrollo energético se ha vuelto cada vez más importante a escala global (Andrée, Chamorro, Spencer, Koomen, \& Dogo, 2019) (Wang \& Su, 2020) (Wang \& Jiang, 2020). En las últimas décadas, la necesidad de incluir aspectos ambientales en el modelo macroeconómico ha atraído una atención académica cada vez mayor. Teniendo en cuenta que la mayoría de las emisiones de carbono se producen dentro del sector energético y en relación con su nexo con el crecimiento económico, tiene sentido centrarse en los modelos Energía Economía - Medio ambiente (Nieto, Carpintero, Miguel, \& de Blas, 2020).

Los modelos de simulación se basan en un enfoque diferente. La principal contribución de los modelos de simulación es que describen las relaciones Energía - Economía - Medio Ambiente de una manera que permite examinar la propagación de perturbaciones en el sistema y evaluar los resultados de las diferentes políticas (Nieto, Carpintero, Miguel, \& de Blas, 2020). (Capellán-Pérez Í. Mediavilla, de Castro, \& Miguel, 2014) (Capellán-Pérez I. , Mediavilla, de Castro, Carpintero, \& Miguel, 2014) describen la relación entre la economía, el medio ambiente y la energía, centrándose en los límites biofísicos, el potencial de despliegue de energías renovables y no renovables, la eficiencia, las tecnologías alternativas y el cambio climático antropogénico. Una debilidad común en los modelos de simulación y optimización proviene de la falta de integración entre la economía y el sistema biofísico. El nexo economía y energía 
no está bien desarrollado, suponiendo en el mejor de los casos una simple relación lineal positiva entre ellos, está matizada por las ganancias de eficiencia energética, pero su pendiente positiva normalmente permanece sin cambios. La mayoría de los modelos convencionales suponen un alto grado de sustituibilidad energética entre las tecnologías y los recursos energéticos, dejando implícitamente desatendida la disponibilidad de energía. Esto, junto con la débil integración entre la economía y el medio ambiente, lleva a estos modelos a producir vías de transición estables y graduales (Nieto, Carpintero, Miguel, \& de Blas, 2020). Los modelos globales de energía-economía-ecología y más específicamente los de energía-economía-cambio climático, están en general orientados a la toma de decisiones políticas especialmente en materia de política energética y política medioambiental (de Castro, 2009). El camino que se abre para estudios y modelos que incorporen un pensamiento más holístico, dinámico y realimentado dentro del esquema economía - energía - cambio climático.

Las emisiones de $\mathrm{CO}_{2}$ de los combustibles fósiles han resultado ser uno de los problemas más peligrosos y complejos que impulsan el debate sobre el cambio climático. La cuestión de aumentar la demanda de electricidad al mismo tiempo que reducir las emisiones de $\mathrm{CO}_{2}$ se ha vuelto importante en todo el mundo. Con el aumento del cambio climático global, las emisiones de $\mathrm{CO}_{2}$ se convertirán cada vez más en una limitación para el crecimiento económico (Lin \& Raza, 2019). El consumo de energía y su eficiencia afectan todas las actividades económicas e industriales, mientras que la productividad energética y el consumo mejorado de energía son temas primordiales que afectan la economía de cualquier país (Mirzaei \& Bekri, 2017). La emisión de dióxido de carbono está estrechamente relacionada con la estructura energética, el consumo y la eficiencia energética (Jinnan, y otros, 2004).

El consumo de energía y el aumento de las emisiones de $\mathrm{CO}_{2}$ relacionadas con el crecimiento económico suponen un desafío para el desarrollo sostenible que requiere un análisis profundo y el desarrollo de políticas apropiadas. Muchos de los análisis de los futuros cambios en la economía de países o de regiones concretas se basan en predicciones cuantitativas para las cuales es complicado garantizar una precisión adecuada (Robalino López A. , 2014). Las actividades humanas han provocado el calentamiento global debido a la emisión de gases de efecto invernadero. Los principales gases de efecto invernadero son el dióxido de carbono, $\mathrm{CO}_{2}$, el metano, $\mathrm{CH}_{4}$, los óxidos nitrosos, $\mathrm{N}_{2} \mathrm{O}$, y los halocarburos ${ }^{1}$ (Cárdenas Herrera, 2014).

Los modelos de economía climática-energética son una herramienta fundamental para evaluar estrategias de mitigación y evaluar sus costos económicos. Estos modelos incluyen una representación de procesos

\footnotetext{
${ }^{1}$ Grupo de gases que contienen flúor, cloro y bromo.
} 
socioeconómicos, como el crecimiento económico y la dinámica del consumo y la inversión (Capellán-Pérez, et al., 2013). Para tener en cuenta el hecho de que el cambio climático es un desafío global y a largo plazo, se requieren modelos de economía climática - energética para representar a toda la economía mundial y realizar simulaciones a lo largo plazo. El modelo climático representa los vínculos y las retroalimentaciones entre el impacto de las actividades humanas en el clima, la atmósfera y los ecosistemas, que a su vez se ven afectados por la alteración de los ciclos naturales y la degradación de los servicios del ecosistema.

Ecuador (oficialmente la República de Ecuador) tiene una superficie de $272,046 \mathrm{~km}^{2}$ que incluye las islas Galápagos que, según el Centro de Monitoreo de la Conservación del Ambiente, un organismo del Programa de las Naciones Unidas para el Medio Ambiente, Ecuador es uno de los 17 países que pueden ser considerados como "megadiversos" es decir tiene la biodiversidad más densa del planeta. La nueva Constitución ecuatoriana de 2008 es la primera en el mundo en reconocer los derechos jurídicamente exigibles de la naturaleza, o de un ecosistema derechos (Robalino López A. , 2014). Según el Instituto Nacional de Estadísticas y Censos (INEC) la población ecuatoriana alcanzó los 17.096.789 habitantes en el 2018 (El Comercio, 2018).

La economía ecuatoriana está basada en un sistema productivo extractivista y la producción de los bienes primarios basados en la explotación del patrimonio natural (SENPLADES, 2009). Actualmente los ingresos del Ecuador dependen principalmente del petróleo, y por ende de las condiciones volátiles y especulativas del mercado internacional que rigen sus precios (Bettoga, 2013). El Ecuador de hoy, es un país netamente exportador de energías primarias, siendo el petróleo su principal rubro de exportación, el cual en el 2016 llego a representar para el país el 32,5\% de los ingresos. Según el Banco Central del Ecuador en el año 2018, el PIB alcanzó un crecimiento anual de $1,4 \%$, totalizando USD 108.398 millones en términos corrientes ${ }^{2}$ y USD 71.933 millones en términos constantes ${ }^{3}$ (Banco Central del Ecuador, 2019a), la producción de petróleo fue de 188,8 millones de barriles (Banco Central del Ecuador, 2019b).

Las autoridades del frente económico estimaron para el año 2019 un precio de barril de petróleo de USD 50,05. Ecuador fue parte de la Organización de Países Exportadores de Petróleo (OPEP) hasta el 01 de enero de 2020 lo que le significó sacrificios en sus niveles de producción. El país al ser miembro de la (OPEP) se comprometió a bajar su producción de 548.000 barriles diarios a 522.000 barriles. Desde 1972, en vísperas de iniciar las exportaciones de crudo oriente, el sector petrolero asume importancia inusitada en la estructura

\footnotetext{
${ }^{2}$ Se refiere a la valoración del PIB a precios de cada año.

${ }^{3}$ Valoración del PIB a precios del año base $=2007$.
} 
económica del país citado en (Panchana, 2015), donde la matriz de energía primaria ha sido dominada por el petróleo. La brecha entre la producción de energía secundaria total y la demanda se ha ampliado, situación que ha sido resuelta mediante importación de derivados. Esas importaciones cubren la demanda sectorial de transporte, industria, residencial y generación de electricidad. Los recursos petroleros ya están en una fase de declive, incluso si la producción basada en la adición de nuevas reservas se expande, el horizonte para cruzar la línea entre el exportador neto de energía y el importador neto podría estar entre 25 y 30 años, razón por la cual es necesario llevar a cabo transformaciones económicas y estructurales en el campo energético del Ecuador.

En el año 2007 el sistema energético nacional se encontraba en una situación compleja como consecuencia de las dificultades existentes para asegurar el abastecimiento energético, notorias ineficiencias en el consumo, explotación, transformación y producción de energía, y un importante grado de dependencia energética (con necesidad creciente de recurrir a importaciones de derivados de petróleo y electricidad para abastecer el mercado interno), a pesar de que el Ecuador era un exportador neto de energía (Ministerio Coordinador de Sectores Estratégicos, 2016b). La expansión de la capacidad de generación eléctrica en el Ecuador fue menor que la demanda, exponiendo al país a una posible escasez en condiciones climáticas adversas. Para satisfacer la demanda requiere la instalación de aproximadamente $250 \mathrm{MW}$ de nueva capacidad de todos los años, que no está siendo tratado adecuadamente y por lo tanto el déficit tendría que ser cubierta por importaciones. Una complicación adicional es que la generación de la infraestructura de generación térmica está envejeciendo y tiene que ser reemplazado o modernizado, por ejemplo, algunos motores diésel son mayores de 25 años. Ecuador tiene un gran potencial para explotar recursos renovables como el agua, la biomasa, la energía fotovoltaica, la energía solar térmica, etc. La Ley de Eficiencia Energética, vigente desde el 19 de marzo del 2019, tiene por objeto promover el uso eficiente, racional y sostenible de la energía.

El país tiene una sólida experiencia en el uso de recursos hidroeléctricos para la generación de electricidad, y el gobierno nacional ha asignado todos los recursos técnicos, equipos y capital para implementar tales proyectos (Observatorio de Energía Renovable para América Latina y el Caribe, 2011) (Peláez Samaniego, Garcia Perez, Cortez, Oscullo, \& Olmedo, 2007). El uso de recursos hidroeléctricos para proporcionar energía de bajo costo es una política prioritaria para el gobierno, se están desarrollando varios proyectos con recursos financieros aportados directamente por el gobierno.

El Ecuador ha enfrentado un proceso de transformación económica y social en los últimos años, dentro del cual el recurso energético juega un papel primordial, debido a su importancia como recurso esencial en todas las 
actividades productivas, así como para satisfacer las necesidades básicas de la población (Ministerio del Ambiente, 2017). Se ha planificado e implementado una serie de programas y proyectos que apuntan al cambio de la matriz energética. La propuesta estatal tiene como estrategia principal en el sector eléctrico impulsar el desarrollo de grandes centrales hidroeléctricas, sobre todo en la vertiente amazónica. Así, el $86 \%$ de la expansión planificada para el período 2009-2020 será con base en fuentes hidroeléctricas (Consejo Nacional de Electricidad, 2013). De esta expansión, el 32\% se centrará en una sola central hidroeléctrica, Coca Codo Sinclair (1500 MW). Sin embargo, esta planificación no cumpliría con la meta 4.3.3 del Plan Nacional para el Buen Vivir (PNBV) que consiste en alcanzar el $6 \%$ de fuentes de energía renovable diferentes de la hidroelectricidad en la matriz eléctrica (Castro, 2011).

Por otra parte el Ecuador empieza a sentir el impacto del cambio climático y se hace necesario tomar acciones correctivas y diseñar una planificación energética que no comprometa el medio ambiente. El Gobierno de la República de Ecuador reconoce que el cambio climático es un desafío que puede afectar negativamente la seguridad, el desarrollo y el bienestar de la población (Ministerio del Ambiente, 2012). Las tendencias observadas de la temperatura en la región latinoamericana, presentadas en el Quinto Informe del Grupo Intergubernamental de Expertos sobre el Cambio Climático (IPCC, por sus siglas en inglés), señalan un calentamiento de $0,7^{\circ} \mathrm{C}$ a $1^{\circ} \mathrm{C}$ desde la década de 1970 , exceptuando la costa chilena, donde se observó un enfriamiento aproximado de $-1{ }^{\circ} \mathrm{C}$. Las proyecciones de clima futuro realizadas en el marco de la Tercera Comunicación Nacional (TCN), muestran que de mantenerse la tendencia actual de la temperatura, el cambio que podría esperarse en el Ecuador sería de aproximadamente un aumento de $2^{\circ} \mathrm{C}$ hasta fin de siglo; e, incluso, la Amazonía y Galápagos presentarían incrementos muy superiores. (Ministerio del Ambiente, 2017).

Para el año 2017, Ecuador alcanzó un nivel relativamente bajo de $\mathrm{CO}_{2}$, emisiones 2,44 toneladas per cápita mientras Catar, el más grande del mundo emisor de $\mathrm{CO}_{2}$ per cápita emite 38,52 toneladas per cápita. Estados Unidos de América emite 15,56 toneladas per cápita. En la Unión Europea, Rusia produce 11,54 toneladas per cápita. Venezuela el mayor emisor de $\mathrm{CO}_{2}$ en América Latina, emite 5,57 toneladas per cápita (BP, 2018). Se espera que el desarrollo social y económico en los próximos años aumentará significativamente las emisiones de Ecuador. Varias organizaciones internacionales, en particular, el Intergovernmental Panel on Climate Change (IPCC) advierte sobre la necesidad de estabilizar el $\mathrm{CO}_{2}$ y otros gases de efecto invernadero antropogénico con el fin de evitar una advertencia catastrófica del sistema climático durante este siglo (Intergovernmental Panel on Climate Change, 2018a). Para la estimación de gases de efecto invernadero o emisiones, el IPCC ha desarrollado varios métodos que utilizan datos del suministro de energía del país para calcular las 
emisiones de $\mathrm{CO}_{2}$, principalmente de la quema de combustibles fósiles. Es un método sencillo que puede ser aplicado sobre la base de las estadísticas de suministro de energía disponible. Sin embargo, el problema surge cuando los datos no están disponibles o no está suficientemente desagregada para su uso con este método (Robalino López, García Ramos, Golpe, \& Mena Nieto, 2014).

Las mayores emisiones corresponden a las emisiones de $\mathrm{CO}_{2}$ por la combustión de combustibles fósiles en el transporte, sistemas de calefacción, aire acondicionado en edificaciones y procesos industriales, se producen emisiones por los cambios del uso del suelo y silvicultura, ya que con la deforestación se libera $\mathrm{CO}_{2}$, y se reduce la absroción del $\mathrm{CO}_{2}$ de las plantas. EI $\mathrm{CO}_{2}$ se libera también como proceso natural, con la descomposición de la materia vegetal. Los sectores de mayor emisión de GEI son el sector de generación de electricidad y calor, el sector industrial y el sector de transporte (Cárdenas Herrera, 2014). En este contexto, Ecuador necesita reducir la vulnerabilidad de su economía al cambio climático, y al mismo tiempo, prepararlo para una senda baja en carbono que limite las futuras emisiones de gases GEI. Las posibles sinergias entre las acciones de adaptación y las acciones de mitigación del cambio climático son importantes para sostener un desarrollo sostenible de la economía.

De acuerdo con el análisis de la Segunda Comunicación Nacional sobre Cambio Climático, entre los impactos más probables que se podrían verificar en el Ecuador se destacan:

1. La intensificación de eventos climáticos extremos, como los ocurridos a causa del fenómeno "Oscilación Sur El Niño";

2. El incremento del nivel del mar;

3. El retroceso de los glaciares;

4. La disminución de la escorrentía anual;

5. El incremento de la transmisión de dengue y otras enfermedades tropicales;

6. La expansión de las poblaciones de especies invasoras en Galápagos y otros ecosistemas sensibles del Ecuador continental;

7. La extinción de especies. Los impactos sobre la población, infraestructura y producción podrían ser considerables (Ministerio del Ambiente, 2012).

Estimaciones señalan que para el año 2025 el país perdería aproximadamente US\$ 5,6 billones por efectos de eventos extremos meteorológicos generados por el cambio climático (Amat y León, Seminario, Cigarán, Bambarén, \& Macera, 2008) citado por (Ministerio del Ambiente, 2012).

La Constitución de la República del Ecuador (2008) contiene dos artículos específicos relacionados con la gestión sobre cambio climático en el país. El artículo 413 busca promover la eficiencia energética; el desarrollo y uso de prácticas y tecnologías ambientalmente limpias y sanas; las energías 
renovables, diversificadas, de bajo impacto que no pongan en riesgo la soberanía alimentaria; el equilibrio ecológico de los ecosistemas; y el derecho al agua. El artículo 414 busca la adopción de medidas adecuadas y transversales para la mitigación del cambio climático mediante la limitación tanto de las emisiones de GEl, como de la deforestación y la contaminación atmosférica; adoptando además medidas para la conservación de los bosques y la vegetación; y para la protección de la población en riesgo (Asamblea Constituyente, 2008).

La estrategia a largo plazo del Plan Nacional del Buen Vivir (PNBV) plantea cuatro fases. La primera fase es de transición en términos de acumulación, en la cual persiste la dependencia de los bienes primarios, pero profundiza la redistribución, impulsa al sector turístico, la inversión pública estratégica, la producción sistemática, el cambio en la matriz energética, la desagregación y transferencia de tecnología, y la formación y fortalecimiento de capacidades humanas. La segunda fase se fundamenta en el fortalecimiento de la industria nacional frente a la de base primaria, buscando consolidar un superávit, principalmente a través de la producción y consumo de energía limpia y bio-energía. La tercera fase consolida una estrategia de diversificación y sustitución de importaciones, además busca sustituir exportaciones por bienes con mayor valor agregado y no exclusivamente dependientes de procesos productivos; incluye también la inversión en ciencia y tecnología para la innovación productiva. Finalmente, la cuarta fase busca entre otros, el despegue de los bio-servicios y su aplicación tecnológica (SENPLADES, 2009) citado por (Ministerio del Ambiente, 2012).

Por otra parte, la gestión ambiental desde el sector público está sustentada en el objetivo 4 del PVBV, el cual establece garantizar los derechos de la naturaleza y promover un ambiente sano y sustentable. La misma política cuenta con un acápite específico sobre cambio climático. La política 4.5 del PNBV determina fomentar la adaptación y mitigación a la variabilidad climática con énfasis en el proceso de cambio climático. Adicionalmente, se plantean ocho lineamientos que buscan:

a) Generar programas de adaptación y respuesta al cambio climático que promuevan la coordinación interinstitucional y la socialización con actores clave, con particular atención a ecosistemas frágiles (páramos, manglares y humedales);

b) Incorporar programas y planes de contingencia ante eventuales impactos que puedan afectar la infraestructura del país;

c) Impulsar programas de adaptación enfatizando en la soberanía energética y alimentaria;

d) Valorar el impacto del cambio climático sobre los bienes y servicios que proporcionan los ecosistemas; 
e) Incorporar el cambio climático como variable a considerar en los proyectos y en la evaluación de impactos ambientales, considerando las oportunidades que ofrecen los nuevos esquemas de mitigación;

f) Desarrollar actividades dirigidas a aumentar la concienciación y participación ciudadana en relación con el cambio climático y sus implicaciones en la vida de las personas;

g) Elaborar modelos predictivos para identificar los efectos del cambio climático para todo el país, incluyendo un sistema de información estadístico y cartográfico;

h) Incentivar el cumplimiento de los compromisos por parte de los países industrializados sobre transferencia de tecnología y recursos financieros como compensación a los efectos negativos del cambio de clima en los países no industrializados (Ministerio del Ambiente, 2012).

Además, existen políticas del gubernamentales que tienen directa relación con cambio climático: diversificar la matriz energética nacional, desde la promoción de la eficiencia y una mayor participación de energías renovables sostenibles (Política 4.3); y reducir la vulnerabilidad social y ambiental ante los efectos producidos por procesos naturales y antrópicos generadores de riesgos (Política 4.6). Cada una de esas políticas cuenta con lineamientos específicos. En el caso de la Política 4.3 antes mencionada, los lineamientos incluyen:

1. Aplicar programas, e implementar tecnología e infraestructura orientadas al ahorro y a la eficiencia de las fuentes actuales y a la soberanía energética;

2. Aplicar esquemas tarifarios que fomenten la eficiencia energética en los diversos sectores de la economía;

3. Impulsar la generación de energía de fuentes renovables o alternativas con enfoque de sostenibilidad social y ambiental;

4. Promover investigaciones para el uso de energías alternativas renovables, incluyendo entre otras la mareomotriz y geotérmica bajo parámetros de sustentabilidad en su aprovechamiento;

5. Reducir gradualmente el uso de combustibles fósiles en vehículos, embarcaciones y generación termoeléctrica, y sustituir gradualmente vehículos convencionales por eléctricos en el Archipiélago de Galápagos;

6. Diversificar y usar tecnologías ambientalmente limpias y energías alternativas no contaminantes y de bajo impacto en la producción agropecuaria e industrial y de servicios (Ministerio del Ambiente, 2012).

Ecuador requiere principalmente del compromiso político de incentivar y apoyar al desarrollo de proyectos hidroeléctricos, más aún con el apoyo extra que significa los mercados de carbono, que podrían traer un doble beneficio al 
país. El país requiere aproximadamente entre 8.000 y 12.500 MW de capacidad instalada adicional en hidroelectricidad hasta el 2025 para cubrir con la demanda de energía y así disminuir la dependencia del consumo de combustibles en la generación, tomando en cuenta valores reales (dejando de lado inflación).

\subsection{Objetivo de la tesis}

El objetivo general de la tesis se enfoca en el análisis de las variables más significativas que determinan la evolución del sistema energético de Ecuador, así como la interacción entre ellas. Estas variables, su relación y sus dinámicas temporales serán entendidas como un sistema complejo, cuyo modelado es el principal resultado de la tesis. El diseño de un modelo lo más apegado a la realidad servirá como base en la toma de decisiones políticas, económicas y ambientales encaminados en un desarrollo energético sostenible y la remediación de los ecosistemas en el Ecuador afectados por el impacto del cambio climático que en los últimos días ha registrado condiciones anómalas pasando del frío al calor en un mismo día, se han registrado temperaturas altas tanto en la costa como en la sierra en donde también se han registrado temperaturas de $0^{\circ} \mathrm{C}$. Para contrarrestar los efectos del cambio climático el modelo diseñado permitirá plantear escenarios con posibles medidas encaminadas a la reducción de emisiones de carbono a través de una posible nueva matriz energética sustentada en energías renovables.

El diseño de un modelo en dinámica de sistemas (DS) permitirá alcanzar el objetivo general de la tesis. Se van a analizar y comparar las variables, se describirá cada una de ellas, cómo y cuánto van a influir en un futuro en el sistema energético del Ecuador. Como es conocido la DS es un método que se extiende más allá del dominio convencional para solucionar problemas de ingeniería complejos a gran escala generando un impacto intelectual significativo en todo el mundo.

La DS como método se ha aplicado con éxito en una amplia variedad de campos comerciales y socioeconómicos para comprender los problemas y obtener una idea de las diversas intervenciones de política, razón por la cual es una herramienta poderosa que puede aplicarse con éxito para resolver los problemas de cambio climático y políticas energéticas desde un marco dinámico para dar significado a las fuentes de información y los hechos que se han desarrollado en Ecuador. El modelo propuesto es una representación o reconstrucción del mundo real, el modelo de DS permitirá tener una mayor claridad en la toma de decisiones sobre las diversas proyecciones a mediano y largo plazo en el sector de la economía energética y sus impactos ambientales

Existen muchos modelos de optimización disponibles que se ocupan del sector de la economía energética. Algunos de ellos se utilizan en diversas proyecciones a largo plazo realizadas en el ámbito internacional como por ejemplo: el Modelo de Análisis de Demanda Energética (MAED), PRIMES 
modelo de sistema energético, la familia de modelos de asignación de mercado (MARKAL), el modelo de Alternativas de estrategia de suministro de energía y sus impactos ambientales generales (MESSAGE), el Modelo Energético Mundial (WEM), Modelado para Generar Alternativas (MGA), el Modelo de Límites Mundiales (WOLIM), Modelizando la transición energética renovable en Europa (MEDEAS), entre otros.

\subsection{Distribución de la tesis}

El resto de esta tesis se organiza de la siguiente manera:

En el Capítulo 2, se mencionan las bases metodológicas que abarcan el conjunto de elementos que se refieren de forma directa al problema de investigación, es una recopilación precisa de teorías, metodologías y trabajos previos que están relacionados al objeto de estudio de la tesis.

En el Capítulo 3, se analiza la evolución y situación actual del modelo energético del Ecuador. Se describe la composición de la matriz energética desde la oferta de las diferentes fuentes de energía y el consumo por sector y fuente.

En el Capítulo 4, este capítulo está estructurado por la publicación del artículo: The Trends of the Energy Intensity and CO2 Emissions Related to Final Energy Consumption in Ecuador: Scenarios of National and Worldwide Strategies, publicado el 18 de diciembre de 2019 en la revista Sustainability.

En el Capítulo 5, este capítulo está estructurado por la publicación del artículo: The Role of Renewable Energies for the Sustainable Energy Governance and Environmental Policies for the Mitigation of Climate Change in Ecuador, publicado el 30 de julio de 2020 en la revista Energies.

En el Capítulo 6, este capítulo está estructurado por la publicación del artículo: Low-Carbon Energy Governance: Scenarios to Accelerate the Change in the Energy Matrix in Ecuador, publicado el 11 de septiembre de 2020 en la revista Energies.

En el Capítulo 7, se presentan las conclusiones extraídas del presente trabajo de tesis y las líneas de trabajo futuras a partir de los resultados obtenidos. 


\section{Capítulo 2}

\section{Metodología}

\subsection{Metodología de la Investigación}

La metodología de la investigación explica cómo se realiza la investigación, los métodos de recopilación de datos, los materiales utilizados, los sujetos entrevistados o los lugares visitados (Jabar, Sidi, \& Mohd Hasan Selamat, 2009). Los nuevos debates de planificación sobre sostenibilidad requieren nuevas formas de pensar sobre el futuro, y llaman a los planificadores, los encargados de tomar decisiones y los gobiernos a producir un conocimiento más profundo y explícito de las relaciones existentes entre las acciones presentes y futuras (Carmody, 2012). Las responsabilidades que nos vinculan con las generaciones futuras implican que el pensamiento futuro se aborde de manera más madura, sensible y confiable. Los principios de sostenibilidad requieren que los planificadores piensen en escenarios de posibles desarrollos alternativos durante un período de tiempo más largo que los cinco, diez o incluso veinte años habituales, para garantizar que los activos naturales se conserven para las generaciones futuras (Puglisi, 2001).

Tradicionalmente, las metodologías de investigación se clasifican en términos generales en cualitativos y cuantitativos. La investigación cualitativa es un estudio en profundidad de los fenómenos sociales y culturales y se centra en el texto, mientras que la investigación cuantitativa investiga las tendencias generales en la población y se centra en los números. Para la presente investigación se combinan los dos tipos de investigación, la fase cualitativa inicial del estudio apunta a temas que después conducen a los métodos de recolección y análisis de datos cuantitativos. Los investigadores cuantitativos son cada vez más conscientes de que algunos de sus datos pueden no ser precisos y válidos. Por otro lado, los investigadores cualitativos han desarrollado mejores técnicas para clasificar y analizar datos descriptivos. También se reconoce cada vez más que toda la recopilación de datos, cuantitativa o cualitativa, opera dentro de un contexto cultural y se ve afectada por los sesgos y creencias de los recolectores de datos.

El diseño de método mixto, ampliamente definido, es un diseño de investigación que involucra datos cuantitativos y cualitativos en un solo estudio o en múltiples estudios en un programa sostenido de investigación. La presente investigación se basa en la recopilación y el análisis de datos cualitativos y cuantitativos, se involucran perspectivas teóricas y analíticas al análisis del problema de contaminación ambiental por el uso de energías en Ecuador. Los principales datos cualitativos fueron recopilados de la información publicada en los balances energéticos nacional entre los años 2012-2018 complementados en varias etapas de la investigación mediante el análisis de otros documentos a 
nivel nacional y mundial. Se estructuró un proceso de recopilación de datos, análisis, generación de hipótesis e interpretación de los resultados.

Mediante el análisis estadístico de datos cuantitativos y la exploración de las razones detrás del efecto observado se abordan las preguntas de investigación, el propósito y el objetivo del estudio. Se planifica el estudio oscilando de manera dinámica entre generalización y contextualización, explicación y comprensión, deducción e inducción, y comprobación de hipótesis y generación de hipótesis. La investigación comienza con la recopilación de los datos cualitativos para explorar a profundidad el sector energético y las emisiones de $\mathrm{CO}_{2}$, luego se diseña la fase cuantitativa del estudio de modo que se conecte a los resultados de la primera fase cuantitativa.

\subsection{Métodos de Investigación}

El diseño del método de investigación, apropiado para la presente investigación, implica la consideración de lo siguiente: 1). Objetivos del estudio de investigación; 2). Método de recopilación de datos que se adoptará; 3). Fuente de datos o información; 4). Herramienta para la recopilación de datos; y 5). Análisis de datos: cualitativo y cuantitativo

\section{Escaneo del medio ambiente}

El escaneo ambiental es una técnica básica de estudios de futuros. El objetivo es generar la información de fondo a partir de la cual pronosticar o desarrollar escenarios. Por lo tanto, el primer objetivo es proporcionar el conocimiento necesario para definir las principales áreas de la encuesta y seleccionar los temas relevantes. El proceso permite la recopilación de datos necesaria ( $\mathrm{y}$ la identificación de tendencias pasadas y presentes más relevantes para la encuesta) y la estimación de los valores potenciales de indicadores relacionados con la ocurrencia o no ocurrencia de eventos específicos. Establece criterios organizacionalmente relevantes para permitir que las mentes humanas preparadas puedan discernir información, conocimiento y comprensión de la multitud de 'señales' que ocurren diariamente (Slaughter, 1999).

La información de pronósticos y especulaciones sobre tendencias, y sus implicaciones para posibles eventos relacionados con el tema a ser estudiado, debe ser recopilada y analizada. Esta información puede derivarse de fuentes muy diferentes: periódicos, revistas, internet, televisión, conferencias, informes, y también ficción y ciencia ficción. Esto es útil para comprender las formas en que las cosas están cambiando y las herramientas y los medios utilizados dependen en gran medida del problema específico. Es muy importante que la información se actualice constantemente para identificar las advertencias tempranas de los cambios en curso. (Neufeld, 1985) sugiere que se deben examinar cuatro tipos de indicadores: 
- Señales solitarias (elementos individuales que pueden ser señales de cambio);

- Eventos emblemáticos (en ciencia y tecnología, en sociedad y en política);

- Pronósticos de expertos;

- Descripciones estadísticas (para describir el desarrollo de elementos del tema en estudio).

\section{Escenarios}

Uno de los métodos prospectivos que más apoyo tiene en la actualidad para analizar los acontecimientos futuros a la luz de los acontecimientos presentes es el método de los escenarios. Para analizar el futuro se construyen escenarios, que son descripciones provisorias y exploratorias de un futuro probable. Un escenario es un retrato significativo y detallado de un plausible (aprobable), admisible, recomendable, coherente, mundo futuro. En él se pueden ver y comprender claramente los problemas, amenazas y oportunidades que tales circunstancias pueden presentar. No es una predicción o un pronóstico específico, es la descripción de eventos y tendencias que pueden ocurrir (Cely, 1999).

Los escenarios son un medio extraordinario para enfrentar este desafío. Un escenario es una exploración detallada de una posibilidad futura. Sin embargo, existen muchas definiciones diferentes del término escenario como resultado de una variedad de conceptos, enfoques, significados y contenidos subyacentes a los diferentes usos de los métodos de escenario (Puglisi, 2001).

Shoemaker, que describe los escenarios como una caracterización similar a un guion de un posible futuro presentado en considerable detalle, con especial énfasis en las conexiones causales, la consistencia interna y la concreción (Schoemaker, 1991). El futuro es intrínsecamente desconocido por naturaleza y, por lo tanto, ninguno de los escenarios que podemos desarrollar se desarrollará como se imagina. Siempre habrá eventos inesperados y, además, es improbable que se desarrolle la combinación exacta de eventos utilizados para el trabajo. La existencia de este límite no niega la validez del estudio y de los escenarios en sí, ya que tienen un papel importante en el pronóstico y la planificación (Puglisi, 2001). Los escenarios son quizás más útiles cuando proporcionan imágenes alternativas de diferentes futuros posibles.

Existen muchos métodos y modelos de análisis de escenarios con un rango que va de lo más simple a lo más sofisticado. Algunos de los posibles pasos del proceso de desarrollo de escenarios pueden incluir:

- Definición del problema y el lapso;

- Análisis de factores clave y fuerzas principales;

- Previsión de sectores;

- Análisis de impacto cruzado; 
- Desarrollo de lógica de escenarios;

- Selección de escenarios;

- Escritura de escenarios.

Los escenarios se diseñaron para expandir las visiones de los planificadores al proporcionarles imágenes de futuros alternativas como base para sus decisiones y como una herramienta para la evaluación de acciones de planificación en relación con las diferentes condiciones presentadas en los escenarios. Ayudan a lidiar con el futuro al aceptar sus incertidumbres y la multiplicidad de posibilidades. Por lo tanto, buscan mejorar la capacidad de estar preparados para hacer frente a las incertidumbres y ayudar a tomar decisiones más flexibles y resistentes. Tienen como objetivo proporcionar nuevas herramientas para pensar en el futuro, contemplar otras posibles alternativas, enfrentar riesgos e incertidumbres que generalmente evitamos hasta que se conviertan en una emergencia (Puglisi, 2001).

El modelo combina diferentes sectores a través de mecanismos de retroalimentación para captar la complejidad del comportamiento del sistema económico-climático. La matriz de sectores productivos utilizada en este estudio consta de seis secciones: (i) transporte, (ii) industria, (iii) residencial, (iv) comercial, servicios y administración pública, (v) agricultura, pesca y minería, (vi) construcción y otros. La matriz energética consta de las siguientes fuentes de energía primaria: petróleo, gas natural, energía hidroeléctrica, productos de caña y otros productos primarios. Las fuentes de energía finales son: electricidad, GLP, gasolina, kerosene y jet fuel, diesel, fuel oil, gases, crudo reducido y no energéticos. Las energías renovables no convencionales incluyen: solar fotovoltaica, eólica, biomasa, biogás y biocombustibles. Este enfoque estructural permite una representación más científica de las relaciones de retroalimentación.

Se desarrolló un conjunto de escenarios que busca identificar tendencias en intensidad energética y emisiones de $\mathrm{CO}_{2}$ relacionadas con el consumo de energía final en Ecuador. Los escenarios necesariamente incluyen subjetivos. La formulación de los escenarios es necesaria para predecir la evolución de las principales variables, que pueden impulsar políticas de generación de energía, y para proyectar el consumo y mitigación de emisiones de $\mathrm{CO}_{2}$. Para los propósitos de esta investigación, se propusieron tres escenarios: BAU (abreviatura de business as usual). Este escenario se refiere a la forma actual en que se están desarrollando los sistemas y qué pasaría si continuamos en las mismas condiciones. ESCENARIO1 considera todas las políticas propuestas por el gobierno nacional para proyecciones futuras. ESCENARIO2 es un escenario de tendencias globales de países industrializados.

El primer escenario diseñado es el business as usual (BAU) proyecta las tendencias actuales identificadas por cada nación, asume que las tendencias pasadas continuarán en el futuro y que no se implementarán nuevas políticas 
para este caso de investigación relacionada con la producción y el consumo de energía. El segundo escenario contempla los planes y estrategias de gobierno que se han establecido para los próximos años en Ecuador en materia de producción y consumo de energía. Se tienen en cuenta los siguientes documentos: Agenda Nacional de Energía 2014-2040, Balance Nacional de Energía 2015-2017, Plan Nacional de Eficiencia Energética 2016-2035, Plan Director de Electricidad 2016-2025, Plan Director de Electrificación 2013-2022, Análisis de oportunidades de I + D + i en Energía Eficiencia y energías renovables en Ecuador y Estrategia Nacional de Cambio Climático de Ecuador 2012-2025 (Ministerio del Ambiente, 2012) (CEPAL, 2013) (Conelec, 2013) (EP Petroecuador, 2013) (Economic Commission for Latin America and the Caribbean (ECLAC), 2013) (Ministerio Coordinador de Sectores Estratégicos, 2014) (Ministerio Coordinador de Sectores Estratégicos, 2015) (Ministerio Coordinador de Sectores Estratégicos, 2016a) (Ministerio Coordinador de Sectores Estratégicos, 2016b) (INER, 2016a) (Ministerio del Ambiente, 2017) (Ministerio de Electricidad y Energía Renovable, 2017a) (Ministerio de Electricidad y Energía Renovable, 2017b) (Ministerio de Electricidad y Energía Renovable, 2018) (Ministerio de Electricidad y Energía Renovable, 2020). Las políticas de este escenario plantean preocupaciones que incluyen: priorizar el uso de fuentes de energía renovables, promover el uso de energía hidroeléctrica y reemplazar la generación térmica ineficiente. Se propone la implantación masiva de iluminación eficiente en viviendas y vías públicas. Sugiere la aplicación de normas y reglamentos técnicos para el etiquetado de electrodomésticos y la sustitución de equipos con alto consumo energético. Se propone la sustitución del GLP por electricidad con la implementación de cocinas de inducción, implementación de sistemas de gestión energética en las principales industrias. Este escenario promueve la implementación de un transporte sostenible que considere la electricidad y no los hidrocarburos como la principal fuente de energía. Considera necesaria la mejora en la gestión de las empresas eléctricas, una soberanía energética es considerada como uno de los pilares de un nuevo Ecuador. Finalmente, el tercer escenario considera la dimensión ambiental de los objetivos de desarrollo sostenible, la gobernanza ambiental global, los acuerdos ambientales multilaterales, y las perspectivas macroeconómicas globales para el desarrollo sostenible, las estrategias de reemplazo para la energía limpia y la eficiencia energética, están considerando las proyecciones o tendencias de los informes de organizaciones como el Panel Intergubernamental sobre Cambio Climático (IPCC), la Agencia Internacional de Energía (IEA) y BP, entre otros (United Nations Environment Programme, 2005) (Intergovernmental Panel on Climate Change, 2012) (Intergovernmental Panel on Climate Change, 2014a) (Intergovernmental Panel on Climate Change, 2014b) (Intergovernmental Panel on Climate Change, 2014c) (United Nations Framework Convention on Climate Change, 2016) (International Energy Agency, 2017) (United States Environmental Protection Agency, 2017) (Intergovernmental Panel on Climate Change, 2018a) (Intergovernmental Panel on Climate Change, 
2018b) (IRENA, 2018) (DVG.GL, 2018) (NASA, 2018) (BP, 2018) (International Energy Agency, 2018a) (International Energy Agency, 2018b) (IRENA, 2019) (BP, 2019) (International Energy Agency, 2019a) (International Energy Agency, 2019b) (International Energy Agency, 2019c) (United Nations Environment Programme, 2019) (International Energy Agency, 2020a) (International Energy Agency, 2020b).

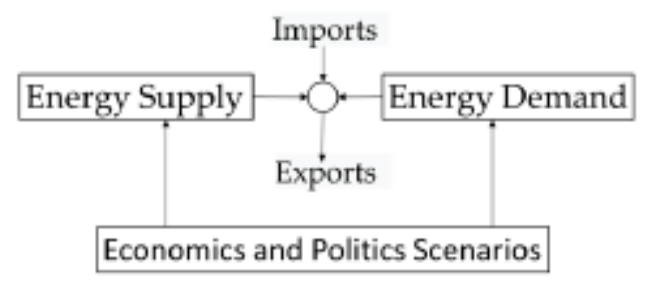

Figura 1. Diagrama de bloque del modelo

\subsection{Dinámica de Sistemas}

La DS se entiende, en el sentido de Forrester (1968), como una metodología para entender el cambio, utilizando las ecuaciones en diferencias finitas o ecuaciones diferenciales. Para entender la Dinámica Sistemas es importante entender que es un sistema. Para Javier Aracil, un sistema se entiende como una unidad cuyos elementos interaccionan juntos, ya que continuamente se afectan unos a otros, de modo que operan hacia una meta común. Por otra parte, el término dinámica lo empleamos por oposición a estática, y queremos con él expresar el carácter cambiante de aquello que adjetivamos con ese término. (Aracil, 1995).

La DS tiene su origen en la década de los años 30 cuando se desarrolló la teoría de los servomecanismos. En la década de los años 50, aprovechando los iniciales avances de la Informática, Jay Forrester desarrolla en el MIT (Massachusetts Institute of Technology) la Dinámica Industrial. La década siguiente, los años 60 , es la década de traspaso desde el mundo de la industria al ámbito social, al final de la década aparecen los primeros resultados "Principles of Systems" (1968), "Urban Dynamics" (1969), "World Dynamics" (1971) para el Club de Roma, "Counterintuitive Behavior of Social Systems" (1971) y "The life Cycle of Economic Development" (1973). Cabe mención aparte el libro de D.L.Meadows "Dynamics of Growth in a finite World" (1972) (García, Sysware, 2004).

Al hablar de la dinámica de un sistema nos referimos a que las distintas variables que podemos asociar a sus partes sufren cambios a lo largo del tiempo, como consecuencia de las interacciones que se producen entre ellas. Su comportamiento vendrá dado por el conjunto de las trayectorias de todas las variables, que suministra algo así como una narración de lo acaecido al sistema. Por otra parte, el término dinámico tiene una connotación no sólo de cambio, 
sino de la fuerza, de la determinación, que lo engendra (Aracil, 1995). Aunque la denominación DS, en un sentido amplio, se refiere al comportamiento dinámico que pueden presentar los sistemas, en sentido restringido se emplea para denominar una metodología concreta, desarrollada por Jay W. Forrester, que utiliza el lenguaje que acabamos de presentar para el modelado y la simulación de determinados problemas complejos.

La metodología sistémica pretende aportar instrumentos con los que estudiar aquellos problemas que resultan de las interacciones que se producen en el seno de un sistema, y no de disfunciones de las partes consideradas aisladamente. Para comprender su comportamiento necesitamos saber cómo se integran; cuáles son los mecanismos mediante los que se produce su coordinación. Necesitamos saber cómo se produce la síntesis de las partes en el sistema (Aracil, 1995). La DS fue concebida para resolver un problema concreto, originalmente el método se denominó dinámica industrial, por el tipo de aplicación (Gordillo \& Aracil, 1997). Los trabajos pioneros se desarrollaron a finales de los años 50. Peros es a mediados de los 60 que se comienza a ver los primeros resultados fuera del campo industrial. Aparecen la dinámica urbana y la dinámica regional que desarrollan modelos o aplicaciones para la planificación de esto sectores, se involucran indicadores socioeconómicos.

En la actualidad las aplicaciones de DS se han extendido desde sus orígenes en cuestiones empresariales y organizativas para abarcar cuestiones de salud, medioambientales, energéticas y climáticas, gestión de proyectos, algunos aspectos de las ciencias biológicas y fisiología humana, gobierno y políticas públicas. En los últimos años una aplicación interesante de la DS es el que analiza los recursos naturales, se tratan de definir estrategias para la utilización de recursos y energías renovables. La DS es radicalmente diferente a otras técnicas aplicadas a la construcción de modelos de sistemas socioeconómicos, como la econometría. Las técnicas econométricas, basadas en un enfoque conductista, emplean los datos empíricos, como base de los cálculos estadísticos para determinar el sentido y la correlación existente entre los diferentes factores. La evolución del modelo se realiza sobre la base de la evolución pasada de las variables denominadas independientes, y se aplica la estadística para determinar los parámetros del sistema de ecuaciones que las relacionan con otras denominas dependientes (Martín García, 2003).

La dinámica del sistema ha demostrado ser muy adecuada cuando se trata de sistemas complejos con retroalimentación y horizontes a largo plazo (Dyson \& Chang, 2005). Para probar su validez o utilidad, el modelo ha sido desafiado a reproducir datos históricos. Además, el modelo reproduce diferentes políticas que simulan futuros alternativos que se pueden esperar (Sterman J. D., 2000). Requiere construir los únicos "diagramas de bucle causal" o "stock", y "diagrama de flujo" para formar un modelo de dinámica del sistema para las aplicaciones. Trabajos relevantes sobre cómo desarrollar modelos de dinámica 
de sistemas se puede encontrar en la literatura (Forrester J. W., Industrial Dynamics, 1961) (Forrester J. W., 1968) (Forrester J. W., 1971) (Forrester \& Senge, 1980) (Randers, 1980) (Richardson \& Pugh, 1981) (Mohapatra, Mandal, \& Bora, 1994) (Sterman J. D., 2000) (Tang \& Vijay, 2001) (Sterman J. D., 2002) (Sterman, et al., 2012) (García, 2017).

\section{Hipótesis Dinámica}

La hipótesis dinámica en términos de diagrama de bucle causal y diagrama de flujo de existencias del sistema puede explicar la dinámica del problema. La hipótesis es provisional y está sujeta a revisión y rechazo, que depende únicamente del modo de comportamiento de referencia observado y simulado en un horizonte temporal (Sterman J. D., 2000). Es un modelo conceptual que generalmente consiste en un diagrama de bucle causal, un diagrama de flujo de existencias o su combinación. La hipótesis dinámica busca definir los circuitos críticos de retroalimentación que impulsan el comportamiento del sistema (Bala, Arshad, \& Noh, 2017). Cuando se simula el modelo basado en el concepto de retroalimentación, la estructura endógena del modelo debe generar el comportamiento del modo de referencia del sistema y, por lo tanto, la estructura endógena provoca los cambios en el comportamiento dinámico del sistema (Sterman J. D., Business dynamics. Systems thinking and modeling for a complex world, 2000). Los siguientes aspectos deben abordarse en el desarrollo de hipótesis dinámicas:

1. Estructura de retroalimentación endógena.

2. Comportamiento del modelo de referencia observado y simulado.

3. Teoría para explicar el comportamiento del modo de referencia.

La DS utiliza stocks y flujos para representar la evolución del sistema, por lo que es necesario identificar los stocks y flujos principales, y esquematizar las influencias existentes entre ellos mediante lo que se denomina un diagrama de Forrester, que pueden ser flechas directas de una variable a otra o bucles de realimentación, tanto con una relación positiva o negativa según el modelo a estudiar (García G., 2013).

Diagrama de bucle causal

El siguiente paso en el pensamiento de sistemas es buscar las relaciones entre las variables y los desarrollos de los circuitos de retroalimentación. Estas estructuras de retroalimentación se representan en forma de diagramas de bucles causales en la dinámica del sistema (Sterman J. D., 2000) y en forma de diagrama de bloques de la teoría de control en el análisis de sistemas (Manetsch \& Park, 1982). La Figura 2 muestra el diagrama de bucle causal. 


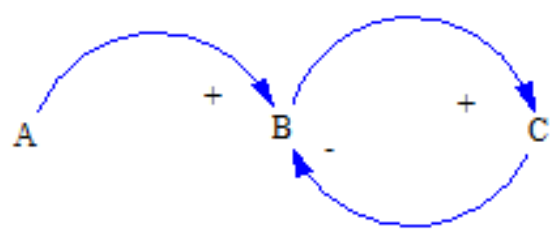

Figura 2. Ejemplo de diagrama causal

Una influencia causal positiva, simbolizada por el "+", significa que si la variable de influencia (que está en el origen de la flecha) aumenta entonces la variable influenciada (que está en la punta de la flecha) se incrementa. Una influencia causal negativa, simbolizada por el "-" significa que si la variable de influencia aumenta entonces la variable influenciada disminuye (García G., 2013).

El diagrama de bucle causal representa la estructura de retroalimentación de los sistemas para capturar las hipótesis sobre las causas de la dinámica y los comentarios importantes. Se supone que la estructura de bucle causal que genera el comportamiento de referencia del sistema es la hipótesis dinámica. Los siguientes pasos se siguen en el desarrollo del diagrama de bucle causal:

1. Definir el problema y los objetivos.

2. Identificar los elementos más importantes de los sistemas.

3. Identificar los elementos secundarios importantes de los sistemas.

4. Identificar los elementos terciarios importantes de los sistemas.

5. Definir las relaciones causa-efecto.

Diagrama de flujo - stock

El diagrama de flujo - stock representa ecuaciones de diferencias finitas integrales que involucran las variables de la estructura del circuito de retroalimentación del sistema y simula el comportamiento dinámico del sistema. Pero las ecuaciones diferenciales se formulan en el análisis de sistemas basado en el diagrama de bloques de la teoría de control (Manetsch \& Park, 1982). El diagrama de flujo de existencias o el sistema de las ecuaciones diferenciales que representan la estructura de retroalimentación de los sistemas captura las hipótesis sobre las causas de la dinámica y las retroalimentaciones importantes (Bala, Arshad, \& Noh, 2017). La Figura 3 muestra el diagrama de flujo de existencias de un modelo de población simple.

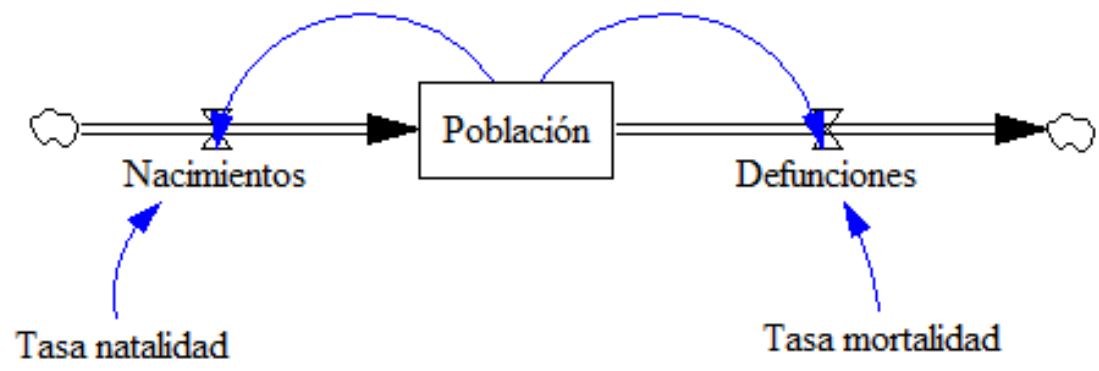


Figura 3. Modelo de flujo - stock

Validación de modelos, análisis de sensibilidad y análisis de políticas

La validez y validación del modelo se ha reconocido desde hace mucho tiempo como uno de los principales problemas en el campo de la dinámica de sistemas (Barlas, 1996) (Forrester J. W., Principles of System, 1968) (Forrester \& Senge, 1980). la validación de un modelo de dinámica de sistemas consta de dos componentes amplios: validación de la estructura y validación del comportamiento (Barlas \& Korhan, 1999) (Lemke \& Łatuszyńska, 2013).

Las pruebas para generar confianza en el modelo de dinámica del sistema consisten en validación, análisis de sensibilidad y análisis de políticas de modelos de dinámica del sistema. Las dos nociones importantes de la construcción de confianza en los modelos de dinámica del sistema son las pruebas y la validación. La prueba significa la comparación de un modelo con la realidad empírica para aceptar o rechazar el modelo, y la validación significa el proceso de establecer confianza en la solidez y utilidad del modelo (Bala, Arshad, \& Noh, 2017). Las pruebas para generar confianza en los modelos de dinámica del sistema pueden clasificarse en términos generales como:

1. Pruebas de estructura.

2. Pruebas de comportamiento.

3. Pruebas de implicación política.

Aplicación del modelo de simulación

Es necesario seguir un orden en el proceso de diseño de un modelo de simulación basado en DS, según (Martín García, 2018) se deben seguir ciertas etapas que se describen a continuación:

a) Crear el diagrama causal. - Es un método sencillo de ordenar las ideas, con frecuencia confusas al inicio de cualquier estudio, es una etapa previa, permite pasar con facilidad los elementos y las relaciones del sistema al diagrama de flujos, permitiendo una comunicación clara y fluida. En esta fase se deben definir los siguientes puntos:

i. Definir problema

ii. Definir las influencias de primer orden

iii. Definir las influencias de segundo orden

iv. Definir las influencias de tercer orden

v. Definir las relaciones

vi. Identificar los bucles de realimentación

vii. Depurar las influencias no relevantes

viii. Idear posibles soluciones al problema 
b) Creación de Diagrama de Flujos. - La creación del diagrama de flujos se hace directamente en el software de simulación. Está compuesto por:

i. Caracterizar los elementos

ii. Escribir las ecuaciones

iii. Asignar Valores a los parámetros

iv. Crear una primera versión del modelo

v. Estabilizar el modelo

vi. Identificar los elementos clave

vii. Simular

c) Obtener las conclusiones. - Elaborar las conclusiones una vez que hemos completado el proceso de simulación, deben ser concisas y muy claras, se puede acompañar de un diagrama causal.

Para hacer el proceso de modelado más sencillo, y también ayudar a su visualización, se divide el modelo en subsistemas. En el programa cada subsistema será incluido en una ventana diferente donde estarán contenidas las variables correspondientes. De esta manera es más fácil identificar las diferentes estructuras y comportamientos, lo que facilita el proceso de modelado (García G., 2013). La DS no es una herramienta diseñada para predecir el futuro, sino más bien es una herramienta para comprender el presente, es decir, comprender las variables que interactúan y de qué manera pueden influir. El modelo de simulación reproduce el comportamiento del sistema debido a los valores de los parámetros y debido a la estructura diseñada (García G., 2013). La descripción general del enfoque de modelado de dinámica del sistema presentada en la Figura 4.

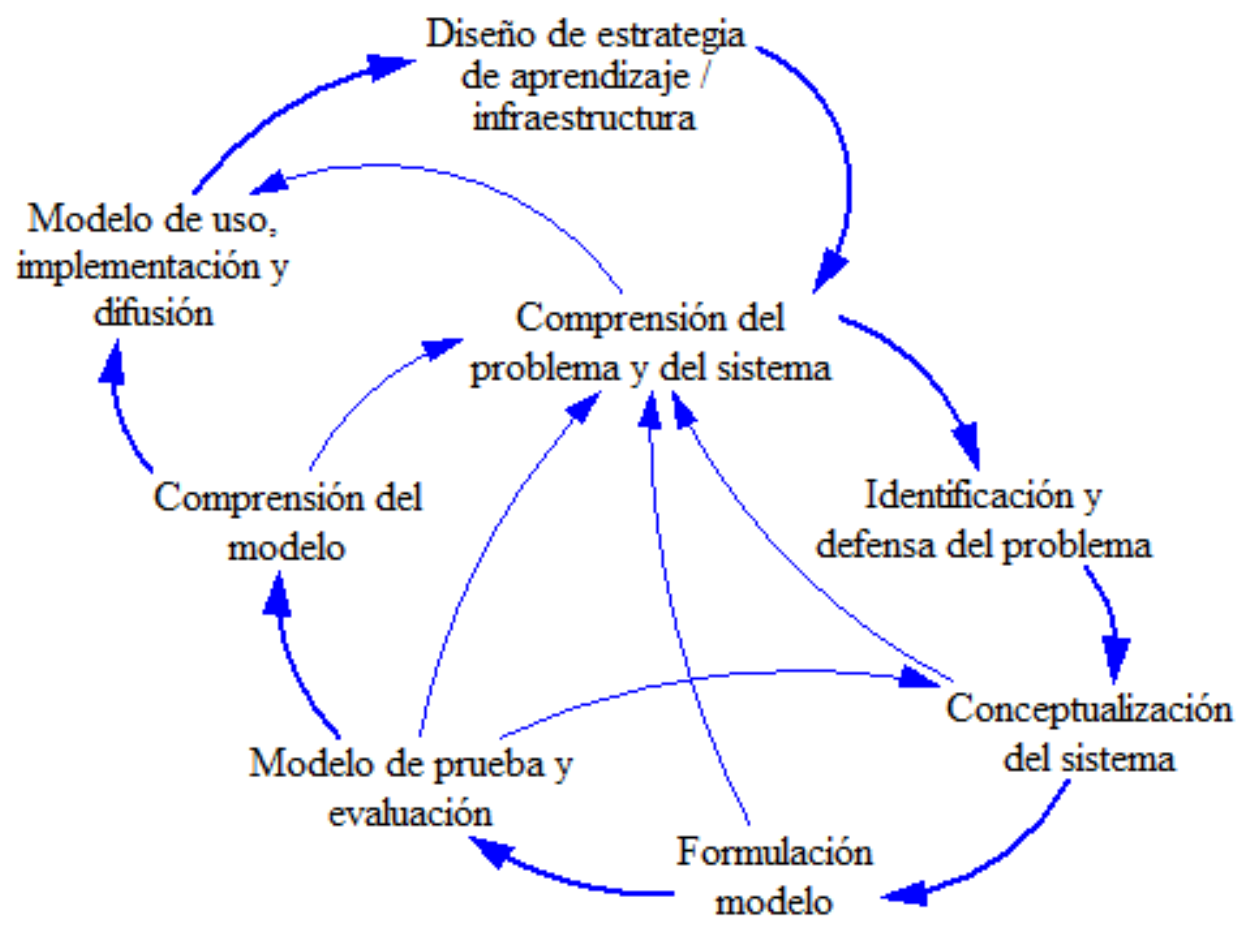


Figura 4 Descripción general del enfoque de modelado de dinámica del sistema (Martinez-Moyano \& Richardson, 2013)

\subsection{Modelado y simulación}

Los modelos de simulación se utilizan cada vez más para resolver problemas y ayudar en la toma de decisiones (Shreckengost, 1985) (Sargent, 2011). El modelo propuesto se divide en cuatro módulos principales: economía, demanda de energía, disponibilidad de energía y clima/emisiones. La descripción esquemática conceptual incluye las principales relaciones entre los diferentes módulos. Las principales características de cada módulo son:

- Economía: se modela la economía, asumiendo un crecimiento impulsado por la demanda y la complementariedad del sector. Por lo tanto, la producción está determinada por la demanda final y la estructura económica, combinadas con restricciones del lado de la oferta, como la disponibilidad de energía.

- Demanda de energía: la demanda de energía final por sector se estima a través de la proyección de la producción económica del sector y la demanda de energía final del sector, considerando las mejoras de eficiencia y los reemplazos de energía inter-finales impulsados por las políticas y la escasez física.

- Disponibilidad de energía: este módulo incluye el potencial y la disponibilidad de las fuentes de energía renovables y no renovables, considerando las limitaciones biofísicas y temporales. En particular, la disponibilidad de recursos energéticos no renovables depende tanto de las limitaciones de stock como de flujo. En total, se consideran 5 fuentes de energía y tecnologías, y 9 energías finales (electricidad, sólidos, gases y líquidos), con un desglose tecnológico. El modelo de la disponibilidad de energía se basa principalmente en el modelo anterior de WoLiM.

- Clima/emisiones: el modelo global calcula los niveles de emisiones de $\mathrm{CO}_{2}$ generadas por la cantidad final de energía utilizada en Ecuador.

La evolución e integración del modelo en todos los módulos requiere, para cada paso de tiempo, que la demanda y el suministro de energía se equilibren dinámicamente. El sistema fue diseñado para establecer políticas energéticas y emisiones de $\mathrm{CO}_{2}$ en el Ecuador en 2030. También se consideran los recursos energéticos tradicionales del país. Se analiza el impacto del crecimiento económico sobre el consumo energético y las emisiones de $\mathrm{CO}_{2}$. El diagrama de flujo del sistema económico-energético-emisiones de carbono se muestra en la Figura 5. El consumo energético de cada uno de los sectores económicos genera emisiones de $\mathrm{CO}_{2}$. 


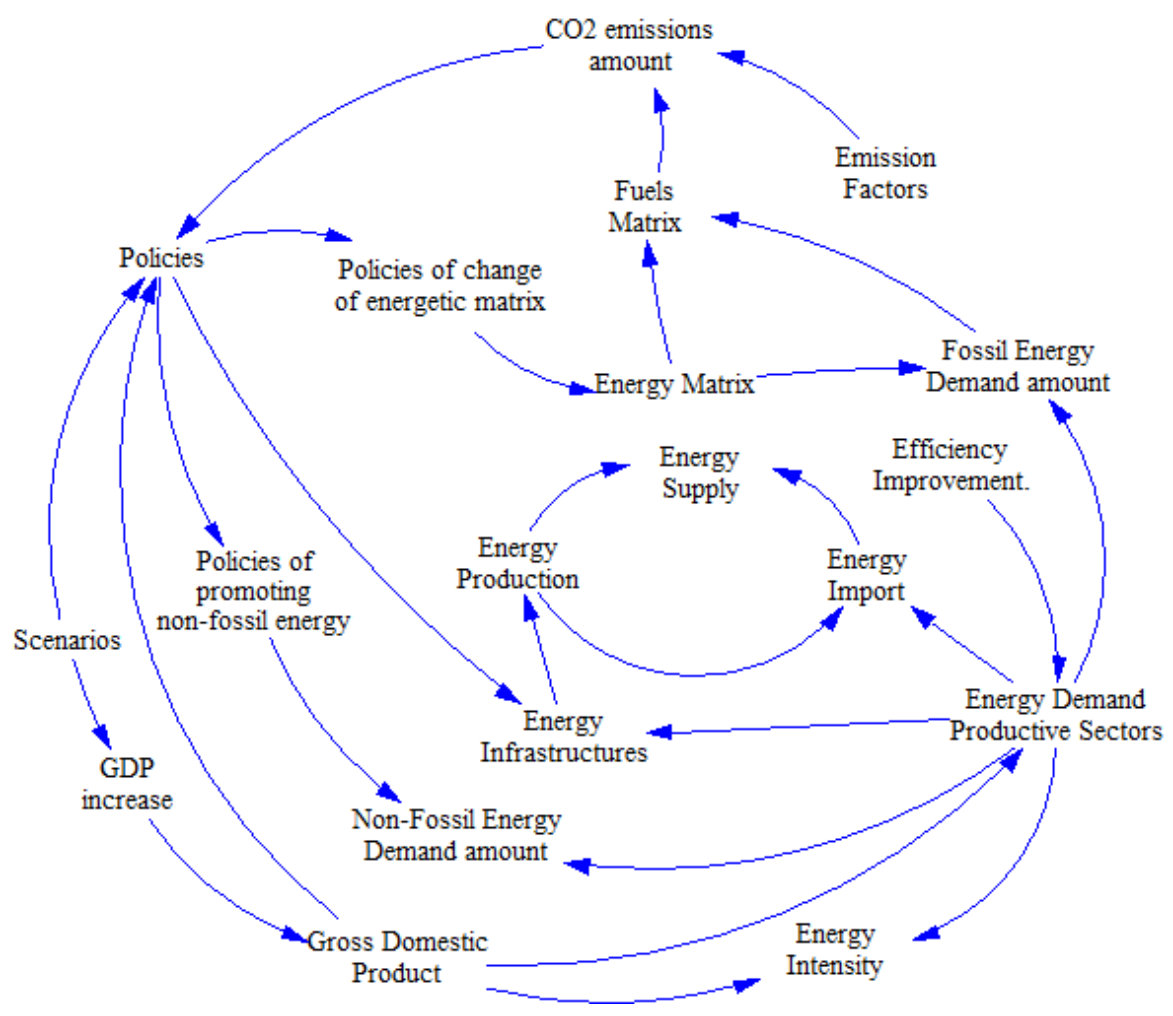

Figura 5 Diagrama de influencia simplificado para el análisis input-output en el modelo de Ecuador

\subsection{Estado del Arte}

Aproximadamente el $97 \%$ de la investigación climática revisada por pares concluye que los GEI de la quema de combustibles fósiles, la agricultura / actividades industriales y la deforestación (todas las actividades causadas por el hombre) son las principales causas del cambio climático antropogénico (Benestad, et al., 2016) (Andrée, Chamorro, Spencer, Koomen, \& Dogo, 2019). El cambio climático como se explicó anteriormente es el responsable de inundaciones pronunciadas, la muerte de la vida silvestre, problemas respiratorios humanos, problemas de eliminación de desechos (que ya son un gran desastre y solo se harán más grandes), más lluvias, más huracanes dañinos y temperaturas más altas (Amoo \& Fagbenle, 2020). La alta concentración de $\mathrm{CO}_{2}$ en la atmósfera aumentará si no se trata de una manera adecuada el problema de las emisiones de $\mathrm{CO}_{2}$. En 2019 se informó que la concentración media de $\mathrm{CO}_{2}$ en la atmósfera $(414,7 \mathrm{ppm})$ era un $45 \%$ superior a la obtenida entre 1980 y 1990 (Apadula, Cassardo, Ferrarese, Heltai, \& Lanza, 2019) (Kelektsoglou, 2018). Las emisiones globales de $\mathrm{CO}_{2}$ debidas a las actividades humanas han aumentado en más del 400\% desde 1950 (Maximillian, Brusseau, Glenn, \& Matthias, 2019). Según el acuerdo de París de 2015, el aumento de la temperatura del interior de la Tierra debería mantenerse por debajo de los $2^{\circ} \mathrm{C}$ en comparación con los niveles preindustriales, y el aumento de la temperatura de la Tierra debería limitarse a menos de $1,5^{\circ} \mathrm{C}$. Para alcanzar el objetivo establecido en el acuerdo de París requiere la captura y almacenamiento de al 
menos 1 gigatonelada (Gt) de $\mathrm{CO}_{2}$ al año hasta 2030 (Rogelj, et al., 2016) (van Soest, et al., 2017) (Intergovernmental Panel on Climate Change, 2018b).

La energía es uno de los temas más ampliamente discutido en la actualidad, es un insumo esencial en la producción de la mayoría de los bienes y servicios. El consumo y la eficiencia energética afectan a todas las actividades económicas e industriales, mientras que la productividad energética y la mejora del consumo energético son temas primordiales que impactan en la economía de cualquier país (Howarth, Galeotti, Lanza, \& Dubey, 2017) (Mirzaei \& Bekri, 2017). La energía sigue dependiendo principalmente de los combustibles fósiles, como el carbón, el petróleo y los productos del gas natural, que emiten $\mathrm{CO}_{2}$. Varias investigaciones evidencian que las emisiones de $\mathrm{CO}_{2}$ han contribuido más al cambio climático (Akpan \& Akpan, 2012) (Lu \& Wu, 2016).

Las emisiones globales de $\mathrm{CO}_{2}$ relacionadas con la energía se estabilizaron en 2019 en alrededor de 33 gigatoneladas (Gt), luego de dos años de aumentos. Esto se debió al papel cada vez mayor de las fuentes renovables (principalmente eólica y solar fotovoltaica), el cambio de combustible del carbón al gas natural y una mayor producción de energía nuclear principalmente en las economías avanzadas (International Energy Agency, 2020a). La creciente preocupación de impactos negativos de la generación y el consumo de energía ha promovido un sin número de investigaciones enfocadas en estudiar la estructura energética, desarrollo de nuevas tecnologías bajas en carbono y la promulgación de políticas que promuevan la seguridad energética, la competitividad industrial y la protección del medio ambiente (Huaman \& Jun, 2014). El sistema energético mundial debe cambiar radicalmente en las próximas décadas para hacer frente a los desafíos de doble presión que suponen el agotamiento de los combustibles fósiles y el cambio ambiental global (CapellánPérez I. , Mediavilla, de Castro, Carpintero, \& Miguel, 2014) (Mohr, Wang, Ellem, Ward, \& Giurco, 2015) (Intergovernmental Panel on Climate Change, 2018a) (International Energy Agency, 2019a).

En la actualidad la literatura sobre trabajos afines con el estudio de la relación existente entre el consumo de energía, crecimiento económico y emisiones de $\mathrm{CO}_{2}$ es extensa. Numerosos estudios han examinado la relación causal entre el consumo de energía y varias variables independientes como el crecimiento económico, el desarrollo financiero, el empleo y la población. La energía es el salvavidas de una economía, el instrumento más vital del desarrollo socioeconómico y reconocido como uno de los productos estratégicos más importantes (Saidi \& Hammami, 2015). La energía se considera un agente principal en la generación de riqueza y un factor significativo en el desarrollo económico de las naciones.

El crecimiento económico si bien elevó los estándares de vida en la mayoría de los países, también fue responsable del aumento en las emisiones 
de $\mathrm{CO}_{2}$ y la reducción de los recursos naturales. Los niveles de emisiones de $\mathrm{CO}_{2}$ están estrechamente relacionados con factores sociales, económicos e industriales (Mardani, Streimikiene, Cavallaro, Loganathan, \& Khoshnoudi, 2019). La mayoría de los estudios previos han confirmado que el nexo entre el crecimiento económico y el uso de energía tienen un efecto significativo en las emisiones de $\mathrm{CO}_{2}$ (Mohapatra, Mandal, \& Bora, 1994) (Xue, Geng, Muller, Lu, \& Ren, 2012) (Zhang \& Da, 2015) (Saidi \& Hammami, 2015) (Wang, Li, Fang, \& Zhou, 2016) (Chen P.-Y. a.-T.-S.-C., 2016) (Riti, Song, Shu, \& Kamah, 2017) (Han, Du, Zhang, \& Qian, 2018) (Sterpu, Soava, \& Mehedintu, 2018) (Muhammad, 2019) (Silva Herran, Tachiiri, \& Matsumoto, 2019) (Munir, Lean, \& Smyth, 2020) (Chontanawat, 2020).

La relación causal entre el consumo de energía, el medio ambiente y el crecimiento económico ha sido bien estudiada en la literatura sobre economía energética. Estos estudios se han centrado en diferentes países, períodos de tiempo, variables proxy y diferentes metodologías que han dado una visión general del campo de la modelización de la evaluación Integrada del cambio climático o de la economía energética-climática (Ang, 2007) (Soytas, Sari, \& Ewing, 2007) (Ang, 2008) (Halicioglu, 2009) (Apergis \& Payne, 2009) (Ozturk \& Acaravci, 2010) (Pao \& Tsai, 2010) (Bartleet \& Gounder, 2010) (Li, et al., 2010) (Menyah \& Wolde-Rufael, 2010) (Niu, Ding, Niu, Li, \& Luo, 2011) (Pao, YU, \& Yang, 2011) (Ma, Ju, Zhang, \& Li, 2011) (Pao \& Tsai, 2011) (Arouri, Youssef, M'henni, \& Rault, 2012) (To, Wijeweera, \& Charles, 2012) (Saboori \& Sulaiman, 2013) (Ozturk \& Acaravci, 2013) (Al-mulali, Lee, Mohammed, \& Sheau-Ting, 2013) (Salahuddin \& Gow, 2014) (Magazzino, 2014) (Mohapatra \& Giri, 2015) (Nain, Ahmad, \& Kamaiah, 2015) (Ara Begum, Sohag, Syed Abdullah, \& Jaafar, 2015) (Saidi \& Hammami, 2015) (Yu, et al., 2015) (Haseeb \& Azam, 2015) (Kais \& Ben Mbarek, 2015) (Wang, Li, Fang, \& Zhou, 2016) (Esso \& Keho, 2016) (Mirzaei \& Bekri, 2017) (Roinioti \& Koroneos, 2017) (Mirza \& Kanwal, 2017) (Arango-Miranda, Hausler, Romero-Lopez, Glaus, \& Ibarra-Zavaleta, 2018) (Mondal, Bryan, Ringler, Mekonnen, \& Rosegrant, 2018) (Muhammad, 2019) (Andrée, Chamorro, Spencer, Koomen, \& Dogo, 2019) (Wasti \& Zaidi, 2020). Estos estudios evalúan el impacto del cambio climático en sistema humano y ecológico y las diferentes estrategias de adaptación, así como el nexo entre el crecimiento económico y la calidad ambiental relacionadas al uso de energía y emisiones de $\mathrm{CO}_{2}$ en busca de un desarrollo sostenible. Las investigaciones revelan la relación de equilibrio a largo plazo entre las emisiones, el uso de energía y la producción real lo que concluye que tanto el crecimiento económico como las políticas de conservación o sustitución de energía pueden reducir las emisiones y no tener un impacto negativo en el desarrollo económico.

La necesidad de comprender y predecir el funcionamiento y el rendimiento de los componentes individuales del sistema energético o el comportamiento general del sistema motivaron el desarrollo de modelos con diferentes 
orientaciones que se esfuerzan por capturar las complejas interacciones involucradas y las altas incertidumbres. Revisa la literatura, son varios los enfoques propuestos de modelado con diferentes propósitos, (de Castro, 2009) (Herbst, Toro, Reitze, \& Jochem, 2012) (Sheinbaum-Pardo, Mora-Pérez, \& Robles-Morales, 2012) (Capellán-Pérez, et al., 2013) (Gambhir, Tong, Munuera, Faist, \& Riahi, 2013) (Capellán-Pérez I. , Mediavilla, de Castro, Carpintero, \& Miguel, 2014) (Akhmetov, 2015) (Chen P.-Y. a.-T.-S.-C., 2016) (Elsawah, y otros, 2017) (Mutingi, Mbohwa, \& Kommula, 2017) (Capellán-Pérez, et al., 2017a) (Capellán-Pérez, et al., 2017b) (Yeh \& Liao, 2017) (Subramanian, Gundersen, \& Adams, 2018) han desarrollado modelos energéticos para proyectar principalmente la demanda y oferta energética, las emisiones de $\mathrm{CO}_{2}$ y otros factores relacionados como el desarrollo económico, población, innovación tecnológica, inversiones en sistemas energéticas y políticas de eficiencia energética. Los enfoques del modelado se han sustentado a lo largo del tiempo en función de su grupo objetivo, uso previsto, la cobertura regional, el marco conceptual y la información disponible.

Varias investigaciones sobre el cambio climático se han centrado en sectores clave, incluidos los sectores de la electricidad y el calor, el transporte, las industrias de la construcción, la agricultura, así como los principales sectores industriales, como las industrias del acero, productos químicos y petroquímicos, aluminio y cemento. Estos estudios han aplicado diferentes metodologías, que analizan las diferentes características de los diferentes sectores que demandan energía y las tendencias de las emisiones de $\mathrm{CO}_{2}$ (Farhani \& Rejeb, 2012) (Aslan, 2013) (Ansari \& Seifi, 2013) (Azhaginiyal \& Umadevi, 2014) (CapellánPérez I. , Mediavilla, de Castro, Carpintero, \& Miguel, 2014) (Yu, et al., 2015) (Karimu, Brännlund, Lundgren, \& Söderholm, 2017) (Bekhet, Matar, \& Yasmin, 2017) (Li, Zhang, Li, \& He, 2017) (Neves, Marques, \& Fuinhas, 2017) (Jokar \& Mokhtar, 2018) (Barisa \& Rosa, 2018) (Wu, Zhu, \& Zhu, 2018) (Wang, Wei, \& Shao, 2020) (Pita, Winyuchakrit, \& Limmeechokchai, 2020).

Las herramientas científicas orientadas a mejorar la formulación de políticas energéticas requieren un compromiso entre practicidad y exhaustividad. Hay miles de trabajos sobre temas relacionados con el cambio climático, la mayoría de ellos centrados en tecnologías específicas, combustibles, sectores o regiones con el objetivo de reducir las emisiones de gases de efecto invernadero (GEI), mitigando así los efectos del cambio climático (García-Gusano \& Iribarren, 2018). Los modelos energéticos tradicionales aplicados a los estudios anteriores han utilizado predicciones deterministas bajo el supuesto de que podemos prever con precisión la evolución del sistema energético. La mayoría de ellos se ejecutan con la ayuda del análisis de escenarios como una instantánea que describe un futuro posible y plausible, lo que dificulta la gestión adecuada de la evolución dinámica y el comportamiento estocástico intrínseco de muchos 
elementos vitales dentro del sistema energético (Feng, Chen, \& Zhang, 2013) (Zhou, Jin, Du, \& Zhang, 2018).

El modelado de sistemas energéticos es un problema complejo debido a la presencia de múltiples tomadores de decisiones, la complejidad de los comportamientos de los consumidores, los procesos de retroalimentación entre los módulos, las limitaciones tecnológicas y diversos tipos de retrasos (Mirzaei \& Bekri, 2017). El modelo de dinámica de sistemas es un enfoque adecuado para modelar tales complejidades, porque es una técnica de modelado poderosa para comprender y explorar la estructura de retroalimentación en sistemas complejos. La DS se adopta para explorar la relación intrínseca entre la demanda de energía y el entorno económico y social para pronosticar la demanda de energía y las emisiones de carbono permitiendo una mejor comprensión de las interconexiones inherentes y las estructuras evolutivas dinámicas que impactan el desarrollo futuro del sistema energético (Deaton \& Winebrake, 2000) (Dyson \& Chang, 2005) (Alam, Begum, Buysse, Rahman, \& Van Huylenbroeck, 2011) (Feng, Chen, \& Zhang, 2013) (Robalino López, García Ramos, Golpe, \& Mena Nieto, 2014) (Liu, et al., 2015) (Mirzaei \& Bekri, 2017) (Mutingi, Mbohwa, \& Dube, 2017) (Stamatiou \& Dritsakis, 2017) (Mutingi, Mbohwa, \& Kommula, System dynamics approaches to energy policy modelling and simulation, 2017) (Wu \& Ning, 2018) (Ansell \& Cayzer, 2018) (Kang, Islam, \& Tiwari, 2019) (Bamooeifard, 2020).

La DS está diseñada para identificar y explicar la dinámica del comportamiento no lineal de factores clave y las formas en que interactúan entre sí. La dinámica de sistemas se centra en los circuitos de retroalimentación y las relaciones causales, que facilitan la identificación y definición de las relaciones entre varios sistemas (Akpınar \& Saysel, 2010) (Akhtar, 2011). Las relaciones causales afectan el sistema de manera diferente (positiva o negativamente) razón por la cual se debe alcanzar un equilibrio entre el consumo de energía, el crecimiento económico y la calidad ambiental. La DS se convierte hoy en día en una herramienta útil para la toma de decisiones a nivel estratégico (Mamatok, Huang, Jin, \& Cheng, 2019). Los Modelos de Evaluación Ambiental Integrada constituyen una poderosa herramienta de modelado para integrar múltiples disciplinas y dimensiones a fin de arrojar luz sobre las posibles vías de sostenibilidad en la era del cambio ambiental global, la integración constante de todos los procesos físicos y sociales se ve desafiada por una combinación de lagunas e incertidumbres del conocimiento científico, así como por la imprevisibilidad inherente de los caminos futuros que deben tomar para explorar las vías de transición a una economía baja en carbono (Capellán-Pérez, et al., 2020).

(Feng, Chen, \& Zhang, 2013) desarrollaron un modelo de dinámica de sistemas integrado basado en el marco del software STELLA para proyectar la 
demanda de energía y las emisiones de CO2 en Beijing durante 2005-2030, este estudio proporcionaría una base cuantitativa para una planificación y gestión de energía urbana eficaz, así como escenarios alternativos. para el desarrollo de una ciudad baja en carbono. Los resultados del modelo muestran que Beijing se enfrentará a una pesada carga de suministro de energía y mitigación de carbono, lo que enfatizará la necesidad urgente de ahorro de energía y reducción de emisiones.

(Capellán-Pérez Í. , Mediavilla, de Castro, \& Miguel, 2014) construyeron el modelo WoliM que se basa en una estructura secuencial que comienza considerando un marco de escenarios que consiste en un conjunto de supuestos y políticas socioeconómicas y tecnológicas que se integran de manera coherente y sensible. Los supuestos socioeconómicos impulsan la evolución de la demanda mundial de energía a lo largo del tiempo (2010-2050). La demanda de energía se desagrega según los diferentes sectores de uso final y por tipos de fuentes de energía y finalmente, se calculan las emisiones netas de $\mathrm{CO}_{2}$ y los niveles de concentración.

(Liu, et al., 2015) utilizaron un modelo de dinámica de sistemas para analizar el consumo de energía tradicional, el consumo de energía alternativa y las emisiones de $\mathrm{CO}_{2}$ hasta 2020 en China. Se simula una serie de escenarios para examinar el impacto de diferentes tasas de crecimiento económico y políticas sobre diferentes combinaciones de usos de energía y emisiones de $\mathrm{CO}_{2}$ en el futuro. El análisis tiene importantes implicaciones en las políticas energéticas, promueve el uso de recursos de energía renovable es una forma eficaz y una tasa de crecimiento económico más rápida también ayudaría a alcanzar este objetivo hasta cierto nivel. Una mayor tasa de crecimiento económico conduciría a un mayor consumo de energía y emisiones totales de $\mathrm{CO}_{2}$. Por lo tanto, se deben implementar una serie de políticas para el desarrollo de energías renovables en la mejora tecnológica y el apoyo financiero de China

(Mirzaei \& Bekri, 2017) para proyectar el consumo de energía y las emisiones de $\mathrm{CO}_{2}$ en Irán durante el período 2000-2025, desarrolló un modelo de dinámica de sistema integrado basado en un marco de software Vensim. Se simularon diferentes políticas de escenarios para investigar el efecto de la reducción de la intensidad energética en la combinación del consumo de energía y las emisiones de $\mathrm{CO}_{2}$ en el futuro. Los resultados del modelo afirman que Irán estará fuertemente cargado con una elevada producción de energía y emisiones de $\mathrm{CO}_{2}$ al 2025.

(de Blas, Miguel, \& Capellán-Pérez, 2019) plantearon un método novedoso para estimar la demanda energética, basado en la proyección de la evolución de las intensidades energéticas finales sectoriales, desarrollado para el marco de modelización de evaluación integrada MEDEAS. La evolución de las intensidades de energía final sectorial se ha desagregado en tres factores: (1) 
tendencia histórica, (2) cambios por mejora de la eficiencia energética y (3) cambios por intercambio entre los tipos de energía final consumida.

(Capellán-Pérez, et al., 2020) describen el marco de modelado de evaluación integrado MEDEAS de código abierto, que ha sido desarrollado con el objetivo de informar la toma de decisiones para lograr la transición a sistemas de energía sostenible con un enfoque en las restricciones biofísicas, económicas, sociales y tecnológicas y la aplicación de supuestos de modelado alternativo y métodos a un conjunto básico de supuestos comunes en modelos de evaluación ambiental. El modelo está diseñado para funcionar hasta 20602100 y están estructurados conceptualmente en nueve módulos: economía, demanda de energía, disponibilidad de energía, infraestructuras de energía y retorno de energía de la energía invertida (EROI), minerales, uso de la tierra, agua, clima / emisiones e indicadores de impacto social y ambiental. De los resultados del modelo MEDEAS-W se puede pronosticar que si las condiciones continúan como los años anteriores los niveles de aumento de temperatura seguirán creciendo por lo que se prevé una crisis socioeconómica y ambiental global sistémica generalizada en las próximas décadas en ausencia de políticas de sostenibilidad global rápidas y drásticas por lo que se hace necesario plantear caminos sostenibles que mejoren el futuro. El sistema energético mundial debe cambiar radicalmente en las próximas décadas a fin de hacer frente a los desafíos doblemente apremiantes del agotamiento de los combustibles fósiles y el cambio ambiental global (de Blas, Miguel, \& Capellán-Pérez, 2019).

Como se indicó anteriormente el sector energético constituye por sí mismo una parte importe de la actividad económica en un país, su relevancia radica en satisfacer las necesidades diarias de los ciudadanos dinamizando la economía para alcanzar un mejor crecimiento económico. Las políticas energéticas deben enfocarse en el abastecimiento energético, calidad y precio (International Energy Agency, 2019c) (IRENA, IEA and REN21, 2018), en este sentido la prospectiva energética resulta una herramienta muy útil para realizar una planificación energética óptima, porque resulta imposible anticipar lo que habrá de ocurrir (Fouquet \& Pearson, 2012). El análisis prospectivo es entendido como la exploración de futuros posibles y supone la formulación de una variedad de escenarios que representen evoluciones bien contrastadas evidenciando las falencias, los puntos en los cuales es posible mejorar y lo más importante plantear estrategias que se aplicaran en un futuro plan energético.

En los últimos cien años, varias iniciativas regionales e internacionales han abordado sobre desafíos de implementar y fomentar las energías renovables y el establecimiento de una economía baja en carbono (Fritzsche, Zejli, \& Tänzlera, 2011) (Kottari, 2016) (Van de Graaf \& Colgan, 2016) (Ringel \& Knodt, 2018). La gobernanza energética juega un papel importante en la estabilidad y sostenibilidad del orden energético global, asegurando la estabilidad de la oferta, 
demanda y precios en el mercado de la energía, abordando los problemas ambientales incluido el cambio climático (Florini \& Sovacool, 2009) (Fontaine, 2011) (Müller, Knodt, \& Piefer, 2015) (Koyama, 2018).

Concretamente los trabajos realizados sobre modelos energéticos, análisis de escenarios o dinámica de sistemas que toman como región de estudio al Ecuador tenemos:

(Morales \& Sauer, 2001) investigan sobre las medidas de gestión del lado de la demanda que pueden conducir a la reducción de la demanda de combustibles fósiles y mitigar las emisiones de gases de efecto invernadero en Ecuador. Las evaluaciones técnicas y económicas se llevan a cabo mediante la construcción de escenarios con el modelo del Sistema de Planificación de Alternativas Energéticas de Largo Alcance (LEAP). Los resultados muestran el atractivo de las medidas basadas tanto en la sustitución de fuentes de energía como en la eficiencia energética.

(Peláez Samaniego, Garcia Perez, Cortez, Oscullo, \& Olmedo, 2007) describen el sector energético actual en Ecuador, su estructura, la industria petrolera, los subsidios y las energías renovables, centrándose en la evolución y la reforma del sector eléctrico.

Andrés Robalino López en su tesis doctoral "Carbon emissions, energy consumption and sustainable development in Ecuador (1980-2025): system dynamics modelling, decomposition analysis and the Environmental Kuznets Curve", aplicó una combinación del llamado análisis de descomposición con un análisis de escenarios para identificar y determinar las fuerzas impulsoras del cambio de emisiones de $\mathrm{CO}_{2}$ en Ecuador. Se ha considerado un histórico, desde 1980 hasta 2010, y un período de pronóstico previo, desde 2011 hasta 2025. El Índice de Divisa Media Logarítmica (LMDI) para llevar a cabo el análisis de descomposición se ha aplicado tanto al período histórico como al pronóstico, utilizando en este último caso diferentes escenarios plausibles de desarrollo (Robalino López A. , 2014) (Robalino López, Mena Nieto, \& García Ramos, 2014).

(Robalino López, García Ramos, Golpe, \& Mena Nieto, 2014) presentaron un modelo de emisiones de $\mathrm{CO}_{2}$ en Ecuador en los próximos años, hasta 2020. El modelo diseñado es una variación de la identidad de Kaya, y un Producto Interno Bruto (PIB) que depende de las energías renovables que introduce un mecanismo de retroalimentación. El objetivo principal de este trabajo es estudiar en detalle la forma en que los cambios en la matriz energética y en el (PIB) afectarán las emisiones de $\mathrm{CO}_{2}$ del país. El estudio concluye que es necesario una reducción de la participación de la energía fósil, así como una mejora en la eficiencia del uso de la energía fósil. 
(Robalino López, García Ramos, Golpe, \& Mena Nieto, 2014) analizan si la hipótesis EKC se mantiene dentro del período 1980-2025 en cuatro escenarios diferentes. Este documento utiliza técnicas de cointegración (Stock \& Watson, 2010) para probar la existencia de la hipótesis EKC en Ecuador a mediano plazo utilizando la especificación de (Jaunky, 2011). La propuesta va un paso más allá de las contribuciones anteriores, y tiene la intención de ver en qué condiciones un país podría acercarse al cumplimiento de esta hipótesis en el mediano plazo. Los resultados no respaldan el cumplimiento del EKC, sin embargo, estas estimaciones muestran que Ecuador podría estar en camino de lograr la estabilización ambiental en un futuro próximo si el crecimiento económico se combina con un aumento en el uso de energías renovables, una mejora de la productividad estructura sectorial y el uso de una tecnología de combustibles fósiles más eficiente.

(Nwani, 2017) utilizando datos anuales para el período 1971-2013, explora la relación causal entre el precio del petróleo crudo, el consumo de energía y las emisiones de $\mathrm{CO}_{2}$ en Ecuador utilizando el enfoque de prueba de límites ARDL. EI PIB real per cápita, la tasa de inflación, el desarrollo financiero, la globalización, la apertura comercial y la formación de capital fijo se incorporan como determinantes adicionales en el análisis. Los resultados proporcionan evidencia de cointegración entre las variables en presencia de ruptura estructural en la serie. El efecto a largo plazo del consumo de energía sobre las emisiones de $\mathrm{CO}_{2}$ en la economía dependiente del petróleo es positivo y estadísticamente significativo. Curiosamente, los efectos causales a largo y corto plazo del precio del petróleo crudo en el consumo de energía y las emisiones de $\mathrm{CO}_{2}$ en la economía se encuentran positivos y estadísticamente significativos, lo que sugiere que un aumento en el precio del petróleo crudo generaría más consumo de energía y emisiones de $\mathrm{CO}_{2}$ en el Economía ecuatoriana.

(Pinzón, 2018) mediante los datos agregados y desagregados sobre Consumo de Energía y Crecimiento Económico determina la dinámica entre estas variables desde una perspectiva tanto general como más específica. Concluye que el consumo de energía en Ecuador ha mantenido una tendencia al alza acelerada durante los últimos años $\mathrm{y}$, al mismo tiempo, se ha modificado significativamente estructuralmente, son temas importantes para que los analicen los responsables políticos en la actualidad. Los resultados obtenidos sugieren, por un lado, que el consumo de energía en Ecuador es un insumo importante para predecir el crecimiento económico, pero lo contrario no es cierto. La necesidad que tiene el Ecuador de sustituir las fuentes de energía fósil principalmente petróleo por fuentes de energía renovable condiciona el plantear algunas medidas de política económica que de alguna manera mitiguen el impacto económico que puede producir el modificar el consumo de petróleo. 
(Castro Verdezoto \& Vidoza, 2019) elaboraron un modelo de pronóstico para el sector energético de Ecuador, utilizando el modelo LEAP, este estudio tiene como objetivo analizar el comportamiento de la matriz energética dependiendo del pronóstico de energía y los escenarios de política de eficiencia, aplicando un análisis de abajo hacia arriba y considerando la última política / planificación de infraestructura antecedentes en Ecuador.

(Bravo, y otros, 2016) realizaron un estudio sobre la prospectiva energética para Ecuador (2013-2040), cuyo objetivo fue evaluar las consecuencias sobre la evolución de la demanda y la oferta de energía de dos escenarios socioeconómicos de crecimientos moderado y alto. Se aplicaron la metodología de escenarios y el modelo LEAP, como resultados se obtuvieron que el consumo final de energía crecerá entre 2013 y 2040 a una tasa promedio de $2,2 \%$ a.a. en el escenario tendencial, mientras que en el escenario alternativo lo hará al 3,4\% a.a. La simulación de 11 medidas/acciones a nivel de la demanda permitió observar importantes reducciones del consumo alcanzando el $6.5 \%$ en el año 2040 del escenario tendencial, y el 13\% al mismo año en el alternativo.

(INER, 2016b) consideró la utilización del modelo LEAP para el análisis de la prospectiva energética del Ecuador. Dentro de este análisis prospectivo, se ha contemplado la formulación de dos tipos de escenarios: socioeconómico y energético, que determinan la demanda o requerimiento de energía. El modelo desarrollado genera información integral del sector energético, las principales interacciones de las cadenas energéticas y su vinculación con las variables conducentes (drivers) como: socioeconómicos, medioambiente y tendencias de comportamiento futuro. Esta información representa un insumo científico técnico para analizar el comportamiento de la demanda y la oferta, bajo distintos contextos y condiciones.

El modelo propuesto en esta investigación se basa en una estructura que parte de la selección de un marco de escenarios concebidos en un conjunto de supuestos y políticas socioeconómicas que se integran de manera coherente. La demanda de energía se desagrega por sectores (transporte, industria, residencial, comercial, servicios y administración pública, agricultura, pesca y minería; y, construcción y otros) y ésta demanda por sectores se desagrega por tipo de energía (petróleo, gas natural, energía hidroeléctrica, productos de caña y otros productos primarios. Las fuentes de energía finales son: electricidad, GLP, gasolina, kerosene y jet fuel, diesel, fuel oil, gases, crudo reducido y no energéticos. Las energías renovables no convencionales incluyen: solar fotovoltaica, eólica, biomasa, biogás y biocombustibles).

Mediante la demanda final de energía por tipo de recurso, se calculan los niveles de emisiones de $\mathrm{CO}_{2}$ hasta el 2030. Al ejecutar el modelo y aplicar los diferentes escenarios se observa cómo va variando la prospectiva energética del 
Ecuador. Las políticas planteadas permiten explorar diferentes escenarios de transición energética de un sistema basado en energías de origen fósil a uno de energías renovables en el mediano plazo, mejorar la eficiencia energética sectorial, promoción de sistemas de transporte sostenible, industria renovable, sustitución de combustibles (Figura 5). 


\section{Capítulo 3}

\section{Evolución de la energía en Ecuador}

Como ha sucedido a nivel mundial, el Ecuador ha tenido una evolución en la manera de producción de energía, en sus métodos de transformación y en los estilos de consumo de los sectores económicos. Es así como a partir de 1972, en vísperas de iniciar las exportaciones de crudo oriente, la producción petrolera asume un rol protagónico en la estructura económica del país (EP Petroecuador, 2013).

Al analizar la producción de energía por fuentes primarias durante los últimos 14 años, podemos darnos cuenta de la importancia que juega el petróleo en la sociedad ecuatoriana, no solo para abastecer la demanda interna (carga a refinerías y generación eléctrica), sino también por la renta derivada de las exportaciones que forman parte de los recursos fiscales con los que cuenta el Gobierno (Ministerio Coordinador de Sectores Estratégicos, 2015).

Históricamente, las energías renovables convencionales, como la biomasa (leña y bagazo) y la hidroenergía, así como las energías renovables no convencionales (fotovoltaica y eólica), han tenido una mínima participación en la matriz de energía primaria, tendencia que se verá influenciada positivamente en los próximos años por la entrada de las nuevas centrales hidroeléctricas principalmente (Ministerio Coordinador de Sectores Estratégicos, 2015). A continuación, se presentan resultados del comportamiento energético del país en el año 2016 y un análisis comparativo con los años 2007 y 2015.

Tabla 1. Resumen producción y consumo de energía en Ecuador (Ministerio de Electricidad y Energía Renovable, 2018)

\begin{tabular}{lllll}
\hline \multicolumn{1}{c}{ Energía Primaria } & Unidades & $\mathbf{2 0 0 7}$ & $\mathbf{2 0 1 5}$ & $\mathbf{2 0 1 6}$ \\
\hline Producción Total de Energía & kBEP & 208488 & 225021 & 229462 \\
Producción Total de Petróleo & kBEP & 186938 & 198527 & 201012 \\
Exportación Total de Petróleo & KBEP & 117821 & 146620 & 139046 \\
Producción Total de Gas Natural (1) & KBEP & 8875 & 10029 & 10488 \\
Producción de hidroenergía & kBEP & 7000 & 10143 & 12263 \\
Producción de leña & kBEP & 2532 & 1865 & 1824 \\
Producción de productos de caña & kBEP & 3143 & 4374 & 3750 \\
Producción de otras energías renovables & kBEP & 1 & 84 & 125 \\
Carga total a centros de Transformación & kBEP & 84652 & 83609 & 94409 \\
Carga a Refinería & kBEP & 59424 & 48578 & 59223 \\
\hline \multicolumn{1}{c}{ Energía Secundaria } & Unidades & $\mathbf{2 0 0 7}$ & $\mathbf{2 0 1 5}$ & $\mathbf{2 0 1 6}$ \\
\hline Producción Total de Energía & kBEP & 69235 & 64841 & 76284 \\
Producción de Electricidad & kBEP & 10742 & 16079 & 16924 \\
Potencia efectiva Nacional & GWh & 17337 & 25950 & 27314 \\
Producción de Diésel oil & MW & 4142 & 5557 & 7607 \\
Importación de Diésel oil & kBEP & 12594 & 10812 & 14112 \\
Producción de Gasolinas y Naftas & miles gal & 528147 & 453406 & 591823 \\
\hline
\end{tabular}




\begin{tabular}{lllll} 
& miles gal & 445929 & 356636 & 573216 \\
Importación de Gasolinas y Naftas & kBEP & 6955 & 17389 & 14310 \\
& miles gal & 326955 & 817496 & 672724 \\
Producción de GLP & kBEP & 1214 & 1146 & 2055 \\
& miles kg & 159076 & 150210 & 269279 \\
Importación de GLP & kBEP & 6500 & 7247 & 6625 \\
\hline \multicolumn{1}{c}{ Consumo de Energía (2) } & miles kg & 851874 & 949799 & 868316 \\
\hline Consumo Total de Energía & Unidades & $\mathbf{2 0 0 7}$ & $\mathbf{2 0 1 5}$ & $\mathbf{2 0 1 6}$ \\
\hline Consumo energético sector transporte & kBEP & 64535 & 90569 & 86645 \\
Consumo energético sector industrial & kBEP & 29314 & 43477 & 44284 \\
Consumo energético sector residencial & kBEP & 11567 & 17880 & 14286 \\
Consumo de Electricidad & kBEP & 9696 & 12123 & 12083 \\
Consumo de Diésel oil & kBEP & 8803 & 14212 & 14555 \\
& GWh & 14208 & 22937 & 23492 \\
Consumo de Gasolinas y Naftas & kBEP & 19523 & 28457 & 26679 \\
Consumo de GLP & miles gal & 818735 & 1193399 & 1118858 \\
Consumo de kerosene & kBEP & 15084 & 25206 & 25803 \\
Consumo de Fuel oíl & miles gal & 709137 & 1184976 & 1213032 \\
& kBEP & 7298 & 8156 & 8408 \\
\hline
\end{tabular}

(1) Al 2015, la producción de gas natural asociado representa el 70\% de la producción total de gas.

(2) No incluye consumo propio.

Al 2016, la oferta total de energía primaria del país alcanzó 229,4 miles de kBEP, de los cuales el $61 \%$ fue con fines de exportación. La energía fósil representó el $92,2 \%$ (petróleo $87,6 \%$ y gas natural $4,6 \%$ ) y el $7,8 \%$ a la energía renovable (hidroenergía con el $5,3 \%$, leña $0,8 \%$, productos de caña y otras con el $1,7 \%)$.

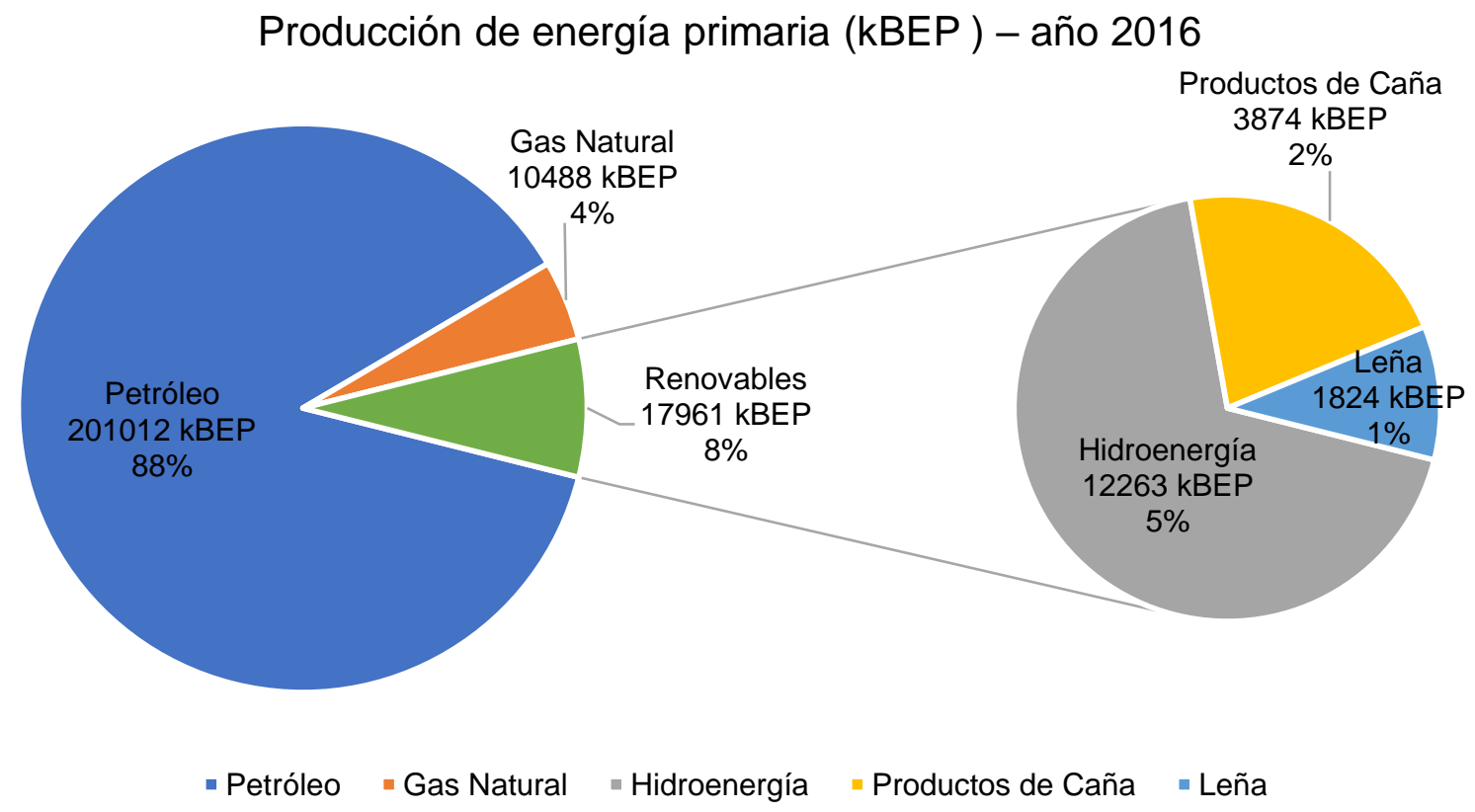


Figura 6. Producción de energía en Ecuador año 2016 (Ministerio de Electricidad y Energía Renovable, 2018)

Según el balance energético 2017 publicado por el Ministerio de Electricidad y Energía Renovable en el año 2016, como se muestra en la figura 6 se registró un consumo de energía de 90,7 miles de KBEP, de los cuales 86,6 miles de KBEP correspondió al consumo energético a nivel de usuarios finales, representando el $95,52 \%$, y 4,1 miles de KBEP al consumo propio con el $4,48 \%$. Los combustibles fósiles representan el $77,65 \%$ del consumo total por energético. Del total de energía el uso del diésel oíl corresponde al $31 \%$, la gasolina el $29 \%$ y la electricidad el $16 \%$.

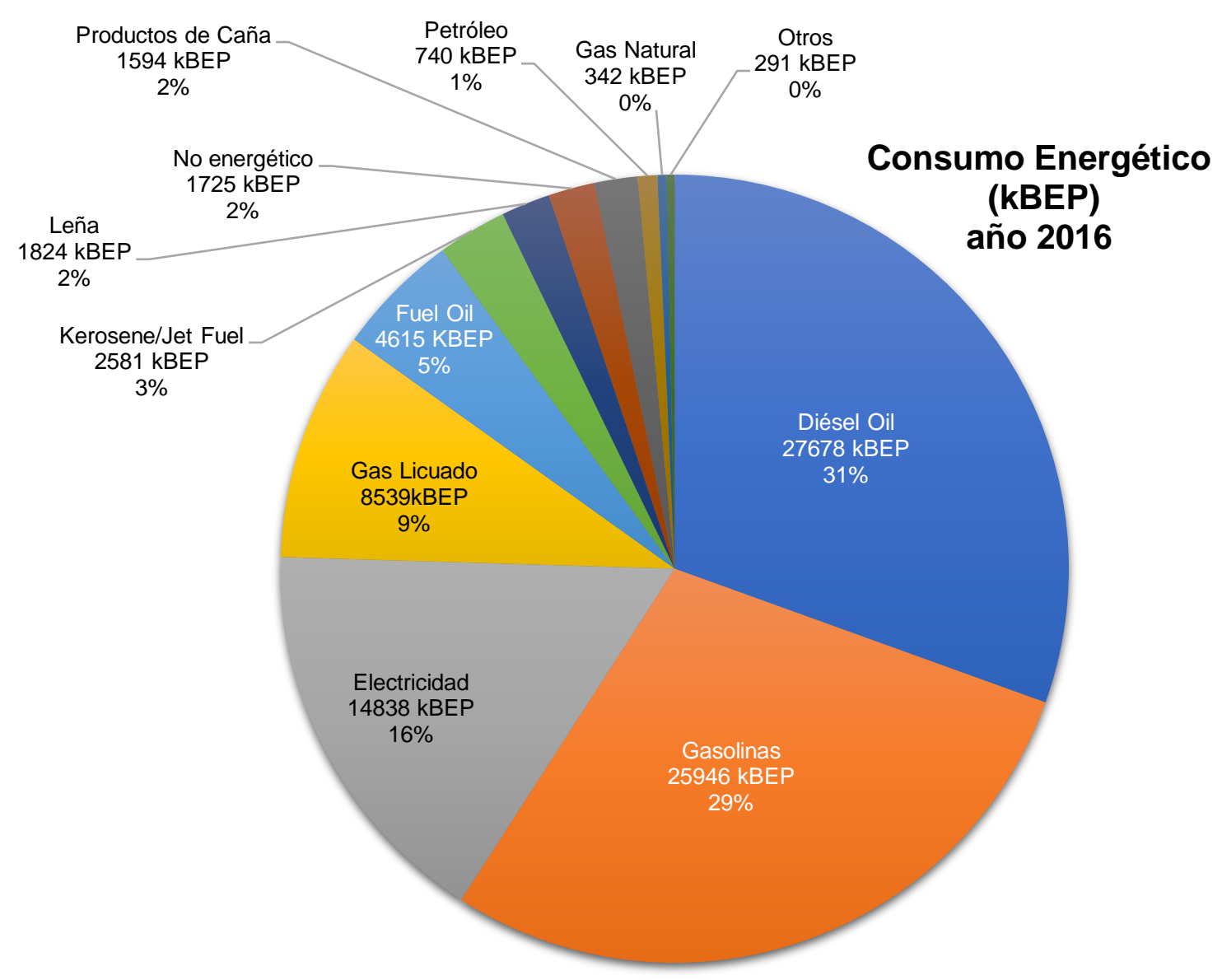

Figura 7. Demanda de energía en Ecuador año 2016 (Ministerio de Electricidad y Energía Renovable, 2018)

En el proceso de planificación, es necesario recopilar información vinculada a las actividades involucradas en el sistema de análisis. En el caso de un sistema energético, los datos obtenidos en sus inicios son la base para la generación de información representativa que refleje la situación actual del sistema y permita realizar un diagnóstico de este, para proyectar su evolución.

Se debe hacer hincapié que con esta tesis no se intenta predecir el futuro en materia energética para el Ecuador, sino más bien ser una herramienta de 
ayuda que permite analizar varios escenarios que pretenden dar una imagen más clara de lo que pasaría si no se toman cambios en el actual modelo. La estructura de la matriz ha variado, pero en general, las tres fuentes dominantes de energía en el país son: petróleo, hidroelectricidad y biomasa. La modernización del país se ha manifestado en la estructura de su matriz energética. Mientras en 1970 , el $44 \%$ de la matriz se basaba en el consumo tradicional de biomasa (carbón vegetal y leña, principalmente), en 2008 apenas el 6\%. La energía que más ha incrementado su parte en la matriz es el petróleo, del $50 \%$ en 1970 al $81 \%$ en 2008 . La hidroelectricidad también incrementó su participación, pero en mucho menor intensidad, del 1\% en 1970 al $10 \%$ en 2008 (Castro, 2011). La producción de crudo llegó a su máximo histórico hasta la fecha en el año 2014, con una producción anual de 203 millones de barriles, y ha mantenido un promedio de 189 millones de barriles en el período comprendido entre 2007 y 2018. La participación de la energía proveniente de fuentes renovables ha sido menor, sin embargo, la producción de este tipo de energía ha mostrado un crecimiento del $33 \%$ entre 2008 y 2018, teniendo como componente principal a la hidroenergía (Ministerio de Electricidad y Energía Renovable, 2018) (Ministerio de Electricidad y Energía Renovable, 2020). La evolución de la demanda energética en comparación con la producción de energía primaria ha sido lo que implica que Ecuador es un exportador neto de energía. A pesar de ello, el país requiere de la importación de derivados de petróleo para el abastecimiento de la demanda energética sectorial. La producción de energía primaria en 2018 fue de 216 millones de BEP. Del total producido, 87,5\% estuvo representado por petróleo, 4,7\% por gas natural, y 7,8\% por energía de origen renovable (hidroenergía, leña, productos de caña, energía eólica, fotovoltaica y biogás) (Ministerio de Electricidad y Energía Renovable, 2018).

En la tabla 2 se muestra la producción de energía primaria en Ecuador alcanzó en el año 2016 los 229461,76 KBEP como, siendo casi un 37,38\% mayor que la producción del año 2000. En la actualidad el petróleo constituye el 87,6\%, de total de la energía primaria producida en Ecuador, mientras que las otras primarias producen un porcentaje mucho menor, la hidroenergía 5,3\% y el gas natural $4,6 \%$.

Tabla 2. Evolución de la producción de energía Primaria (KBEP)

\begin{tabular}{lccccccccc}
\hline & $\mathbf{2 0 0 0}$ & $\mathbf{2 0 0 2}$ & $\mathbf{2 0 0 4}$ & $\mathbf{2 0 0 6}$ & $\mathbf{2 0 0 8}$ & $\mathbf{2 0 1 0}$ & $\mathbf{2 0 1 2}$ & $\mathbf{2 0 1 4}$ & $\mathbf{2 0 1 6}$ \\
\hline Petróleo & 150625,4 & 147338,0 & 187577,6 & 196244,0 & 181603,3 & 177713,0 & 184598,0 & 203456,0 & 201012,0 \\
Gas Natural & 6321,2 & 5970,3 & 8518,2 & 9539,0 & 8519,0 & 8394,0 & 9214,0 & 11455,0 & 10488,0 \\
Hidroenergía & 4715,9 & 4662,0 & 5744,1 & 5522,0 & 8747,0 & 6689,0 & 9478,0 & 8874,0 & 12263,0 \\
Leña & 3031,9 & 2830,5 & 2707,2 & 2574,0 & 2441,0 & 2234,0 & 2095,0 & 2019,0 & 1824,0 \\
Productos de Caña & 2338,6 & 2038,4 & 2962,3 & 2932,0 & 2842,0 & 2939,0 & 3507,0 & 3722,0 & 3750,0 \\
Otras Primarias & & & & 0,0 & 1,7 & 2,1 & 1,7 & 59,6 & 124,8 \\
Total Primarias & $\mathbf{1 6 7 0 3 2 , 9}$ & $\mathbf{1 6 2 8 3 9 , 2}$ & $\mathbf{2 0 7 5 0 9 , 4}$ & $\mathbf{2 1 6 8 1 1 , 0}$ & $\mathbf{2 0 4 1 5 4 , 0}$ & $\mathbf{1 9 7 9 7 1 , 1}$ & $\mathbf{2 0 8 8 9 3 , 7}$ & $\mathbf{2 2 9 5 8 5 , 6}$ & $\mathbf{2 2 9 4 6 1 , 8}$
\end{tabular}


Comparando con el año 2000, la producción de petróleo tuvo un incremento del $33,45 \%$, el gas natural tuvo un incremento del $65,92 \%$, la hidroenergía muestra un aumento del $160 \%$ en su producción, la energía producto de los productos de caña aumentaron un $60,36 \%$, mientras que disminuyó un $39,84 \%$ la producción de energía de la leña, finalmente se evidencia un crecimiento de energías primarias no tradicionales mismas que serán analizadas más a detalle.

Evolución producción energía primaria (kBEP)

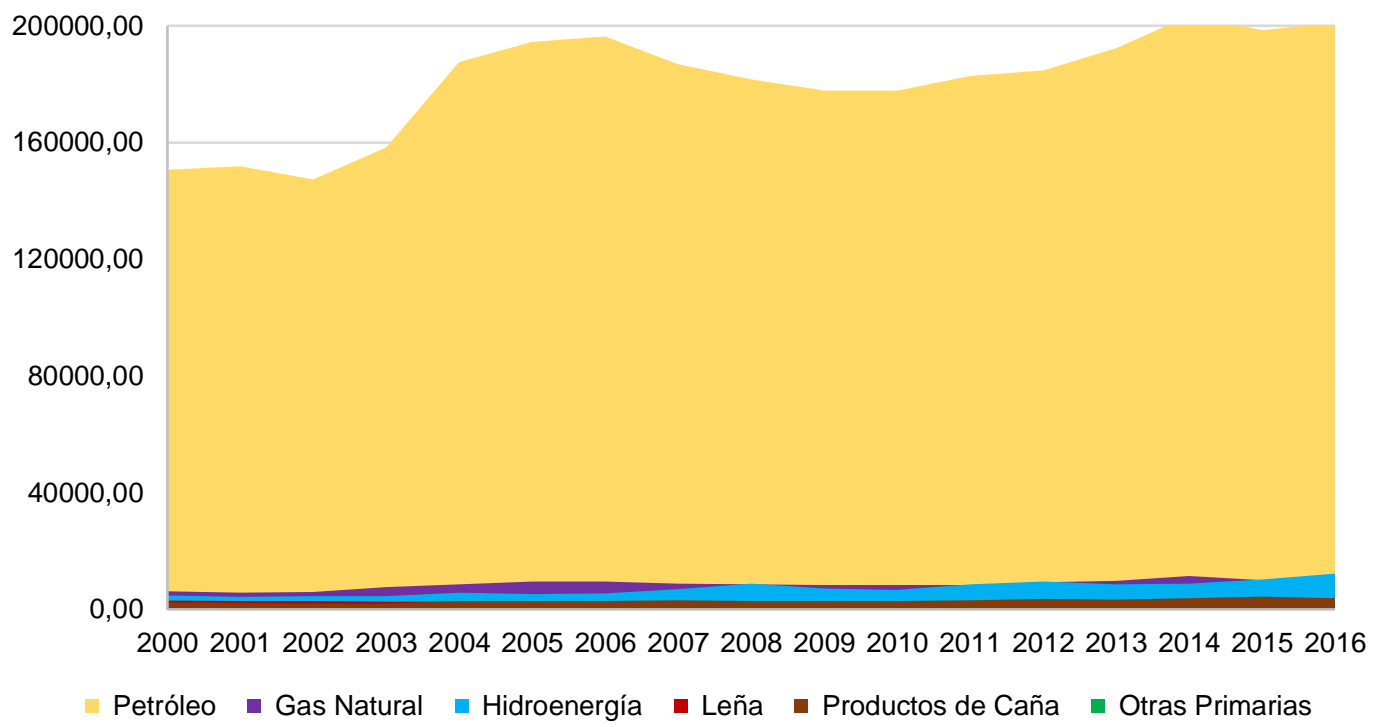

Figura 8. Evolución de la producción de energía primaria

Si bien la producción de energía secundaria en el año 2016 respecto al año 2000 incrementó un $9 \%$ como se puede observar en la tabla 3; el incremento respecto al 2015 fue de un 15,72\%. El Fuel Oíl se mantiene como el combustible de mayor producción, pero en relación con el año 2000 disminuyó su producción un 25,64\%. El Diesel Oíl y el Gas Licuado han mantenido su producción en este período, la disminución de producción del primero llegó al 0,65\%, mientras que el segundo creció un $0,55 \%$. Las gasolinas crecieron un $5,64 \%$ al 2016 en su producción y finalmente, la electricidad creció $157,38 \%$, en el año 2000 se produjeron 6.575,5 KBEP y en el año 2016 la producción alcanzó los 16.924 KBEP, lo que es importante si se busca una transición a una matriz energética más sostenible.

Tabla 3. Evolución de la producción de energía secundaria (KBEP)

\begin{tabular}{lccccccccc}
\hline & $\mathbf{2 0 0 0}$ & $\mathbf{2 0 0 2}$ & $\mathbf{2 0 0 4}$ & $\mathbf{2 0 0 6}$ & $\mathbf{2 0 0 8}$ & $\mathbf{2 0 1 0}$ & $\mathbf{2 0 1 2}$ & $\mathbf{2 0 1 4}$ & $\mathbf{2 0 1 6}$ \\
\hline Electricidad & 6575,5 & 7365,5 & 7797,6 & 9365,8 & 11529,8 & 12088,3 & 14156,4 & 15061,0 & 16924,0 \\
Gas Licuado & 2043,8 & 1603,1 & 1749,2 & 1677,4 & 1603,2 & 1566,0 & 2032,5 & 1508,0 & 2055,0 \\
Gasolinas & 11542,2 & 9855,7 & 10885,2 & 11110,4 & 10806,2 & 8916,1 & 10872,9 & 8686,0 & 12193,0 \\
\hline
\end{tabular}




\begin{tabular}{lccccccccc}
\hline Kerosene/Jet Fuel & 1891,8 & 1744,2 & 2142,0 & 2586,7 & 2726,2 & 2611,4 & 2686,3 & 2662,0 & 2593,0 \\
Diésel Oíl & 14204,6 & 13829,3 & 14108,1 & 13610,0 & 13546,6 & 12225,8 & 13212,2 & 10981,0 & 14112,0 \\
Fuel Oíl & 26869,6 & 24212,4 & 23437,2 & 21829,7 & 23098,7 & 19202,1 & 20750,4 & 16762,0 & 19980,0 \\
Gases & 283,4 & 309,1 & 387,4 & 368,0 & 354,9 & 413,0 & 451,4 & 492,0 & 291,0 \\
Otras secundarias & 5860,8 & 6053,3 & 6294,4 & 6627,9 & 7285,8 & 6662,5 & 6909,6 & 7023,0 & 6412,0 \\
No energético & 722,4 & 1010,1 & 1293,8 & 1261,7 & 1770,3 & 2492,9 & 2824,6 & 2746,0 & 1725,0 \\
Total Secundarias & $\mathbf{6 9 9 9 4 , 1}$ & $\mathbf{6 5 9 8 2 , 8}$ & $\mathbf{6 8 0 9 4 , 9}$ & $\mathbf{6 8 4 3 7 , 5}$ & $\mathbf{7 2 7 2 1 , 7}$ & $\mathbf{6 6 1 7 8 , 2}$ & $\mathbf{7 3 8 9 6 , 4}$ & $\mathbf{6 5 9 2 1 , 0}$ & $\mathbf{7 6 2 8 5 , 0}$ \\
\hline
\end{tabular}

En la figura 9, podemos observar a evolución de cada uno de los tipos de energía secundaria en el período 2000 - 2016, como se mencionó entre los principales aspectos se puede observar el crecimiento de la producción de electricidad esto principalmente se debe a la puesta en marcha de los nuevos proyectos de hidroenergía, si bien en el Ecuador tradicionalmente no se ha impulsado la producción de energías no tradicionales, las energías solar y eólica tienen ya una participación, existen proyectos sobre el aceite de piñón y el uso de residuos sólidos urbanos. Si se busca una matriz energética más sostenible se debe dar un mayor impulso a energías renovables.

\section{Evolución de Producción Energía Secundaria (KBEP)}

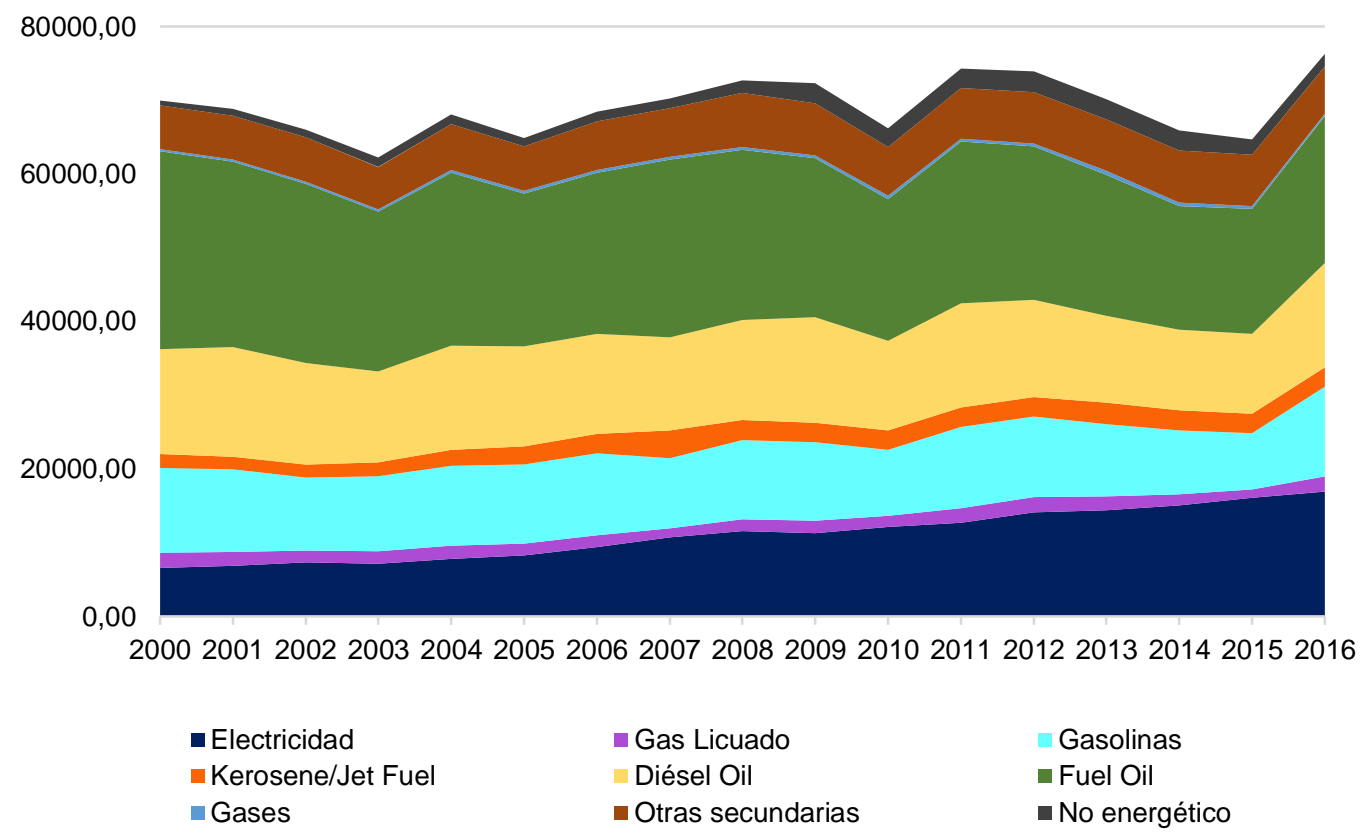

Figura 9. Evolución de la producción de energía secundaria

Las fuentes de energía consumidas en los diferentes sectores de actividad incluyen principalmente:

- Energía primaria: petróleo, gas natural, leña y productos de caña 
- Energía secundaria: electricidad, gas licuado de petróleo, gasolinas, kerosene/jet fuel, diésel oíl, fuel oíl, entre otros (Ministerio de Electricidad y Energía Renovable, 2018).

En la tabla 4 se muestra la evolución del consumo energético en el período de estudio 2000 - 2016. El consumo de energía en el año 2016 alcanzó los 90713 KBEP esto es un incremento del 31,68\% en comparación al año 2007.

Tabla 4. Evolución consumo por fuente (KBEP)

\begin{tabular}{lccccccccc}
\hline & $\mathbf{2 0 0 0}$ & $\mathbf{2 0 0 2}$ & $\mathbf{2 0 0 4}$ & $\mathbf{2 0 0 6}$ & $\mathbf{2 0 0 8}$ & $\mathbf{2 0 1 0}$ & $\mathbf{2 0 1 2}$ & $\mathbf{2 0 1 4}$ & $\mathbf{2 0 1 6}$ \\
\hline Petróleo & 780 & 734 & 616 & 695 & 695 & 716 & 735 & 776 & 740 \\
Gas Natural & $\mathrm{nd}$ & $\mathrm{nd}$ & $\mathrm{nd}$ & $\mathrm{nd}$ & 13 & 15 & 168 & 289 & 342 \\
Leña & 3032 & 2830 & 2707 & 2570 & 2441 & 2234 & 2095 & 2019 & 1824 \\
Productos de Caña & 2339 & 2038 & 2032 & 869 & 1121 & 1742 & 2003 & 1767 & 1594 \\
Electricidad & 4897 & 5594 & 7077 & 8739 & 9555 & 10699 & 12306 & 13823 & 14838 \\
Gas Licuado & 5025 & 5483 & 6493 & 7268 & 7689 & 7738 & 7971 & 8592 & 8539 \\
Gasolinas & 10662 & 11551 & 12210 & 13939 & 15663 & 19027 & 22171 & 25130 & 25946 \\
Kerosene/Jet Fuel & 1162 & 1788 & 2083 & 2440 & 2793 & 2687 & 2688 & 2892 & 2581 \\
Diésel Oíl & 14679 & 15631 & 18620 & 21408 & 21759 & 24268 & 27098 & 31908 & 27678 \\
Fuel Oíl & 6499 & 7276 & 9112 & 8200 & 8621 & 8037 & 7793 & 8130 & 4615 \\
Otros & nd & nd & 387 & 368 & 355 & 413 & 451 & 545 & 291 \\
No energéticos & 963 & 1230 & 1294 & 1262 & 1823 & 2568 & 2909 & 2682 & 1725 \\
\hline Total & $\mathbf{5 0 0 3 8}$ & $\mathbf{5 4 1 5 5}$ & $\mathbf{6 2 6 3 2}$ & $\mathbf{6 7 7 5 8}$ & $\mathbf{7 2 5 2 8}$ & $\mathbf{8 0 1 4 4}$ & $\mathbf{8 8 3 8 8}$ & $\mathbf{9 8 5 5 3}$ & $\mathbf{9 0 7 1 3}$ \\
\hline
\end{tabular}

El diésel oíl y las gasolinas son los tipos de energía más consumidos en el Ecuador. En el período de estudio, las gasolinas incrementaron un 143,35\% su consumo, el kerosene/Jet Fuel alcanzó un incremento del 122,14\%, por otra parte, el diésel oíl tuvo un incremento de $88,55 \%$. La electricidad es el tipo de fuente que tuvo el mayor crecimiento triplicando su consumo de 4897 KBEP en el 2000, en el año 2016 se dio un consumo de 14838 KBEP, factor importante en el cambio de hábitos de consumo en lo referente a tipo de energías.

En la tabla 5 se describe la evolución del consumo energético de cada uno de los sectores socioeconómicos del país (transporte, industria, residencial, comercial y servicios públicos, agro, pesca y minería; otros).

Tabla 5. Evolución consumo energético por sector (KBEP)

\begin{tabular}{lccccccccc}
\hline & $\mathbf{2 0 0 0}$ & $\mathbf{2 0 0 2}$ & $\mathbf{2 0 0 4}$ & $\mathbf{2 0 0 6}$ & $\mathbf{2 0 0 8}$ & $\mathbf{2 0 1 0}$ & $\mathbf{2 0 1 2}$ & $\mathbf{2 0 1 4}$ & $\mathbf{2 0 1 6}$ \\
\hline Transporte & 25069,27 & 27150,86 & 30384,94 & 29253,20 & 29313,17 & 34735,20 & 37576,20 & 42617,32 & 44284,00 \\
\hline Industria & 11477,14 & 11760,68 & 12061,88 & 12197,56 & 12880,52 & 15311,00 & 17449,26 & 18673,00 & 14286,00 \\
\hline
\end{tabular}




\begin{tabular}{lccccccccc} 
Residencial & 9235,37 & 9737,50 & 10594,56 & 9421,02 & 9978,86 & 10601,75 & 11166,99 & 11925,80 & 12083,00 \\
\hline $\begin{array}{l}\text { Comercia, Ser. } \\
\text { Púb. }\end{array}$ & 2881,26 & 3177,33 & 3189,00 & 3874,00 & 4092,00 & 4330,00 & 5148,00 & 5690,00 & 5705,00 \\
\hline $\begin{array}{l}\text { Agro, Pesca, } \\
\text { Miner. }\end{array}$ & 245,75 & 251,73 & 287,59 & 561,09 & 770,32 & 924,00 & 1121,00 & 1160,00 & 900,00 \\
\hline Otros & 7896,14 & 8596,61 & 9297,08 & 8830,00 & 11038,00 & 9786,00 & 11365,00 & 13864,00 & 9387,00 \\
\hline Consumo Total & 56804,91 & 60674,72 & 65815,05 & 64136,86 & 68072,88 & 75687,94 & 83826,45 & 93930,12 & 86645,00 \\
\hline
\end{tabular}

No se considera el consumo propio

En la figura 10 se muestra un incremento del $52,32 \%$ en el consumo energético total de los diferentes sectores socioeconómicos del Ecuador con respecto al año 2000, el consumo total al 2016 fue $86645 \mathrm{KBEP}$. El sector agrícola, pesca y minería es el sector que más ha crecido en consumo, en el año 2000 se consumieron 245,75 KBEP mientras que en el 2016 se alcanzaron los $900 \mathrm{KBEP}$, esto se debe principalmente al impulso que se ha dado a este sector como parte de la transformación de la matriz productiva. El sector comercial y servicios públicos ha tenido un crecimiento del $98 \%$, se han mejorado los servicios básicos a nivel nacional, la cobertura de servicio eléctrico y el alumbrado público ha mejorado estos son los factores del crecimiento en el consumo de este sector. El sector del transporte consume al 201644284 KBEP un $76,65 \%$ más que el año 2000 , el crecimiento del parque automotor, el crecimiento poblacional y el desplazamiento de las personas a nuevas áreas son algunas de las causas de este incremento. Los sectores residencia e industrial han tenido un incremento más moderado, $30,83 \%$ el primero y $24,47 \%$ el segundo, en estos sectores se han desarrollado proyectos de eficiencia energética lo que puede contribuir a que el incremento no haya sido tan alto como en los otros.

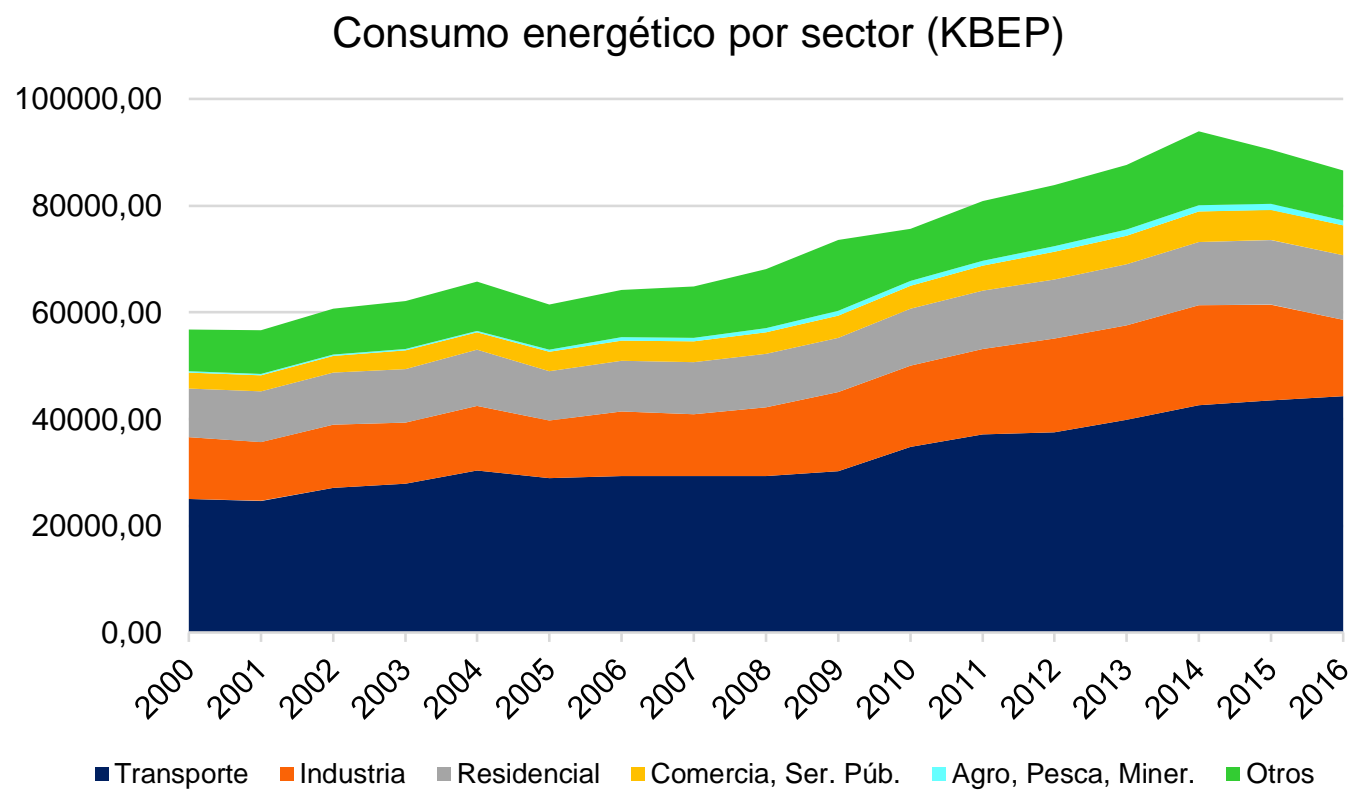




\section{Figura 10. Evolución del consumo energético por sector}

Por otro lado, y como consecuencia del uso de la energía las emisiones de Gases de Efecto Invernadero (GEI) han presentado una tendencia creciente debido al incremento en la demanda de energía en los últimos 11 años. Es así, que de 30.055 kton $\mathrm{CO}_{2}$ equivalentes emitidas en 2008, se alcanzó un valor de 39.720 kton $\mathrm{CO}_{2}$ equivalentes en 2018, lo cual representa un incremento de $32,2 \%$ en este período de tiempo. En 2018 el sector con mayores emisiones es el transporte, al ser este el principal demandante de energía proveniente de fuentes fósiles, generando $48,5 \%$ del total de emisiones de GEl. Otros sectores con emisiones relevantes son el industrial con $8,7 \%$ y el residencial con $8,4 \%$ (Ministerio de Electricidad y Energía Renovable, 2020). Las decisiones de los líderes de turno, así como el comportamiento real de algunas variables exógenas será las razones que realmente determinarán un futuro en el campo energético del Ecuador 


\section{Capítulo 4}

\section{The Trends of the Energy Intensity and $\mathrm{CO}_{2}$ Emissions Related to Final Energy Consumption in Ecuador: Scenarios of National and Worldwide Strategies}

Este capítulo está conformado por la publicación en la revista sustainability del artículo científico que trata sobre la intensidad energética y su relación con las emisiones de $\mathrm{CO}_{2}$ producidas en Ecuador por el uso de energía y los posibles escenarios al año 2030 tomando en cuenta políticas nacionales y mundiales.

\section{The Trends of the Energy Intensity and $\mathrm{CO}_{2}$ Emissions Related to Final Energy Consumption in Ecuador: Scenarios of National and Worldwide Strategies}

Flavio R. Arroyo M. ${ }^{1,2,{ }^{*}}$ and Luis J. Miguel ${ }^{1,{ }^{*}}$

1 Systems Engineering and Automatic Control, School of Industrial Engineering, Paseo del Cauce s/n, University of Valladolid, 47011 Valladolid, Spain

2 Faculty of Engineering, Physical Sciences and Mathematics, Av. Universitaria, Central University of Ecuador, 170129 Quito, Ecuador

* Correspondence: flavio.arroyo@gmail.com (F.R.A.M.); ljmiguel@eii.uva.es (L.J.M.)

Received: 29 November 2019; Accepted: 8 December 2019; Published: 18 December 2019

Revista: Sustainability, volumen 12, número 1, (2019).

DOI: https://doi.org/10.3390/su12010020

Abstract: Climate change and global warming are related to the demand for energy, energy efficiency, and $\mathrm{CO}_{2}$ emissions. In this research, in order to project the trends in final energy demand, energy intensity, and $\mathrm{CO}_{2}$ emission production in Ecuador during a period between 2000 and 2030, a model has been developed based on the dynamics of the systems supported by Vensim simulation models. The energy matrix of Ecuador has changed in recent years, giving more importance to hydropower. It is conclusive that, if industrialized country policies or trends on the use of renewable energy and energy efficiency were applied, the production of $\mathrm{CO}_{2}$ emissions by 2030 in Ecuador would reach 42,191.4 $\mathrm{KTCO}_{2}$, a value well below the $75,182.6 \mathrm{KTCO}_{2}$ that would be seen if the current conditions are maintained. In the same way, by 2030 , energy intensity would be reduced to $54 \%$ compared to the beginning of the simulation period. 


\title{
Capítulo 5
}

\section{The Role of Renewable Energies for the Sustainable Energy Governance and Environmental Policies for the Mitigation of Climate Change in Ecuador}

Este capítulo está conformado por la publicación en la revista energies del artículo científico que trata sobre el rol que deben desempeñar las energías renovables en las políticas ambientales para la mitigación del cambio climático en Ecuador.

\section{The Role of Renewable Energies for The Sustainable Energy Governance and Environmental Policies for the Mitigation of Climate Change in Ecuador}

\author{
Flavio R. Arroyo M. ${ }^{1,2, *}$ and Luis J. Miguel ${ }^{1,3}$
}

1 Systems Engineering and Automatic Control, School of Industrial Engineering, Paseo del Cauce $s / n$, University of Valladolid, 47011 Valladolid, Spain; ljmiguel@eii.uva.es

2 Faculty of Engineering, Physical Sciences and Mathematics, Av. Universitaria, Central University of Ecuador, 170129 Quito, Ecuador

3 Research Group on Energy, Economy and System Dynamics, School of Industrial Engineering, Paseo del Cauce s/n, University of Valladolid, 47011 Valladolid, Spain

* Correspondence flavio.arroyo@gmail.com

Received: 19 April 2020; Accepted: 21 July 2020; Published: 30 July 2020

Revista: Energies, volumen 13, número 15, (2020).

DOI: https://doi.org/10.3390/en13153883

\begin{abstract}
This article presents a comparative analysis of energy governance with respect to renewable energy sources in Ecuador. The use of renewable energy sources increases energy security and enables countries to achieve their climate mitigation goals. Ecuador's energy mix is dominated using fossil fuels and produces only $7.8 \%$ of its energy supply from renewable energy. The scenario analysis suggests that using the example of international renewable energy policies will achieve sustainable energy development in Ecuador. Relying less on fossil fuels and decentralizing the electricity sector from the use of thermoelectric plants is the great challenge for the country. Using the enormous water potential that Ecuador has and taking advantage of the sources of solar, biomass and wind energy available in the country will reduce the forecast of $60,233.70 \mathrm{KT} \mathrm{CO}_{2}$ by 2030 that would be reached if current consumption conditions and energy mix are maintained, while designing a long-term energy planning with a greater participation of renewable energies would forecast a $\mathrm{CO}_{2}$ emission of 41232.30 $\mathrm{KT}$, that is, a reduction of $31.5 \%$ in emissions.
\end{abstract}




\section{Capítulo 6}

\section{Low-Carbon Energy Governance: Scenarios to Accelerate the Change in the Energy Matrix in Ecuador}

Este capítulo está conformado por la publicación en la revista energies del artículo científico que trata sobre la necesidad de plantear una gobernanza energética baja en carbono en Ecuador y de ese modo acelerar el cambio a una matriz energética sostenible.

\section{Low-Carbon Energy Governance: Scenarios to Accelerate the Change in the Energy Matrix in Ecuador}

Flavio R. Arroyo M. ${ }^{1,2, \star}$ and Luis J. Miguel ${ }^{1,3}$

1 Systems Engineering and Automatic Control, School of Industrial Engineering, Paseo del Cauce s/n, University of Valladolid, 47011 Valladolid, Spain; ljmiguel@eii.uva.es

2 Faculty of Engineering, Physical Sciences and Mathematics, Av. Universitaria, Central University of Ecuador, 170129 Quito, Ecuador

3 Research Group on Energy, Economy and System Dynamics, School of Industrial Engineering, Paseo del Cauce s/n, University of Valladolid, 47011 Valladolid, Spain

* Correspondence: flavio.arroyo@gmail.com

Received: 5 August 2020; Accepted: 9 September 2020; Published: 11 September 2020

Revista: Energies, volumen 13, número 18, (2020).

DOI: https://doi.org/10.3390/en13184731

Abstract: This article describes the results of a study of Ecuador's energy status, using the system dynamics methodology to model supply, demand and $\mathrm{CO}_{2}$ emissions scenarios for the year 2030. Primary energy production increased in the different projected scenarios, with oil as the most important source of energy. The increase observed in final energy consumption was mainly associated with the transport and industry sectors. A reduction in energy intensity was projected for the different scenarios, which could be associated with the projected economic growth. The results obtained were used to build a proposal for energy policies aimed at mitigating emissions. The proposed changes to the national energy matrix could be the factors that will contribute most to the achievement of carbon emission reductions projected by the different scenarios; changes in the energy matrix are mainly associated with the development of projects to replace fossil fuels with renewable energies, mainly hydropower. 


\section{Capítulo 7}

\section{Conclusiones}

En este capítulo se presentan las principales aportaciones y conclusiones obtenidas durante el desarrollo de la tesis. A continuación, se describen los resultados y las políticas que se deberían tomar en cuenta en la construcción de una política energética sostenible para Ecuador en busca de mitigar el cambio climático.

El Panel Intergubernamental sobre Cambio Climático de la ONU concluyó que el mundo debe reducir las emisiones netas de dióxido de carbono en casi un $50 \%$ para 2030 y eliminarlas para el año 2050 para de esa manera mantener gran parte la habitabilidad del planeta. Si bien el Ecuador es un país pequeño y las emisiones de $\mathrm{CO}_{2}$ alcanzaron en el año 2018 los 37,1 millones de toneladas de emisiones de $\mathrm{CO}_{2}$, un valor menor en relación con los 33.890,8 millones del mundo, lo que llama la atención es el al porcentaje de crecimiento del 7,9\% con respecto al 2007 en donde inclusive las emisiones bajaron (BP, 2019).

Ecuador necesita políticas más estrictas para reducir las emisiones de $\mathrm{CO}_{2}$, si bien todas las medidas que se puedan llegar a tomar influirán directamente en el consumidor medio y tradicionalmente los políticos en Ecuador no han tomado medidas por el costo político que están han generado históricamente. Actualmente más ecuatorianos comprenden los efectos negativos del cambio climático. Sin embargo, no todos están dispuestos a contribuir de una u otra manera en la lucha contra el calentamiento global.

Cada uno de los sectores económicos es responsable del incremento de las emisiones de $\mathrm{CO}_{2}$, la demanda de energía ha crecido en comparación al año 2000, año que es el punto de partida de esta investigación. En el año 2000 la demanda de energía fue de 49.258 KBEP mientras que en el año 2018 fue de 99.958 KBEP, obteniendo un crecimiento del 103\%. Lo más preocupante de este crecimiento es que en Ecuador sigue predominando el uso de energía de origen fósil; sectores como el transporte y la industria son los que históricamente han demandado más energía, más del $98 \%$ de energía consumida por el sector del transporte provino de diésel y gasolinas; mientras que, en el sector de la industria el $22,3 \%$ corresponde al consumo de diésel, $10,7 \%$ de Fuel Oil y un $5 \%$ de GLP todos estos combustibles producen más emisiones de $\mathrm{CO}_{2}$. Un punto importante que tomar en consideración es el uso del GLP en el sector residencial, en el año 2018 el 51,7\% del total de lo consumido por este sector corresponde a este tipo de energía que tradicionalmente ha sido el predominante pese a las políticas planteadas por los gobiernos para sustitución de tipo de energía. 
De la literatura revisada se concluye que el número de investigaciones relacionadas al consumo de energía y las emisiones de $\mathrm{CO}_{2}$ es extenso. Los grupos de investigadores han desarrollado varias hipótesis para determinar la responsabilidad que ha tenido y tendrá a futuro el consumo de los diversos tipos de energía en la generación de emisiones de $\mathrm{CO}_{2}$ en el mundo. Existen diferentes factores socioeconómicos que se toman en cuenta para el diseño de los posibles modelos o escenarios, que se han diseñado con la finalidad de determinar el panorama que tendremos a mediano o largo plazo si no se toman medidas para reducir las emisiones de $\mathrm{CO}_{2}$ y a su vez, también se podrá simular un escenario óptimo en base a las políticas planteadas a nivel local, regional o mundial cuyos resultados permitirán tomar las medidas correctivas sobre el tipo de energía que se utiliza en cada región de estudio.

Un factor clave para el desarrollo económico de los países es la energía, fundamentalmente para mejorar el bienestar social y económico que permite atraer riqueza industrial y comercial (OECD and IEA, 2011). El sector de la energía plantea un desafío en el contexto del crecimiento verde, el sistema energético actual depende en gran medida de los combustibles fósiles, cuya combustión representó más del $90 \%$ de las emisiones mundiales en el año 2018 (IEA, 2020). La demanda mundial de energía está aumentando rápidamente, debido al crecimiento demográfico y económico, especialmente en los grandes países emergentes, que representarán el $90 \%$ del crecimiento de la demanda de energía hasta 2035 (OECD and IEA, 2011).

En la actualidad existe una necesidad de realizar modelos sobre energía, economía y medioambiente. Este estudio permitió realizar el análisis del sector energético del Ecuador y su prospectiva mediante el modelado de escenarios para servir de base bibliográfica o guía metodológica de posibles políticas nacionales. Se desarrolló un modelo con un conjunto de escenarios relacionados con el crecimiento económico, demanda de energía por sector económico y por tipo de energía final; $\mathrm{y}$, emisiones de $\mathrm{CO}_{2}$ para Ecuador a mediano plazo.

Los dos escenarios que toman en cuenta las políticas o planes locales y mundiales muestran tendencias mucho más amigables con el medioambiente mientras que la tendencia que se ha mantenido durante el período de investigación (2000 - 2016) plantea un escenario más amplio de emisiones de $\mathrm{CO}_{2}$.Tomando en consideración los resultados de la simulación al 2030 la reducción de emisiones de $\mathrm{CO}_{2}$ sería del $30 \%$ en relación con el escenario BAU que sería la proyección más alta de emisiones. La aplicación de políticas que cuidan el medioambiente, que proponen la sustitución de energías fósiles por energías de origen renovable, que plantean la innovación tecnológica permitirían plantearse objetivos ecológicos dentro de las políticas energéticas futuras para Ecuador. 
La matriz energética del Ecuador tradicionalmente se ha caracterizado por una mayor participación de energía de origen fósil concretamente el petróleo y por la mínima participación de energías renovables, sin embargo, la producción de este tipo de energías en los últimos años ha mostrado un crecimiento, principalmente la hidroenergía ha crecido un 108\% entre el 2000 y el 2016. Los dos escenarios que contemplan políticas nacionales, regionales o mundiales muestran un incremento importante en la demanda de energía $100 \%$ y $50 \%$, razón por la cual es importante plantear políticas que promuevan el uso de energías renovables y se promueva el cambio de matriz energética, a una matriz más sostenible y que considere el cuidado medioambiental como uno de los ejes principales.

Uno de los sectores que mayor atención demanda es el sector del transporte, desde el punto de vista energético es el más ineficiente, la intensidad energética en el año 2016 fue de 9,0 BEP/miles (USD 2007). El 98\% de energía consumida de este sector en el año 2016 es de origen fósil, razón por la cual es el sector que más emisiones de $\mathrm{CO}_{2}$ produce. Los escenarios propuestos plantean la urgencia en tomar medidas correctivas en este sector para reducir las emisiones de $\mathrm{CO}_{2}$ a mediano plazo. Se debe impulsar el uso de energías renovables a través de nuevos sistemas de transporte que utilicen electricidad aprovechando el gran potencial eléctrico que dispone Ecuador. Es importante impulsar los programas sobre biocombustibles y el impulso al uso de vehículos eléctricos.

La prospectiva energética es parte fundamental de la estrategia en la gobernanza energética. Los escenarios simulados muestran la necesidad de plantear un cambio de matriz energética, que si bien se ha dado en los últimos años debe impulsarse con mayor fuerza con la finalidad de alcanzar el objetivo de mitigación del cambio climático. Los proyectos de generación de energía que más repercusión tendrán serán las hidroeléctricas, pero falta mucho más por hacer y se requieren más investigaciones de factibilidad de proyectos de otro tipo de energías renovables como es el caso de la energía eólica, energía solar, biocombustibles entre otras. La volatilidad del precio del petróleo es un factor importante para tomar en cuenta para el crecimiento económico del Ecuador y debe considerarse como un tema a tratar en una gobernanza energética sostenible. Mantener las políticas que se han implementado e incorporar otras le permitirá al Ecuador mantener un desarrollo económico progresivo, que en la actualidad apunta a invertir en nuevas tecnologías y en proyectos enfocados al uso de energías limpias y al cuidado del medio ambiente. El cambio de matriz energética y nuevas políticas energéticas enfocadas en el cambio climático debe ir de la mano, proyectando una imagen más alentadora para el futuro de las emisiones de $\mathrm{CO}_{2}$ en Ecuador. 
Para los próximos años, las políticas energéticas del Ecuador deben considerar una recuperación económica importante, de lo investigado un mayor crecimiento económico permitirá una mayor inversión en innovación y desarrollo tecnológico en el sector energético, lo que generaría un impacto positivo para alcanzar las tan anhelas metas de cuidado medioambiental y la lucha contra el cambio climático.

Las publicaciones de los artículos científicos en medios de impacto y que forman parte de la presente tesis doctoral, sustentan la importancia del tema investigado y permiten alcanzar el objetivo del mismo, convirtiendo el documento en una herramienta de apoyo en la posible toma de decisiones a mediano plazo en el campo de la economía energética del Ecuador. 


\section{Bibliografía}

Akhmetov, A. (2015). Decomposition analysis of industry sector CO2 emissions from fossil fuel combustion in Kazakhstan. International Journal of Energy and Environment, 6(1), 37-46.

Akhtar, M. K. (2011). A system dynamics based integrated assessment modelling of global-regional climate change: a model for analyzing the behaviour of the social-energy-economy-climate system (Doctoral dissertation). Ontario: The University of Western Ontario.

Akpan, U. F., \& Akpan, G. E. (2012). The contribution of energy consumption to climate change: a feasible policy direction. International Journal of Energy Economics and Policy, 2(1), 21-33.

Akpınar, Y. A., \& Saysel, A. K. (2010). A Dynamic Simulation Model of Carbon Circulation and Methane Feedbacks in Anthropogenic Climate Change. The 28 th International Conference of the System Dynamics Society, (págs. 1-27). Istanbul.

Alam, M. J., Begum, I. A., Buysse, J., Rahman, S., \& Van Huylenbroeck, G. (2011). Dynamic modeling of causal relationship between energy consumption, $\mathrm{CO} 2$ emissions and economic growth in India. Renewable and Sustainable Energy Reviews, 15(6), 3243-3251.

Al-mulali, U., Lee, J. Y., Mohammed, A. H., \& Sheau-Ting, L. (2013). Examining the link between energy consumption, carbon dioxide emission, and economic growth in Latin America and the Caribbean. Renewable and Sustainable Energy Reviews, 26, 42-48.

Alves, F., Leal Filho, W., Casaleiro, P., Nagy, G., Diaz, H., Al-Amin, A. Q., . . Morgado, F. (2020). Climate change policies and agendas: Facing implementation challenges and guiding responses. Environmental Science and Policy, 104, 190-198.

Amat y León, C., Seminario, B., Cigarán, M. P., Bambarén, S., \& Macera, L. (2008). El Cambio Climático no tiene fronteras, impacto del cambio climático en la Comunidad Andina. Lima: Secretaría General de la Comunidad Andina.

Amoo, L. M., \& Fagbenle, R. L. (2020). Climate change in developing nations of the world. In R. Fagbenle, O. M. Amoo, A. Falana, \& S. Aliu, Applications of Heat, Mass and Fluid Boundary Layers (pp. 437-471). Sawston: Woodhead Publishing Limited. 
Andrée, B. P., Chamorro, A., Spencer, P., Koomen, E., \& Dogo, H. (2019). Revisiting the relation between economic growth and the environment; a global assessment of deforestation, pollution and carbon emission. Renewable and Sustainable Energy Reviews, 114, 109221.

Ang, J. B. (2007). CO2 emissions, energy consumption, and output in France. Energy Policy, 35(10), 4772-4778.

Ang, J. B. (2008). Economic development, pollutant emissions and energy consumption in Malaysia. Journal of Policy Modeling, 30(2), 271-278.

Ansari, N., \& Seifi, A. (2013). A system dynamics model for analyzing energy consumption and $\mathrm{CO} 2$ emission in Iranian cement industry under various production and export scenarios. Energy Policy, 75-89.

Ansell, T., \& Cayzer, S. (2018). Limits to growth redux: A system dynamics model for assessing energy and climate change constraints to global growth. Energy Policy, 120, 514-525.

Apadula, F., Cassardo, C., Ferrarese, S., Heltai, D., \& Lanza, A. (2019). Thirty Years of Atmospheric $\mathrm{CO} 2$ Observations at the Plateau Rosa Station, Italy. Atmosphere, 10(7), 418.

Apergis, N., \& Payne, J. E. (2009). CO2 emissions, energy usage, and output in Central America. Energy Policy, 3282-3286.

Ara Begum, R., Sohag, K., Syed Abdullah, S. M., \& Jaafar, M. (2015). CO2 emissions, energy consumption, economic and population growth in Malaysia. RenewableandSustainableEnergyReviews, 594-601.

Aracil, J. (1995). Dinámica de Sistemas. Madrid: Gráficas Marte, S.A.

Arango-Miranda, R., Hausler, R., Romero-Lopez, R., Glaus, M., \& IbarraZavaleta, S. P. (2018). Carbon dioxide emissions, energy consumption and economic growth: A comparative empirical study of selected developed and developing countries. “The role of exergy". Energies, 11(10), 2668.

Arouri, M. E., Youssef, A. B., M'henni, H., \& Rault, C. (2012). Energy consumption, economic growth and $\mathrm{CO} 2$ emissions in Middle East and North African countries. Energy policy, 45, 342-349.

Arroyo M., F. R., \& Miguel, L. J. (2019). Analysis of energy demand scenarios in Ecuador: National government policy perspectives and global trend to reduce $\mathrm{CO} 2$ emissions. International Journal of Energy Economics and Policy, 9(2), 364-374. 
Arroyo M., F. R., \& Miguel, L. J. (2019). The Trends of the Energy Intensity and CO2 Emissions Related to Final Energy Consumption in Ecuador:

Scenarios of National and Worldwide Strategies. Sustainability, 12(1), 20.

Arroyo, F., \& Bravo, L. (2017). Escenarios futuros de emisiones de CO2 producidas por el consumo final de energía en Ecuador. Revista Energía Mecánica Innovación y Futuro, 31-38.

Arroyo, F., \& Miguel, L. (2019a). Analysis of energy demand scenarios in Ecuador: National government policy perspectives and global trend to reduce $\mathrm{CO} 2$ emissions. International Journal of Energy Economics and Policy, 364-374.

Arroyo, F., \& Miguel, L. (2019b). Analysis of the variation of CO2 emissions and possible scenarios to 2030 in Ecuador. Revista Espacios, 5-23.

Asamblea Constituyente. (2008). Constitución de la República del Ecuador. Montecristi: Asamblea Constituyente.

Aslan, A. (2013). Energy Consumption and GDP: The Strong Relationship in OECD Countries. Energy Sources, Part B: Economics, Planning, and Policy, 339-345.

Azhaginiyal, A., \& Umadevi, G. (2014). System Dynamics Simulation Modeling of Transport, Energy and Emissions Interactions. Civil Engineering and Architecture, 2(4), 149-165.

Bala, B. K., Arshad, F. M., \& Noh, K. M. (2017). Systems Thinking: System Dynamics. En System Dynamics: Modelling and Simulation (págs. 1535). Singapure: Springer.

Bamooeifard, A. (2020). Future studies in Iran development plans for wind power, a system dynamics modeling approach. Renewable Energy, 162, 1054-1064.

Banco Central del Ecuador. (29 de Marzo de 2019a). La economía ecuatoriana creció $1,4 \%$ en 2018. Obtenido de

https://www.bce.fin.ec/index.php/boletines-de-prensa-archivo/item/1158la-economia-ecuatoriana-crecio-14-en-2018

Banco Central del Ecuador. (2019b). Reporte del sector petrolero IV Trimestre de 2018. Quito: Banco Central del Ecuador.

Barisa, A., \& Rosa, M. (2018). A system dynamics model for CO2 emission mitigation policy design in road transport sector. Energy Procedia, 147, 419-427. 
Barlas, Y. (1996). Formal aspects of model validity and validation in system dynamics. System Dynamics Review: The Journal of the System Dynamics Society, 12(3), 183-210.

Barlas, Y., \& Korhan, K. (1999). A dynamic pattern-oriented test for model validation. In Proceedings of 4th systems science European congress, 269-286.

Bartleet, M., \& Gounder, R. (2010). Energy consumption and economic growth in New Zealand: Results of trivariate and multivariate models. Energy Policy, 38(7), 3508-3517.

Bazilian, M., Nakhooda, S., \& Van de Graaf, T. (2014). Energy governance and poverty. Energy Research \& Social Science, 1, 217-225.

Bekhet, H. A., Matar, A., \& Yasmin, T. (2017). CO2 emissions, energy consumption, economic growth, and financial development in GCC countries: Dynamic simultaneous equation models. Renewable and Sustainable Energy Reviews, 117 -132.

Benestad, R. E., Nuccitelli, D., Lewandowsky, S., Hayhoe, K., Hygen, H. O., Van Dorland, R., \& Cook, J. (2016). Learning from mistakes in climate research. Theoretical and Applied Climatology, 126(3-4), 699-703.

Bernauer, T., \& Schaffer, L. M. (2010). Climate change governance. CIS Working Paper, 1-29.

Bettoga. (19 de Noviembre de 2013). Matriz Energética del Ecuador. Obtenido de Globedia: http://ec.globedia.com/matriz-energetica-ecuador

Bindoff, N., Willebrand, J., Artale, V., Cazenave, A., Gregory, J., Gulev, S., . . Alakkat, U. (2007). Observations: Oceanic Climate Change and Sea Level. The Physical Science Basis. Working Group I Contribution to the Intergovernmental Panel on Climate Change Fourth Assessment Report, $1-48$.

BP. (2018). BP Statistical Review of World Energy. London: BP.

BP. (2019). BP Statistical Review of World Energy. London: BP.

Bravo, G., Di Sbroiavacca, N., Dubrovsky, H., Lallana, F., Landaveri, R., Recalde, M., \& Ruchansky, B. (2016). Estudio de Prospectiva Energética del Ecuador 2012-2040. Quito: Fundación Bariloche de Argentina Ministerio Coordinador de Sectores Estratégicos.

Brundtland Commission. (1987). DescriptionOur Common Future. Oxford: Oxford University Press. 
Capellán-Pérez, I., Arto, I., Markandya, A., González-Eguinob, M., Filatova, T., inouche, F., . . . Hasselmann, K. (2013). State of the art review of climate - energy - economic modeling approaches.

Capellán-Pérez, I., de Blas, I., Nieto, J., de Castro, C., Miguel, L. J., Carpintero, Ó., ... Álvarez Antelo, D. (2020). MEDEAS: a new modeling framework integrating global biophysical and socioeconomic constraints. Energy \& Environmental Science, 3(13), 986-1017.

Capellán-Pérez, I., de Blas, I., Nieto, J., de Castro, C., Miguel, L. J., Mediavilla, ... Santiago, C. (2017b). Global Model: MEDEAS-World Model and IOA implementation at global geographical level. Valladolid: EU Framework Program for Research and Innovation actions.

Capellán-Pérez, I., de Castro, C., Mediavilla, Margarita, Miguel, L. J., de Blas, I., ... Nieto, J. (2017a). World Limits Model (WoLiM) 1.5. Valladolid: Geeds.

Capellán-Pérez, Í., Mediavilla, M., de Castro, C., \& Miguel, L. J. (2014). World limits model (WoLiM) 1.0-model documentation. Valladolid: Energy, Economy and System Dynamics.

Capellán-Pérez, I., Mediavilla, M., de Castro, C., Carpintero, Ó., \& Miguel, L. J. (2014). Fossil fuel depletion and socio-economic scenarios: An integrated approach. Energy, 641-666.

Capellán-Péreza, I., de Castro, C., \& Miguel González, L. J. (2019). Dynamic Energy Return on Energy Investment (EROI) and material requirements in scenarios of global transition to renewable energies. Energy Strategy Reviews, 1-26.

Cárdenas Herrera, J. (2014). Estudio de la reducción de emisiones de carbono en el Ecuador (Tesis Maestría). Quito: Escuela Politécnica Nacional.

Carmody, C. (2012). Considering future generations - sustainability in theory and practice. Economic Roundup, 65-91.

Castro Verdezoto, P. L., \& Vidoza, J. A. (2019). Analysis and projection of energy consumption in Ecuador: Energy efficiency policies in the transportation sector. Energy Policy, 1-14.

Castro, M. (2011). Hacia una Matriz Energética Diversificada en Ecuador. Quito: CEDA.

Cely, A. (1999). Metodología de los Escenarios para Estudios. Revista Ingeniería e Investigación, 26-35. 
CEPAL. (2013). La economía del cambio climático en el Ecuador 2012. Santiago de Chile: Naciones Unidas .

Chen, P.-Y. a.-T.-S.-C. (2016). Modeling the global relationships among economic growth, energy consumption and $\mathrm{CO} 2$ emissions. Renewable and Sustainable Energy Reviews, 65, 420-431.

Chen, X., Zhang, X., Church, J. A., Watson, C. S., King, M. A., Monselesan, D., ... Harig, C. (2017). The increasing rate of global mean sea-level rise during 1993-2014. Nature Climate Change, 492-495.

Chontanawat, J. (2020). Relationship between energy consumption, CO2 emission and economic growth in ASEAN: Cointegration and causality model. Energy Reports, 6, 660-665.

Conelec. (2013). Plan Maestro de Electrificación 2013 - 2022. Quito: CONELEC.

Consejo Nacional de Electricidad. (2013). Estudio y gestión de la demanda eléctrica. Plan maestro de electrificación 2013-2022. Cuenca: CONELEC.

de Blas, I., Miguel, L. J., \& Capellán-Pérez, I. (2019). Modelling of sectoral energy demand through energy intensities in MEDEAS integrated assessment model. Energy Strategy Reviews, 26, 100419.

de Castro, C. (2009). Escenarios de Energía-Economía mundiales con modelos de Dinámica de Sistemas (Tesis Doctoral). Valladolid: Universidad de Valladolid.

de Castro, C., Mediavilla, M., Miguel, L. J., \& Frechoso, F. (2013). Global solar electric potential: A review of their technical and sustainable limits. Renewable and Sustainable Energy Reviews, 28, 824-835.

Deaton, M. I., \& Winebrake, J. (2000). Dynamic Modeling of Environmental Systems. New York: Springer.

Döll, P., Trautmann, T., Gerten, D., Schmied, H. M., Ostberg, S., Saaed, F., \& Schleussner, C.-F. (2018). Risks for the global freshwater system at 1.5 $\mathrm{C}$ and $2 \mathrm{C}$ global warming. Environmental Research Letters, 044038.

Dong, C., Dong, X., Jiang, Q., Dong, K., \& Liu, G. (2018). What is the probability of achieving the carbon dioxide emission targets of the Paris Agreement? Evidence from the top ten emitters. Science of the Total Environment, 622, 1294-1303.

DVG.GL. (2018). Energy Transition Outlook 2018. Oslo: DVG.GL. 
Dyson, B., \& Chang, N.-B. (2005). Forecasting municipal solid waste generation in a fast-growing urban region with system dynamics modeling. Waste Management, 669-679.

Economic Commission for Latin America and the Caribbean (ECLAC). (2013). The economy of climate change in Ecuador. Santiago de Chile: United Nations.

Edelenbosch, O., van Vuuren, D., Blok, K., Calvin, K., \& Fujimori, S. (2020). Mitigating energy demand sector emissions: The integrated modelling perspective. Applied Energy, 261, 114347.

El Comercio. (13 de Octubre de 2018). La población de Ecuador superó los 17 millones de habitantes. Quito, Pichincha, Ecuador.

Elsawah, S., Pierce, S. A., Hamilton, S. H., van Delden, H., Haase, D., Elmahdi, A., \& Jakeman, A. J. (2017). An overview of the system dynamics process for integrated modelling of socio-ecological systems: Lessons on good modelling practice from five case studies. Environmental Modelling \& Software, 127-145.

Emodi, N. V., Chaiechi, T., \& Beg, A. R. (2019). The impact of climate variability and change on the energy system: A systematic scoping review. Science of the total environment, 676, 545-563.

EP Petroecuador. (2013). El petróleo en el Ecuador la nueva era petrolera. Quito: Manthra Comunicación integral y Producción editorial.

Esso, L. J., \& Keho, Y. (2016). Energy consumption, economic growth and carbon emissions: Cointegration and causality evidence from selected African countries. Energy, 727-736.

European Environment Agency. (2017). Climate change, impacts and vulnerability in Europe 2016. Luxembourg: Publications Office of the European Union.

Fais, B., Sabio, N., \& Strachan, N. (2016). The critical role of the industrial sector in reaching long-term emission reduction, energy efficiency and renewable targets. Applied Energy, 162, 699-712.

Farhani, S., \& Rejeb, J. B. (2012). Energy Consumption, Economic Growth and CO2 Emissions: Evidence from Panel Data for MENA Region. International Journal of Energy Economics and Policy, 71-81.

Feng, Y., Chen, S., \& Zhang, L. (2013). System dynamics modeling for urban energy consumption and $\mathrm{CO} 2$ emissions: A case study of Beijing, China. Ecological Modelling, 44-52. 
Florini, A., \& Sovacool, B. K. (2009). Who governs energy? The challenges facing global energy governance. Energy Policy, 37(12), 5239-5248.

Fontaine, G. (2011). The effects of governance modes on the energy matrix of Andean countries. Energy Policy, 39(5), 2888-2898.

Ford, A. (2010). Modeling the Environment, Second Edition. Washington, DC: Island Press.

Forrester, J. W. (1961). Industrial Dynamics. Massachusetts: The MIT Press.

Forrester, J. W. (1968). Principles of System. Cambridge: Productivity Press.

Forrester, J. W. (1971). World dynamics. Cambridge: Wright-Allen Press.

Forrester, J. W., \& Senge, P. M. (1980). Tests for building confidence in system dynamics models. Amsterdam: North Holland Press.

Fouquet, R., \& Pearson, P. J. (2012). Past and prospective energy transitions: Insights from history. Energy Policy, 50, 1-7.

Fritzsche, K., Zejli, D., \& Tänzlera, D. (2011). The relevance of global energy governance for Arab countries: The case of Morocco. Energy Policy, 39(8), 4497-4506.

Fujimori, S., Kainuma, M., Masui, T., Hasegawa, T., \& Dai, H. (2014). The effectiveness of energy service demand reduction: A scenario analysis of global climate change mitigation. Energy Policy, 75, 379-391.

Gallegos, J. (2015). Análisis de la evolución de las emisiones de dióxido de carbono (CO2) en Ecuador (1980 - 2010), mediante la Identida de Kaya. Loja: Universidad Técnica Particular de Loja.

Gambhir, A. a., Tong, D., Munuera, L., Faist, M., \& Riahi, K. (2013). A hybrid modelling approach to develop scenarios for China's carbon dioxide emissions to 2050. Energy Policy, 59, 614-632.

García G., I. (2013). Análisis de factores esconómicos, tecnológicos y políticos en el futuro mercado del vehículo eléctrico en España (Tesis Doctoral). Valladolid: Universidad de Valladolid.

García, J. M. (2004). Sysware. Barcelona: Juan Martín Garcia.

García, J. M. (2017). Teoría y ejercicios parácticos de dinámica de sistemas. Zarafoza: Juan Martín García.

García-Gusano, D., \& Iribarren, D. (2018). Prospective energy security scenarios in Spain: The future role of renewable power generation 
technologies and climate change implications. Renewable Energy, 126, 202-209.

Gordillo, F., \& Aracil, J. (1997). Dinámica de Sistemas. México: Alianza Editorial.

Greenleaf, J., Harmsen, R., Angelini, T., Green, D., Williams, A., Rix, O., ... Blyth, W. (2009). Analysis of impacts of climate change policies on energy security. Berlin: Ecofys.

Halicioglu, F. (2009). An econometric study of CO2 emissions, energy consumption, income and foreign trade in Turkey. Energy Policy, 37(3), 1156-1164.

Han, J., Du, T., Zhang, C., \& Qian, X. (2018). Correlation analysis of CO2 emissions, material stocks and economic growth nexus: evidence from Chinese provinces. Journal of Cleaner Production, 180, 395-406.

Hasan, M. A., Abubakar, I. R., Rahman, S. M., Aina, Y. A., Chowdhury, M. M., \& Khondaker, A. (2020). The synergy between climate change policies and national development goals: Implications for sustainability. Journal of Cleaner Production, 249, 119369.

Haseeb, M., \& Azam, M. (2015). Energy consumption, economic growth and $\mathrm{CO} 2$ emission nexus in Pakistan. Asian Journal of Applied Sciences, 8(1), 27-36.

Herbst, A., Toro, F., Reitze, F., \& Jochem, E. (2012). Introduction to energy systems modelling. Swiss journal of economics and statistics, 148(2), 111-135.

Howarth, N., Galeotti, M., Lanza, A., \& Dubey, K. (2017). Economic development and energy consumption in the GCC: an international sectoral analysis. Energy Transitions, 1(6), 1-19.

Huaman, R. N., \& Jun, T. X. (2014). Energy related CO2 emissions and the progress on CCS projects: a review. Renewable and Sustainable Energy Reviews, 31, 368-385.

IEA. (2020). CO2 Emissions from Fuel Combustion: Overview. Paris: IEA.

INER. (2016a). Análisis de las oportunidades de I+D+i en eficiencia energética y energías renovables. Quito: INER.

INER. (2016b). Escenarios de prospectiva energética para Ecuador a 2050. Quito: INER. 
Intergovernmental Panel on Climate Change. (2012). Managing the Risks of Extreme Events and Disasters to Advance Climate Change Adaptation. Cambridge: Cambridge University Press.

Intergovernmental Panel on Climate Change. (2014a). Climate Change 2014. Synthesis Report Summary for Policymakers. Geneva: IPCC.

Intergovernmental Panel on Climate Change. (2014b). Climate Change 2014. Mitigation of Climate Change. Working Group III Contribution to the Fifth Assessment Report of the Intergovernmental Panel on Climate Change. Cambridge: Cambridge University Press.

Intergovernmental Panel on Climate Change. (2014c). Impacts, Adaptation, and Vulnerability. Cambridge: Cambridge University Press.

Intergovernmental Panel on Climate Change. (2018a). Global Warming of 1.5ํ․ Geneva: IPCC.

Intergovernmental Panel on Climate Change. (2018b). Summary for

Policymakers. In: Global Warming of $1.5^{\circ} \mathrm{C}$. Geneva: IPCC.

International Energy Agency. (2017). Market Report Series: Energy Efficiency 2017. París: International Energy Agency.

International Energy Agency. (2018a). Global Energy \& CO2 Status Report.

París: International Energy Agency. Obtenido de

https://www.iea.org/geco/emissions/

International Energy Agency. (2018b). World Energy Outlook 2018. París: IEA Publications.

International Energy Agency. (2019a). Energy Efficiency. Paris: IEA.

International Energy Agency. (2019b). Global Energy \& CO2 Status Report 2019. París: IEA.

International Energy Agency. (2019c). World Energy Outlook 2019. Paris: IEA publications.

International Energy Agency. (2020a). Global CO2 emissions in 2019. Paris: IEA.

International Energy Agency. (2020b). Defining energy access: 2020 methodology. Paris: IEA.

IRENA. (2018). Global Energy Transformation: A roadmap to 2050. Masdar City: International Renewable Energy Agency. 
IRENA. (2019). A New World: The Geopolitics of the Energy Transformation. Abu Dhabi: IRENA.

IRENA, IEA and REN21. (2018). Renewable Energy Policies in a Time of Transition. IRENA - IEA - REN21.

Jabar, M. A., Sidi, F., \& Mohd Hasan Selamat, A. A. (2009). An Investigation into Methods and Concepts of Qualitative Research in Information System Research. Computer and Information Science, 47-54.

Jaunky, V. C. (2011). The CO2 emissions-income nexus: Evidence from rich countries. Energy Policy, 1228-1240.

Jinnan, W., Dong, C., Zhizhong, Z., Hanli, C., Shuting, G., Yuantang, L., \& Chazhong, G. (2004). Energy, Environment and Its Public Health Impact . En W. Jinnan, \& C. Dong, China National Energy Strategy and Policy 2020 (págs. 1-135). Beijing: Chinese Academy for Environmental Planning.

Johansson, T. B., Patwardhan, A. P., Nakicenovic, N., \& Gomez-Echeverri, L. (2012). Global Energy Assessment: Toward a Sustainable Future. Cambridge: Cambridge University Press.

Jokar, Z., \& Mokhtar, A. (2018). Policy making in the cement industry for $\mathrm{CO} 2$ mitigation on the pathway of sustainable development-A system dynamics approach. Journal of Cleaner Production, 201, 142-155.

Jordaan, S. M., Romo-Rabago, E., McLeary, R., Reidy, L., Nazari, J., \& Herremans, I. M. (2017). The role of energy technology innovation in reducing greenhouse gas emissions: A case study of Canada. Renewable and Sustainable Energy Reviews, 78, 1397-1409.

Kais, S., \& Ben Mbarek, M. (2015). Dynamic relationship between CO2 emissions, energy consumption and economic growth in three North African countries. International Journal of Sustainable Energy, 840-854.

Kang, J.-N., Wei, Y.-M., Liu, L.-C., Han, R., Yu, B.-Y., \& Wang, J.-W. (2020). Energy systems for climate change mitigation: A systematic review. Applied Energy, 114602.

Kang, S. H., Islam, F., \& Tiwari, A. K. (2019). The dynamic relationships among CO2 emissions, renewable and non-renewable energy sources, and economic growth in India: Evidence from time-varying Bayesian VAR model. Structural Change and Economic Dynamics., 50, 90-101.

Karimu, A., Brännlund, R., Lundgren, T., \& Söderholm, P. (2017). Energy intensity and convergence in Swedish industry: A combined econometric and decomposition analysis. Energy Economics, 347-356. 
Karjalainen, J., Käkönen, M., Luukkanen, J., \& Vehmas, J. (2014). Energy models and scenarios in the era of climate change. Turku: Writers \& Finland Futures Research Centre.

Karlsson-Vinkhuyzena, S. I., Jollands, N., \& Staudt, L. (2012). Global governance for sustainable energy: The contribution of a global public goods approach. Ecological Economics, 83, 11-18.

Kelektsoglou, K. (2018). Carbon capture and storage: A review of mineral storage of CO2 in Greece. Sustainability, 10(12), 4400.

Klemeš, J. J., Varbanov, P. S., Oclón, P., \& Chin, H. H. (2019). Towards Efficient and Clean Process Integration: Utilisation of Renewable Resources and Energy-Saving Technologies. Energies, 12(21), 4092.

Kottari, M. (2016). A new era for global energy governance? The environmental imperatives and the EU perspective. Politikon: IAPSS Journal of Political Science, 29, 124-139.

Koyama, K. (2018). Global Energy Governance: Past, Presente, and Future. IEEJ Energy Journal, 1-4.

Krey, V., Luderer, G., Clarke, L., \& Kriegler, E. (2014). Getting from here to there--energy technology transformation pathways in the EMF27 scenarios. Climatic change, 369-382.

Kriegler, E., Weyant, J. P., Blanford, G. J., Krey, V., Clarke, L., Edmonds, J., . . . van Vuuren, D. (2014). The role of technology for achieving climate policy objectives: overview of the EMF 27 study on global technology and climate policy strategies. Climatic Change, 123, 353-367.

Kuriakose, A. T., Bizikova, L., \& Bachofen, C. A. (2009). Assessing Vulnerability and Adaptive Capacity to Climate Risks: Methods for Investigation at Local and National Levels. Washington, DC: The World Bank .

Lemke, J., \& Łatuszyńska, M. (2013). Validation of System Dynamics Models A Case Study . Journal of Entrepreneurship Management and Innovation, 9(2), 45-59.

Li, L., Chen, C., Xie, S., Huang, C., Cheng, Z., Wang, H., . . Dhakal, S. (2010). Energy demand and carbon emissions under different development scenarios for Shanghai, China. Energy Policy, 4797-4807.

Li, Q., Zhang, W., Li, H., \& He, P. (2017). CO2 emission trends of China's primary aluminum industry: A scenario analysis using system dynamics model. Energy Policy, 225-235. 
Lin, B., \& Raza, M. Y. (2019). Analysis of energy related CO2 emissions in Pakistan. Journal of Cleaner Production, 219, 981-993.

Liu, X., Mao, G., Ren, J., Li, R. Y., Guo, J., \& Zhang, L. (2015). How might China achieve its 2020 emissions target? A scenario analysis of energy consumption and $\mathrm{CO} 2$ emissions using the system dynamics model. Journal of Cleaner Production, 103, 401-410.

Lu, C., \& Wu, D. (2016). Environment and economic risk: An analysis of carbon emission market and portfolio management. Environmental Research, 297-301.

Ludeña, C., \& Wilk, D. (2013). ECUADOR: Mitigación y Adaptación al Cambio Climático. Washington D. C.: Banco Interamericno de Desarrollo.

Luderer, G., Vrontisi, Z., Bertram, C., Edelenbosch, O. Y., Pietzcker, R. C., Rogelj, J., ... Keramidas, K. (2018). Residual fossil CO2 emissions in $1.5-2{ }^{\circ} \mathrm{C}$ pathways. Nature Climate Change, 626-633.

Ma, C., Ju, M. T., Zhang, X. C., \& Li, H. Y. (2011). Energy consumption and carbon emissions in a coastal city in China. Procedia Environmental Sciences, 4(2011), 1-9.

Magazzino, C. (2014). The relationship between CO2 emissions, energy consumption and economic growth in Italy. International Journal of Sustainable Energy , 844-857.

Mamatok, Y., Huang, Y., Jin, C., \& Cheng, X. (2019). A System Dynamics Model for CO2 Mitigation Strategies at a Container Seaport. Sustainability, 10(11), 2806.

Manetsch, T. J., \& Park, G. L. (1982). System analysis and simulation with applications to economic and social systems. Michigan: Michigan State University.

Mardani, A., Streimikiene, D., Cavallaro, F., Loganathan, N., \& Khoshnoudi, M. (2019). Carbon dioxide (CO2) emissions and economic growth: A systematic review of two decades of research from 1995 to 2017. Science of the total environment, 649, 31-49.

Martín García, J. (2003). Teoría y ejercicios prácticos de Dinámica de Sistemas. Barcelona: Juan Martín García.

Martín García, J. (2018). Teoría y ejercicios prácticos de Dinámica de Sistemas. Zaragoza: Juan MArtín García.

Martinez-Moyano, I. J., \& Richardson, G. P. (2013). Best practices in system dynamics modeling. System Dynamics Review, 29(2), 102-123. 
Máttar, J., \& Cuervo, L. M. (2017). Planificación para el desarrollo en América Latina y el Caribe: enfoques, experiencias y perspectivas. Santiago: CEPAL.

Matthews, T. K., Wilby, R. L., \& Murphy, C. (2017). Communicating the deadly consequences of global warming for human heat stress. Proceedings of the National Academy of Sciences, 3861-3866.

Maximillian, J., Brusseau, M., Glenn, E., \& Matthias, A. (2019). Pollution and environmental perturbations in the global system. En M. L. Brusseau, I. L. Pepper, \& C. P. Gerba, Environmental and Pollution Science (págs. 457-476). Amsterdam: Elsevier.

Meadowcroft, J. (2009). Climate change governance. Washington, D.C.: The World Bank.

Mearns, R., \& Norton, A. (2010). Social Dimensions of Climate Change. Washington, DC: The World Bank.

Menyah, K., \& Wolde-Rufael, Y. (2010). Energy consumption, pollutant emissions and economic growth in South Africa. Energy Economics, 32(6), 1374-1382.

Ministerio Coordinador de Sectores Estratégicos. (2016a). Balance Energético Nacional 2015. Quito: Ministerio Coordinador de Sectores Estratégicos.

Ministerio Coordinador de Sectores Estratégicos. (2014). Balance Energético Nacional 2013. Quito: Ministerio Coordinador de Sectores Estratégicos.

Ministerio Coordinador de Sectores Estratégicos. (2015). Balance Energético Nacional 2014. Quito: Ministerio Coordinador de Sectores Estratégicos.

Ministerio Coordinador de Sectores Estratégicos. (2016b). Agenda nacional de energía 2016-2040. Quito: Ministerio Coodinador de Sectores Estartégicos.

Ministerio de Electricidad y Energía Renovable. (2017a). Plan maestro de electricidad 2016 - 2025. Quito: Ministerio de Electricidad y Energía Renovable.

Ministerio de Electricidad y Energía Renovable. (2017b). Plan Nacional de Eficiencia Energética 2016-2035. Quito: Ministerio de Electricidad y Energía Renovable.

Ministerio de Electricidad y Energía Renovable. (2018). Balance Energético Nacional 2017. Quito: MEER.

Ministerio de Electricidad y Energía Renovable. (2020). Balance Energético Nacional 2018. Quito: MEER. 
Ministerio del Ambiente. (2012). Estrategia Nacional de Cambio Climático del Ecuador. Quito: Ministerio del Ambiente (MAE).

Ministerio del Ambiente. (2017). Tercera Comunicación Nacional del Ecuador sobre Cambio Climático. Quito: Ministerio del ambiente.

Mirza, F. M., \& Kanwal, A. (2017). Energy consumption, carbon emissions and economic growth in Pakistan: Dynamic causality analysis. Renewable and Sustainable Energy Reviews, 72, 1233-1240.

Mirzaei, M., \& Bekri, M. (2017). Energy consumption and CO2 emissions in Iran, 2025. Environmental Research, 154, 345-351.

Mohapatra, G., \& Giri, A. K. (2015). Energy consumption, economic growth and $\mathrm{CO} 2$ emissions: Empirical evidence from India. The Empirical Econometrics and Quantitative Economics Letters, 4(1), 17-32.

Mohapatra, P. K., Mandal, P., \& Bora, M. C. (1994). Introduction to System Dynamics Modeling. New York: Universities Press.

Mohr, S., Wang, J., Ellem, G., Ward, J., \& Giurco, D. (2015). Projection of world fossil fuels by country. Fuel, 141, 120-135.

Mondal, A. H., Bryan, E., Ringler, C., Mekonnen, D., \& Rosegrant, M. (2018). Ethiopian energy status and demand scenarios: Prospects to improve energy efficiency and mitigate GHG emissions. Energy, 161-172.

Morales, Á. C., \& Sauer, I. L. (2001). Mitigation of greenhouse gas emissions originating from energy consumption by the residential sector in Ecuador. Energy for Sustainable Development, 47-59.

Muhammad, B. (2019). Energy consumption, CO2 emissions and economic growth in developed, emerging and Middle East and North Africa countries. Energy, 179(15), 232-245.

Müller, F., Knodt, M., \& Piefer, N. (2015). Conceptualizing emerging powers and Eu energy governance: Towards a research agenda. En Challenges of European External Energy Governance with Emerging Powers (págs. 17-32). Farnham: Ashgate Publishing, Ltd.

Munir, Q., Lean, H. H., \& Smyth, R. (2020). CO2 emissions, energy consumption and economic growth in the ASEAN- 5 countries: A crosssectional dependence approach. Energy Economics, 85, 104571.

Mutingi, M., Mbohwa, C., \& Dube, P. (2017). System dynamics archetypes for capacity management of energy systems. Energy Procedia, 141, 199205. 
Mutingi, M., Mbohwa, C., \& Kommula, V. P. (2017). System dynamics approaches to energy policy modelling and simulation. Energy Procedia, $141,532-539$.

Nain, M. Z., Ahmad, W., \& Kamaiah, B. (2015). Economic growth, energy consumption and $\mathrm{CO} 2$ emissions in India: a disaggregated causal analysis. International Journal of Sustainable Energy , 807-824.

NASA. (19 de Marzo de 2018). Global Climate Change. Obtenido de https://climate.nasa.gov/evidence/

Neufeld, W. P. (1985). Environmental scanning: its use in forecasting emerging trends and issues in. Futures Research Quarterly, 39-52.

Neves, S. A., Marques, A. C., \& Fuinhas, J. A. (2017). Is energy consumption in the transport sector hampering both economic growth and the reduction of $\mathrm{CO} 2$ emissions? A disaggregated energy consumption analysis. Transport Policy, 59, 64-70.

Nieto, J., Carpintero, Ó., \& Miguel, L. J. (2018). Less than $2{ }^{\circ} \mathrm{C}$ ? An EconomicEnvironmental Evaluation of the Paris Agreement. Ecological Economics, 69-84.

Nieto, J., Carpintero, Ó., Miguel, L. J., \& de Blas, I. (2020). Macroeconomic modelling under energy constraints: Global low carbon transition scenarios. Energy Policy, 137, 111090.

Niu, S., Ding, Y., Niu, Y., Li, Y., \& Luo, G. (2011). Economic growth, energy conservation and emissions reduction: A comparative analysis based on panel data for 8 Asian-Pacific countries. Energy Policy, 39(4), 21212131.

Noboa, E., Upham, P., \& Heinrichs, H. (2018). Collaborative energy visioning under conditions of illiberal democracy: results and recommendations from Ecuador. Energy, Sustainability and Society, 8(1), 1-17.

Nwani, C. (2017). Causal relationship between crude oil price, energy consumption and carbon dioxide (CO2) emissions in Ecuador. OPEC Energy Review, 41(3), 201-225.

Observatorio de Energía Renovable para América Latina y el Caribe. (2011). Ecuador: Reporte final. Brasil: OLADE \& ONUD.

OECD and IEA. (2011). OECD Green Growth Studies: Energy. Paris: OECD.

Overland, I. (2016). Energy: The missing link in globalization. Energy Research \& Social Science, 14, 122-130. 
Ozturk, I., \& Acaravci, A. (2010). CO2 emissions, energy consumption and economic growth in Turkey. Renewable and Sustainable Energy Reviews, 14(9), 220-3225.

Ozturk, I., \& Acaravci, A. (2013). The long-run and causal analysis of energy, growth, openness and financial development on carbon emissions in Turkey. Energy Economics, 36, 262-267.

Panchana, I. (2015). Proyectos de energía renovable en la matriz energética y desarrollo del país. Guayaquil: Universidad de Guayaquil.

Panda, D. (2011). Impact of renewable energy sources in power supply of India-a system dynamics approach. International Journal of Power System Operation and Energy Management, 5-9.

Pao, H.-T., \& Tsai, C.-M. (2010). CO2 emissions, energy consumption and economic growth in BRIC countries. Energy Policy, 38(12), 7850-7860.

Pao, H.-T., \& Tsai, C.-M. (2011). Modeling and forecasting the CO2 emissions, energy consumption, and economic growth in Brazil. Energy, 36(5), 2450-2458.

Pao, H.-T., YU, H.-C., \& Yang, Y.-H. (2011). Modeling the CO2 emissions, energy use, and economic growth in Russia. Energy, 36(8), 5094-5100.

Park, J.-k., Ryu, D., \& Lee, K. (2019). What determines the economic size of a nation in the world: Determinants of a nation's share in world GDP vs. per capita GDP. Structural Change and Economic Dynamics, 51, 203214.

Peláez Samaniego, M., Garcia Perez, M., Cortez, L., Oscullo, J., \& Olmedo, G. (2007). Energy sector in Ecuador: Current status. Energy Policy, 41774189.

Pelaez, M., \& Espinoza, J. (2015). Renewable energies in Ecuador. Current situation, trends and perspectives. Cuenca: University of Cuenca.

Pinzón, K. (2018). Dynamics between energy consumption and economic growth in Ecuador: A granger causality analysis. Economic Analysis and Policy, 57, 88-101.

Pita, P., Winyuchakrit, P., \& Limmeechokchai, B. (2020). Analysis of factors affecting energy consumption and $\mathrm{CO} 2$ emissions in Thailand's road passenger transport. Heliyon, 6(10), e05112.

Puglisi, M. (2001). The study of the futures: An Overview of futures studies methodologies. CIHEAM Options Méditerranéennes, 439-463. 
Qudrat-Ullah, H. (2016). Modeling and Simulation in Service of Energy Policy: The Challenges. En H. Qudrat-Ullah, The Physics of Stocks and Flows of Energy Systems (págs. 7-12). Cham: Springer.

Randers, J. (1980). Elements of the system dynamics method. Cambridge: Productivity Press.

Rao, S., Klimont, Z., Leitao, J., Riahi, K., Van Dingenen, R., Reis, L. A., .. . Tavoni, M. (2016). A multi-model assessment of the co-benefits of climate mitigation for global air quality. Environmental Research Letters, 124013.

Richardson, G. P., \& Pugh, A. L. (1981). Introduction to System Dynamics Modeling with Dynamo. Cambridge: MIT Press.

Ringel, M., \& Knodt, M. (2018). The governance of the European Energy Union: Efficiency, effectiveness and acceptance of the Winter Package 2016. Energy Policy, 112, 209-220.

Riti, J. S., Song, D., Shu, Y., \& Kamah, M. (2017). Decoupling CO2 emission and economic growth in China: is there consistency in estimation results in analyzing environmental Kuznets curve? Journal of Cleaner Production, 166, 1448-1461.

Robalino López, A. (2014). Carbon emissions, energy consumption and sustainable development in Ecuador (1980-2025): System dynamics modelling, decomposition analysis and the environmental kuznets curve. (Tesis Doctorado). Huelva: Universidad de Huelva.

Robalino López, A., García Ramos, J. E., Golpe, A. A., \& Mena Nieto, Á. (2014). System dynamics modelling and the environmental Kuznets curve in Ecuador (1980-2025). Energy Policy, 923-931.

Robalino López, A., Mena Nieto, A., \& García Ramos, J. E. (2014). System dynamics modeling for renewable energy and $\mathrm{CO} 2$ emissions: A case study of Ecuador. Energy for Sustainable Development, 11-20.

Rogelj, J., Den Elzen, M., Höhne, N., Fransen, T., Fekete, H., Winkler, H., . . . Meinshausen, M. (2016). Paris Agreement climate proposals need a boost to keep warming well below $2 \mathrm{C}$. Nature, 534, 631-639.

Roinioti, A., \& Koroneos, C. (2017). The decomposition of CO2 emissions from energy use in Greece before and during the economic crisis and their decoupling from economic growth. Renewable and Sustainable Energy Reviews, 76, 448-459. 
Rosenzweig, C., Arnell, N., Ebi, K., Lotze-Campen, H., Raes, F., Rapley, C., . . . van Vuuren, D. (2017). Assessing inter-sectoral climate change risks: the role of ISIMIP. Environmental Research Letters, 010301.

Ruth, M., \& Hannon, B. (2012). Modeling Dynamic Economic Systems. New York: Springer.

Saboori, B., \& Sulaiman, J. (2013). CO2 emissions, energy consumption and economic growth in Association of Southeast Asian Nations (ASEAN) countries: A cointegration approach. Energy, 55, 813-822.

Saeed, F., Bethke, I., Fischer, E., Legutke, S., Shiogama, H., Stone, D. A., \& Schleussner, C.-F. (2018). Robust changes in tropical rainy season length at $1.5^{\circ} \mathrm{C}$ and $2^{\circ} \mathrm{C}$. Environmental Research Letters, 064024 .

Sahir, M. H., \& Qureshi, A. H. (2007). Specific concerns of Pakistan in the context of energy security issues and geopolitics of the region. Energy Policy, 35(4), 2031-2037.

Saidi, K., \& Hammami, S. (2015). The impact of CO2 emissions and economic growth on energy consumption in 58 countries. Energy Reports, 62-70.

Salahuddin, M., \& Gow, J. (2014). Economic growth, energy consumption and CO2 emissions in Gulf Cooperation Council countries. Energy, 73, 44-58.

Sargent, R. G. (2011). Validation and verification of simulation models. Proceedings of the 2011 Winter Simulation Conference, 1, 183-198.

Schewe, J., Heinke, J., Gerten, D., Haddeland, I., Arnell, N., Clark, D., . . Portmann, F. (2014). Multimodel assessment of water scarcity under climate change. Proceedings of the National Academy of Sciences, 3245-3250.

Schoemaker, P. J. (1991). When and how to use scenario planning: A heuristic approach with illustration. Journal of Forecasting, 549-564.

SENPLADES. (2009). Plan Nacional para el Buen Vivir 2009 - 2013: Construyendo un Estado Plurinacional e Intercultural. Quito: SENPLADES.

Shafiei, E., Davidsdottir, B., Leaver, J., Stefansson, H., \& Asgeirsson, E. I. (2015). Simulation of Alternative Fuel Markets using Integrated System Dynamics Model of Energy System. Procedia Computer Science, 513521.

Sheinbaum-Pardo, C., Mora-Pérez, S., \& Robles-Morales, G. (2012). Decomposition of energy consumption and $\mathrm{CO} 2$ emissions in Mexican 
manufacturing industries: Trends between 1990 and 2008. Energy for Sustainable Development, 16(1), 57-67.

Shreckengost, R. C. (1985). Dynamic simulation models: how valid are they? NIDA research monograph, 57, 63-70.

Silva Herran, D., Tachiiri, K., \& Matsumoto, K. (2019). Global energy system transformations in mitigation scenarios considering climate uncertainties. Applied Energy, 243(1), 119-131.

Simsek, Y., Lorca, Á., Urmee, T., Bahri, P. A., \& Escobar, R. (2019). Review and assessment of energy policy developments in Chile. Energy Police, 127, 87-101.

Slaughter, R. A. (1999). A new framework for environmental scanning. Foresigh, 441-451.

Sovacool, B. K., \& Florini, A. (2012). Examining the Complications of Global Energy Governance. Journal of Energy and Natural Resources Law, 30(3), 235-263.

Soytas, U., Sari, R., \& Ewing, B. T. (2007). Ecological Economics. Energy consumption, income, and carbon emissions in the United States, 62(34), $482-489$.

Stamatiou, P., \& Dritsakis, N. (2017). Dynamic modeling of causal relationship between energy consumption, $\mathrm{CO} 2$ emissions, and economic growth in Italy. En Advances in Applied Economic Research (págs. 99-109). Cham: Springer.

Sterman, J. D. (2000). Business dynamics. Systems thinking and modeling for a complex world. New York: McGraw-Hill Higher Education.

Sterman, J. D. (2002). All models are wrong: reflections on becoming a systems scientist. System Dynamics Review: The Journal of the System Dynamics Society, 18(4), 501-531.

Sterman, J., Fiddaman, T., Franck, T. R., Jones, A., McCauley, S., Rice, P., . . . Siegel, L. (2012). Climate interactive: the C-ROADS climate policy model. System Dynamics Review, 28(3), 295-305.

Stern, P. C., Sovacool, B. K., \& Dietz, T. (2016). Towards a science of climate and energy choices. Nature Climate Change, 6(6), 547-555.

Sterpu, M., Soava, G., \& Mehedintu, A. (2018). Impact of Economic Growth and Energy Consumption on Greenhouse Gas Emissions: Testing Environmental Curves Hypotheses on EU Countries. Sustainability, 10(9), 3327. 
Stock, J. H., \& Watson, M. W. (2010). A simple estimator of cointegrating vectors in higher order integrated systems. Econometrica, 783-820.

Subramanian, A. S., Gundersen, T., \& Adams, T. A. (2018). Modeling and simulation of energy systems: A review. Processes, 6(12), 238.

Tang, V., \& Vijay, S. (2001). System Dynamics. Origins, development, and future prospects of a method. Research Seminar in Engineering Systems, 1-12.

Tayupanta, P. (2016). Análisis del impacto de las políticas energèticas relacionadas con el cambio de la matriz energética del Ecuador en el período 2007-2014 y sus perspectivas al 2020 (Tesis Maestría). Quito: Escuela Politécnica Nacional.

To, H., Wijeweera, A., \& Charles, M. B. (2012). Energy consumption and economic growth - The case of Australia. Business School, Southern Cross University, 1-25.

United Nations. (2018). The Sustainable Development Goals Report 2018. New York: United Nations.

United Nations. (2019). Report of the Secretary-General on the 2019 Climate action summit and the way forward in 2020. New York: United Nations.

United Nations Environment Programme. (2005). Report on Atmosphere and Air Pollution. Addis Ababa: UNEP.

United Nations Environment Programme. (2019). Global Environment Outlook GEO-6: Healthy Planet. Nairobi: UN Environment.

United Nations Framework Convention on Climate Change. (5 de Octubre de 2016). United Nations Climate Change. Obtenido de Paris Agreement Status of Ratification: https://unfccc.int/process/the-parisagreement/status-of-ratification

United States Environmental Protection Agency. (28 de junio de 2017). Global Greenhouse Gas Emissions Data. Obtenido de https://www.epa.gov/ghgemissions/global-greenhouse-gas-emissionsdata\#Country

Vallejo Carpio, C. (2015). Analysis of Energy Intensity in the end-use sectors of the Ecuadorian Economy (master's thesis). Sydney: University of Technology.

Van de Graaf, T., \& Colgan, J. (2016). Global energy governance: a review and research agenda. Palgrave Communications, 2(1), 1-12. 
van Soest, H. L., de Boer, H. S., Roelfsema, M., Den Elzen, M. G., Admiraal, A., van Vuuren, D. P., . . Forsell, N. (2017). Early action on Paris Agreement allows for more time to change energy systems. Climatic Change, 144(2), 165-179.

Wang, Q., \& Jiang, R. (2020). Is carbon emission growth decoupled from economic growth in emerging countries? New insights from labor and investment effects. Journal of Cleaner Production, 119188.

Wang, Q., \& Su, M. (2020). Drivers of decoupling economic growth from carbon emission - an empirical analysis of 192 countries using decoupling model and decomposition method. Environmental Impact Assessment Review, 81, 106356.

Wang, S., Li, Q., Fang, C., \& Zhou, C. (2016). The relationship between economic growth, energy consumption, and CO2 emissions: Empirical evidence from China. Science of the Total Environment, 542, 360-371.

Wang, X., Wei, Y., \& Shao, Q. (2020). Decomposing the decoupling of CO2 emissions and economic growth in China's iron and steel industry. Resources, Conservation and Recycling, 152, 104509.

Wasti, S. K., \& Zaidi, S. W. (2020). An empirical investigation between CO2 emission, energy consumption, trade liberalization and economic growth: A case of Kuwait. Journal of Building Engineering, 28, 101104.

Wolstenholme, E. (2004). Using generic system archetypes to support thinking and modelling. System Dynamics Review: The Journal of the System Dynamics Society, 341-356.

World Energy Council. (2019). World Energy Issues Monitor 2019. London: World Energy Council.

Wu, D., \& Ning, S. (2018). Dynamic assessment of urban economyenvironment-energy system using system dynamics model: A case study in Beijing. Environmental Research, 164, 70-84.

Wu, Y., Zhu, Z. Q., \& Zhu, B. (2018). Decoupling analysis of world economic growth and $\mathrm{CO} 2$ emissions: A study comparing developed and developing countries. Journal of Cleaner Production, 190, 94-103.

Xue, B., Geng, Y., Muller, K., Lu, C., \& Ren, W. (2012). Understanding the Causality between Carbon Dioxide Emission, Fossil Energy Consumption and Economic Growth in Developed Countries: An Empirical Study. Sustainability, 1037-1045. 
Yeh, J.-C., \& Liao, C.-H. (2017). Impact of population and economic growth on carbon emissions in Taiwan using an analytic tool STIRPAT. Sustainable Environment Research, 27(1), 41-48.

Yu, H., Pan, S.-Y., Tang, B.-J., Mi, Z.-F., Zhang, Y., \& Wei, Y.-M. (2015). Urban energy consumption and $\mathrm{CO} 2$ emissions in Beijing: current and future. Energy efficiency, 8(3), 527-543.

Zhang, Y.-J., \& Da, Y.-B. (2015). The decomposition of energy-related carbon emission and its decoupling with economic growth in China. Renewable and Sustainable Energy Reviews, 41, 1255-1266.

Zhou, J., Jin, B., Du, S., \& Zhang, P. (2018). Scenario Analysis of Carbon Emissions. Energies, 11(6), 1489. 